\title{
SURVEY OF SURFACE FAULT RUPTURE AND STRUCTURE INTERACTION
}

\author{
A Thesis \\ Presented to \\ the Faculty of California Polytechnic State University \\ San Luis Obispo, California
}

In Partial Fulfillment

of the Requirements for the Degree

Master of Science in Architecture with a Specialization in Architectural Engineering

by

Lucy Redmond

October 2012 
(C) 2012

Lucy Redmond ALL RIGHTS RESERVED 


\section{COMMITTEE MEMBERSHIP}

TITLE: $\quad$ Survey of Surface Fault Rupture and Structure Interaction

AUTHOR: $\quad$ Lucy Redmond

DATE SUBMITTED: October 2012

COMMITTEE CHAIR: $\quad$ Ansgar Neuenhofer, Ph.D., P.E.

COMMITTEE MEMBER: Joseph Maffei, Ph.D., S.E.

COMMITTEE MEMBER: Kevin Dong, S.E.

COMMITTEE MEMBER: Cole McDaniel, Ph.D., P.E. 


\section{ABSTRACT \\ Survey of Surface Fault Rupture and Structure Interaction Lucy Redmond}

This report aims to raise awareness of the hazards of surface fault rupture and to identify parameters that influence structural performance during earthquake fault rupture. In researching structures subject to surface rupture, both damaged and sound, guidelines and procedures to evaluate buildings in potential hazard areas are developed herein. Little to no guidance on how to design for surface fault offset exists in current codes and design guides. Thus it is important create tools for designers to appropriately analyze structures by developing guidance and requirements to aid designers in their strength assessment of a structure subject to this particular hazard. Case studies of structures damaged by fault rupture, detailed in Section 4.0, provide important clues as to how structures respond when subject to surface offset. These case studies highlight structures that have been tested under the imposed deformations of the ground, providing insight into how building layout and construction techniques can protect the structure, even under extreme offsets. A sample evaluation for Bowles Hall (UC Berkeley) is provided herein in addition to preliminary code equations that may be used to verify and determine a structure's resistance to surface rupture. 


\section{ACKNOWLEDGEMENTS}

I would like to foremost extend my gratitude to Joe Maffei and Rutherford \& Chekene. The mentoring and encouragement Joe provided throughout the research and writing of this project were extremely instrumental in its completion. His direct contribution of Section 6.3 is acknowledged and greatly appreciated.

Thank you to committee advisors, Professor Neuenhofer, Professor Dong, and Professor McDaniel for their support and guidance. A special thanks is extended to Professor Dong for the tremendous effort he has put forth to develop the ARCE Master's program. 


\section{TABLE OF CONTENTS}

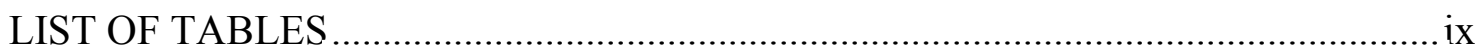

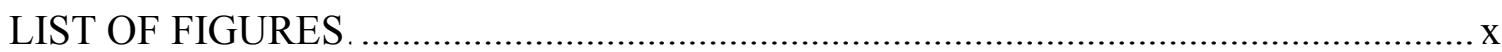

CHAPTER

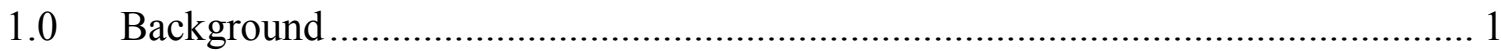

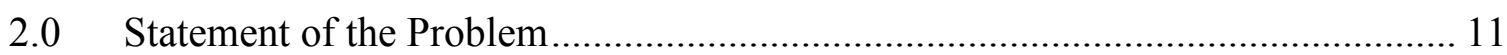

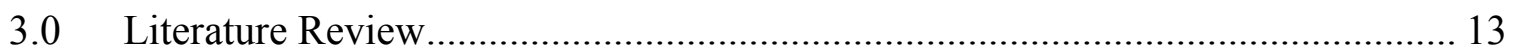

3.1 Developing Mitigation Measures for the Hazards Associated with

Earthquake Surface Fault Rupture ................................................... 13

3.2 Observations of Surface Fault Rupture from the 1906 Earthquake in the

Context of Current Practice ......................................................... 15

3.3 Foundation-structure systems over a rupturing normal fault: Part I.

Observations after the Kocaeli 1999 earthquake ................................ 17

3.4 Foundation-structure systems over a rupturing normal fault: Part II.

Analysis of the Kocaeli case histories .............................................. 18

3.5 Earth Pressures on Structure Due to Fault Movement............................ 20

3.6 The Relationship of Foundation Deformation to Surface and Near-Surface Faulting Resulting from the 1992 Landers Earthquake ......................... 22

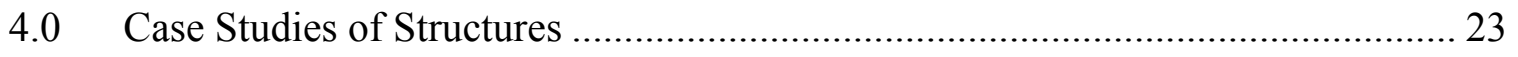

4.1 Landers, California Earthquake, 28 June 1992 .................................... 24

4.1.1 Lannom Residence ............................................................ 25

4.2 Izmit (Kocaeli), Turkey Earthquake, 17 August 1999 .......................... 27

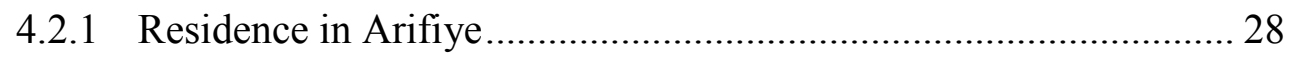

4.2.2 Gölcük Naval Base Bunker ....................................................... 29 
4.2.3 Koran School.......................................................................... 30

4.2.4 Concrete MRF Building Under Construction East of Gölcük ........ 31

4.2.5 Single Story Building in Gölcük ………………………............... 33

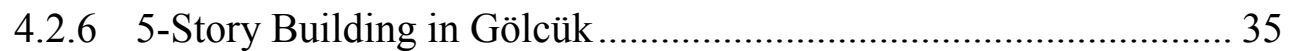

4.2.7 Primary School in Kullar............................................................. 36

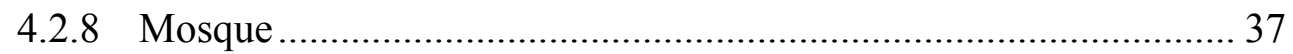

4.3 Duzce, Turkey Earthquake, 12 November 1999....................................... 38

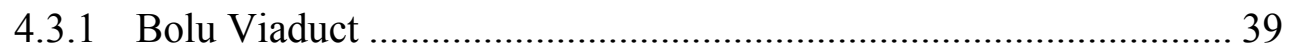

4.4 Chi-Chi, Taiwan Earthquake, 21 September 1999 .................................... 41

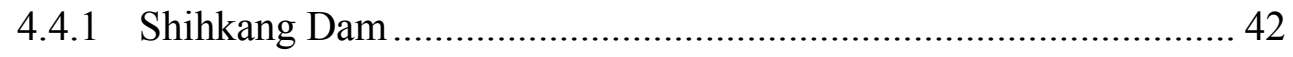

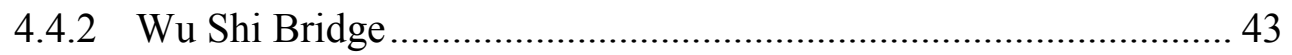

4.4.3 Multi-story Building in Fengyuan................................................. 45

4.4.4 Wu Feng Apartment Building .......................................................... 46

4.4.5 Kuangfu Middle School ................................................................ 47

4.5 Denali, Alaska Earthquake, 3 November 2002 ……............................... 49

4.5.1 Trans Alaska Pipeline (TAPS) ....................................................... 50

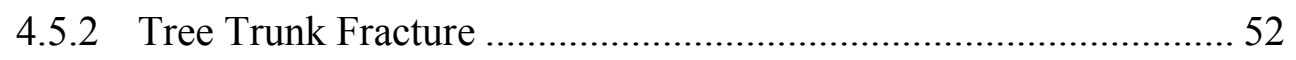

5.0 Example Evaluation and Mitigation of a Structure for Fault Offset: Bowles Hall,

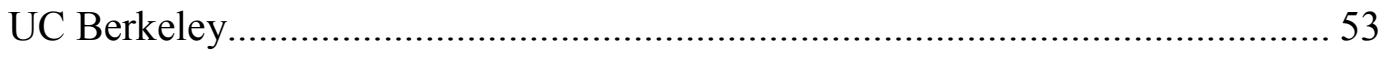

$5.1 \quad$ Description of the Current Structure ……………..................................... 54

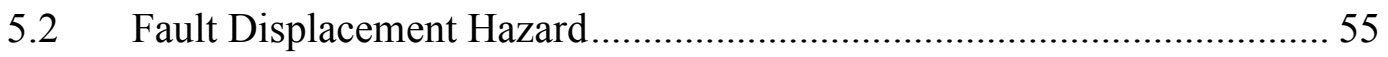

5.3 Evaluation of Structure for Horizontal Fault Offset .................................. 61

5.4 Retrofit of Structure for Horizontal Fault Offset ...................................... 66 


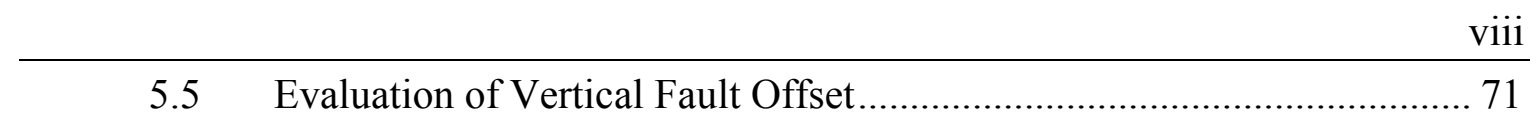

5.6 Retrofit of Structure for Vertical Fault Offset ................................... 73

6.0 Recommendation for Addressing Fault Offset ......................................... 74

6.1 Procedure for Evaluation of Existing Buildings .................................. 74

6.2 Variables \& Their Effects ............................................................. 80

6.3 Retrofit and Mitigation Strategies for Existing and New Buildings........ 91

6.4 Simplified Building Code Requirement for Integrity of Foundations ...... 95

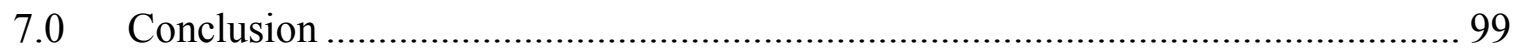

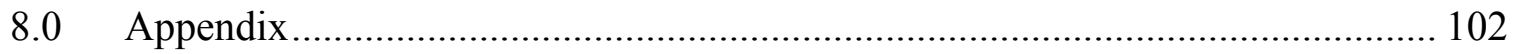

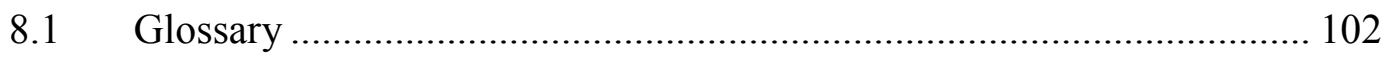

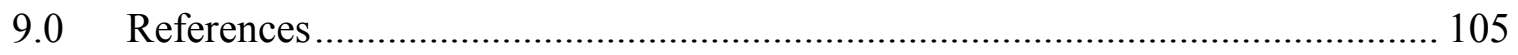




\section{LIST OF TABLES}

Table 1-A: Geologic age of faults characterized by AP Act (CGS)............................... 10

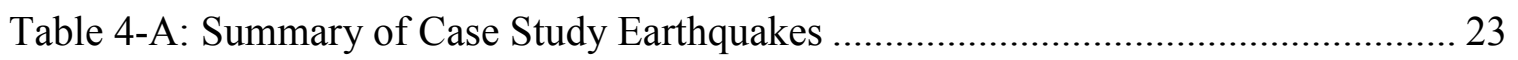

Table 5-A: Historic Earthquake Data (Lettis \&Associates 2007) …………………........ 56

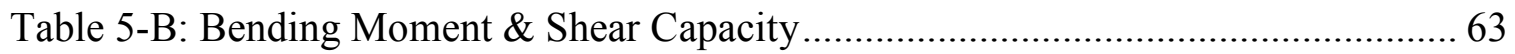

Table 5-C: Weight Room Passive Soil Pressure Moment \& Shear Demand .................... 64

Table 5-D: Hart Library Passive Soil Pressure Moment \& Shear Demand....................... 64

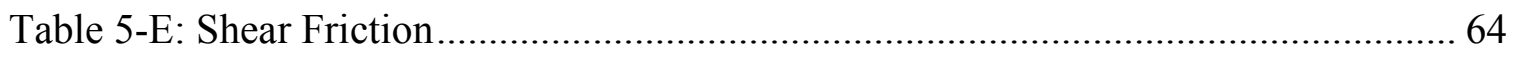

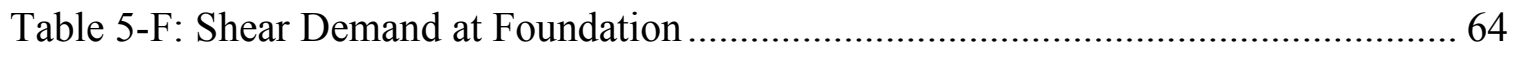

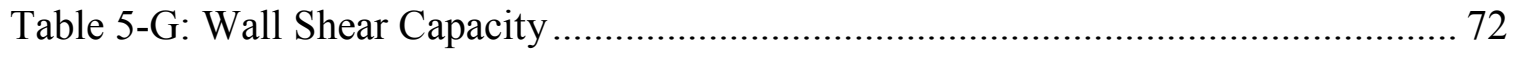

Table 5-H: Wall Shear Friction Capacity …………………...................................... 73

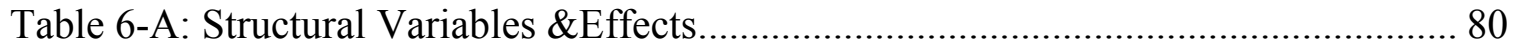

Table 6-B: Comparative Structural Foundation Configurations in Plan .......................... 89

Table 6-C: Comparative Structural Foundation Configurations in Section....................... 90

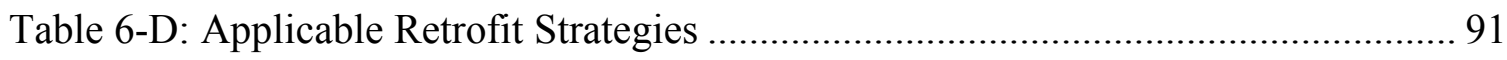

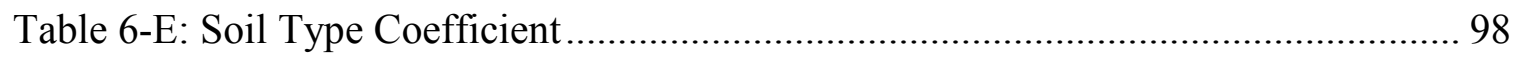




\section{LIST OF FIGURES}

Fig. 1.1-A: Lateral spreading cracks (GEER)......................................................... 3

Fig. 1.1-B: Liquefaction induced bearing capacity failure (Youd et al 2002) ................... 3

Fig. 1.1-C: Surface fault rupture; vertical offset (GEER),........................................... 4

Fig. 1.1-D: Surface fault rupture; horizontal offset. …………………....................... 4

Fig. 1.1-E: Regression plots (Wells and Coppersmith 1994)......................................... 5

Fig. 1.1-F: Faulting mechanisms: reverse, strike-slip, and normal................................ 6

Fig. 1.1-G: Stiff soil response to normal faulting (Modified from Bray 1989) ……......... 7

Fig. 1.1-H: Ductile soil response to normal faulting (Modified from Bray 1989), ........... 7

Fig. 1.1-I: A regulatory fault zone established by AP Act (USGS)................................ 8

Fig. 1.1-J: Active faults mapped in California and Nevada (USGS).............................. 9

Fig. 3.4-A: Finite element model of soil band. (Anastasopoulos and Gazetas 2007)..... 19

Fig. 3.5-A: Pressure wedges from fault offset (Duncan \& Lefebvre 1973). .................... 20

Fig. 4.1-A: Fault traces in '92 Landers earthquake (Murbach 1999)............................ 24

Fig. 4.1-B: Mapped shear zone near Lannom home (Murbach 1999),............................ 25

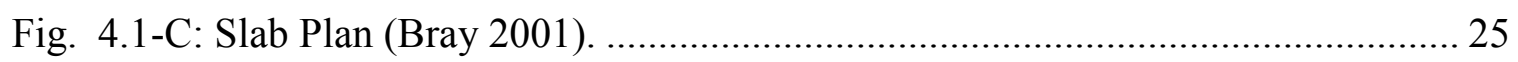

Fig. 4.2-A: North Anatolian Fault versus the San Andreas Fault (USGS)...................... 27

Fig. 4.2-B: Plan of Arifiye Residence (Lettis et al.2000)............................................ 28

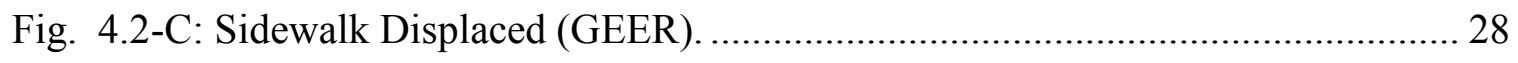

Fig. 4.2-D: Fault rupture at bunkers on the Gölcük Naval Base (Lettis et al. 2000)....... 29

Fig. 4.2-E: Fault passing under Koran school (Bray 2001)........................................... 30

Fig. 4.2-F: Concrete MRF under construction (Sezen 2000).......................................... 31

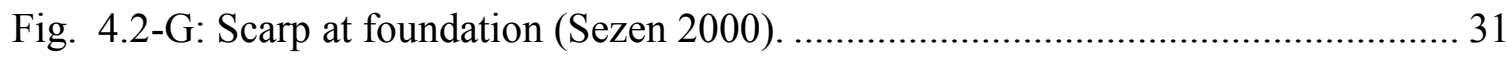




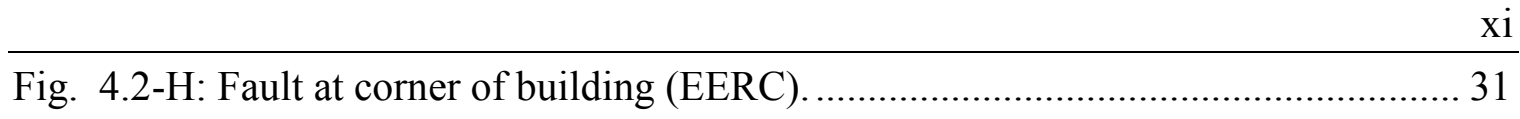

Fig. 4.2-I: Plan view of structure with fault trace under foundation (Sezen 2000)........ 32

Fig. 4.2-J: Golcuk building destroyed by fault (Bray 2000)......................................... 33

Fig. 4.2-K: Plan \& elevation of fault damage (Anastasopoulos and Gazetas 2007) ....... 33

Fig. 4.2-L: Damaged building in Golcuk(EERI) ………………………………….... 35

Fig. 4.2-M: Another View of damage to building (EERI)........................................... 35

Fig. 4.2-N: Damaged school in Kullar (Lettis et al. 2000)............................................ 36

Fig. 4.2-O: Partially collapsed mosque (Anastasopoulos and Gazetas 2007), ................ 37

Fig. 4.2-P: Isolated column footings (Anastasopoulos and Gazetas 2007).................... 37

Fig. 4.3-A: The Duzce Fault (Park et al. 2004). ............................................................ 38

Fig. 4.3-B: Horizontal offset at Viaduct (Park et al 2004)............................................ 39

Fig. 4.3-C: Detail at pier connection to deck (Roussi 2003).......................................... 39

Fig. 4.3-D: Duzce Fault Trace intersects Bolu Viaduct (Roussi 2003).......................... 40

Fig. 4.3-E: Seismic isolator displaced (Park et al 2004)................................................. 40

Fig. 4.4-A: Chelungpu fault trace in Taiwan (Lettis \& Associates 2003)....................... 41

Fig. 4.4-B: Warped Shihking Dam Spillways (GEER), ................................................. 42

Fig. 4.4-C: Shear failure in southbound pier (Lettis \& Associates 2003)........................ 43

Fig. 4.4-D: Plan of the pier style and construction (Lettis \& Associates 2003).............. 44

Fig. 4.4-E: Northbound decks collapses (Lettis \& Associates 2003)............................. 44

Fig. 4.4-F: Chelungpu fault scarp near Fengyuan (Lettis \& Associates 2003)............... 45

Fig. 4.4-G: Damage to multi-story apartment building (Lettis \& Associates 2003). ...... 46

Fig. 4.4-H: Fault trace through the middle school (Lettis \& Associates 2003)............... 47

Fig. 4.4-I: The Northern Classroom Building collapse (Lettis \& Associates 2003)....... 47 
\begin{tabular}{lr} 
xii \\
\hline Fig. 4.4-J: West View, Northern Classroom Building (Lettis \& Associates 2003)......... 47
\end{tabular}

Fig. 4.4-K: Wall cracks in Eastern Classroom Building (Lettis \& Associates2003)...... 48

Fig. 4.5-A: Pipeline crossing Denali Fault (Honnegar2004).................................... 50

Fig. 4.5-B: Concrete slider beam and teflon shoe (Honnegar 2004). .......................... 50

Fig. 4.5-C: Damaged slider shoe following the earthquake (Honnegar 2004).............. 51

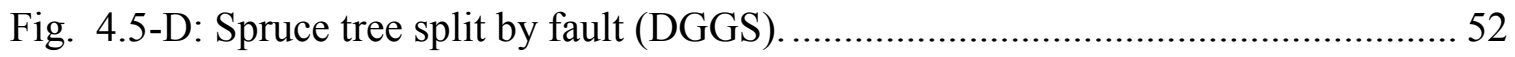

Fig. 5.0-A: Bowles Hall South Elevation. ............................................................. 53

Fig. 5.1-A: Aerial View of Bowles with library addition highlighted.......................... 54

Fig. 5.2-A: Western fault trace at Bowles Hall (Lettis \& Associates 2007)................... 55

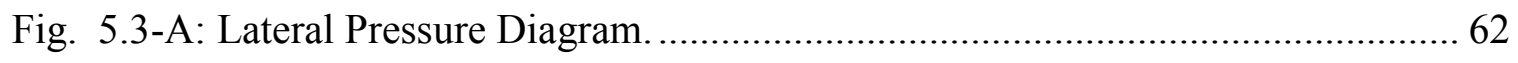

Fig. 5.3-B: Conceptual shearing damage due to horizontal offset............................... 65

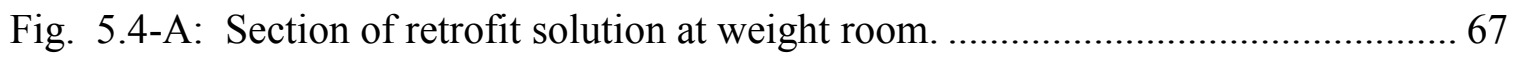

Fig. 5.4-B: Plan and elevation of retaining wall system (Image Courtesy of R\&C )..... 68

Fig. 5.4-C: Section of weight room and retaining wall (Image Courtesy of R\&C)........ 69

Fig. 5.5-A: Critical sections on northeast elevation................................................ 71

Fig. 5.5-B: Northeast Elevation of Hart Library ................................................ 72

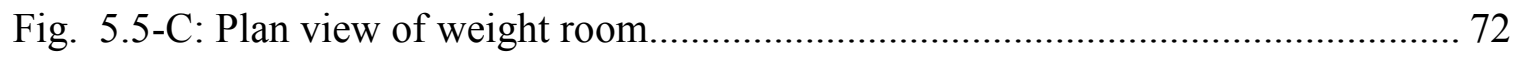

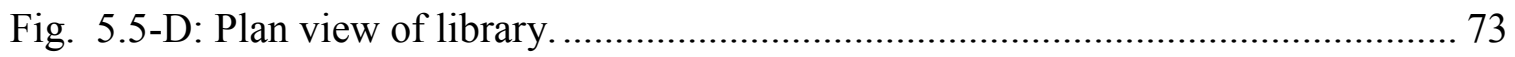

Fig. 6.2-A: Amount of ground displacements versus amount of structural damage. .... 82

Fig. 6.2-B: Amount of deformation in the ground near structure .............................. 82

Fig. 6.2-C: Effect of vertical fault offset on a concrete wall and pilaster building. ........ 83

Fig. 6.2-D: Case of structure with a strike-slip fault passing through center of building. 85

Fig. 6.2-E: Free body diagram showing shear force through section P-P. .................. 86 
Fig. 6.2-F: Free body diagram with strike-slip near the edge of the building. ............... 86

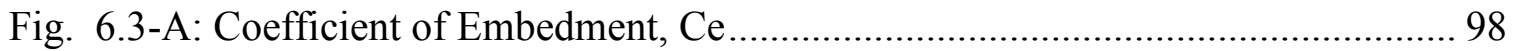




\subsection{BACKGROUND}

Earthquakes are an unpreventable hazard which occur all over the world, typically near active tectonic plate boundaries. When earthquakes occur in densely populated regions the results are often fatal and catastrophic. Higher numbers of fatalities due to building collapse are common in developing nations where construction techniques and building materials are not highly scrutinized in contrast to nations where strict building codes are enforced. Most deaths associated with earthquakes result from structural collapse and therefore a great deal of research has been devoted to structural earthquake engineering. Generally, the magnitude of an earthquake is directly proportional to the amount of structural damage observed, especially in countries where strict seismic design codes do not exist or are not abided by during construction.

To improve building codes and to raise the awareness of designing to expected earthquake forces, a variety of organizations are leading earthquake engineering research, collecting and analyzing earthquake data. Organizations in the United States include the Earthquake Engineering Research Institute (EERI), Earthquake Engineering Research Center (EERC), the Multidisciplinary Center for Earthquake Engineering Research (MCEER), the United States Geological Survey (USGS), and the Geo-Engineering Earthquake Reconnaissance (GEER). The groups use collected data as a tool to develop mitigation techniques and to identify building practices that work best to resist earthquake forces for a minimum of life safety performance. Following major earthquakes, teams from each organization visit the regions most affected to collect information for research. Reconnaissance reports are published that detail the ruptured 
fault system, recorded ground motions - if available, types of structural damage, ground failure and deformation, as well as the economical and societal impact.

Based on reconnaissance investigations it has been found that the most critical earthquake hazard for structures is shaking, both in intensity and duration. As a result the majority of research in structural earthquake engineering focuses on design methods that enable ductile structural response and prevent collapse from cyclic loading. This research is a basis for building code design requirements and mandates that a minimum performance level (typically life safety) be achieved for new structures. Applied design methods vary by construction material, but general concepts carry through all building systems independent of material. For example, the 'weak beam - strong column' design philosophy aims to preserve the vertical integrity of a structure and requires detailing guidance at critical beam column joints.

The damaging effects of earthquakes, however, are not limited to the structures. Shaking induced soil failure beneath and around the structure can result in catastrophic damage as well as damage to major utility systems and roadways; thus a majority of geotechnical engineering research has been committed to identifying the precursors associated with these hazards. Ground failures are commonly seen in earthquakes, especially in areas with poor soil conditions and high water tables. Examples of shaking induced ground failures include landslides, lateral spreading (Fig. 3.1-A), and liquefaction induced bearing capacity failures (Fig. 3.1-B). Intensity, duration of ground shaking, and soil conditions at the site are major factors contributing to these effects.

In the event of ground failure the stability of even a well-designed structure may be compromised. Geotechnical engineering research has investigated methods relating to 
site preparation and soil strengthening to mitigate ground failure in seismic prone areas.

These techniques include: site grading, foundation design, site strengthening through compaction, soil replacement, and grouting. Applying these methods can greatly reduce the potential for damage caused by earthquakes to building structures, utilities, and roads.

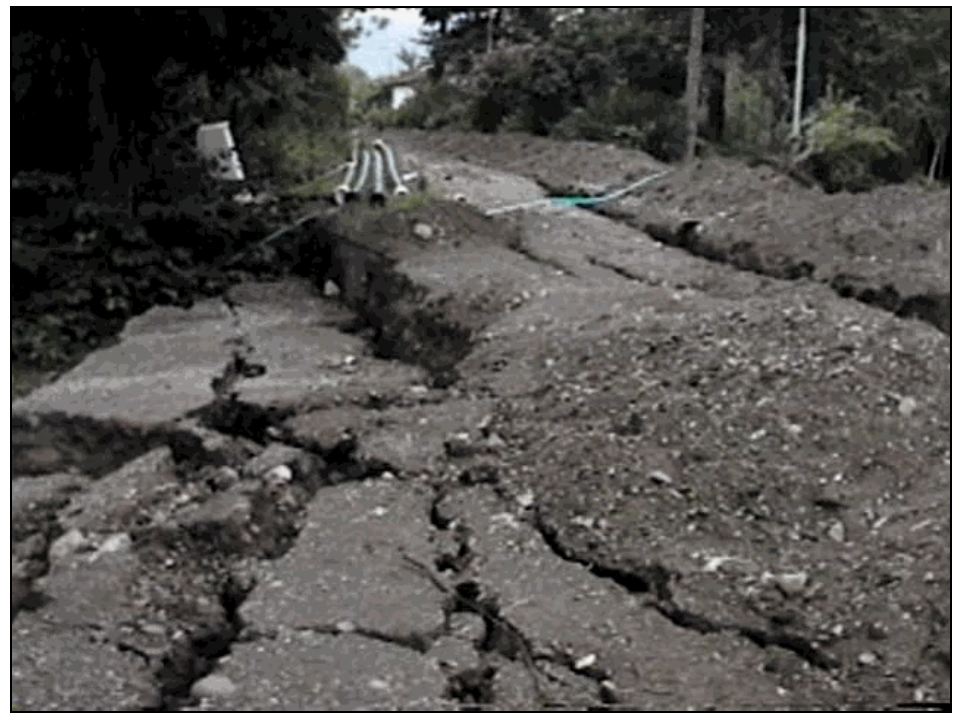

Fig. 3.1-A: Lateral spreading cracks (GEER).

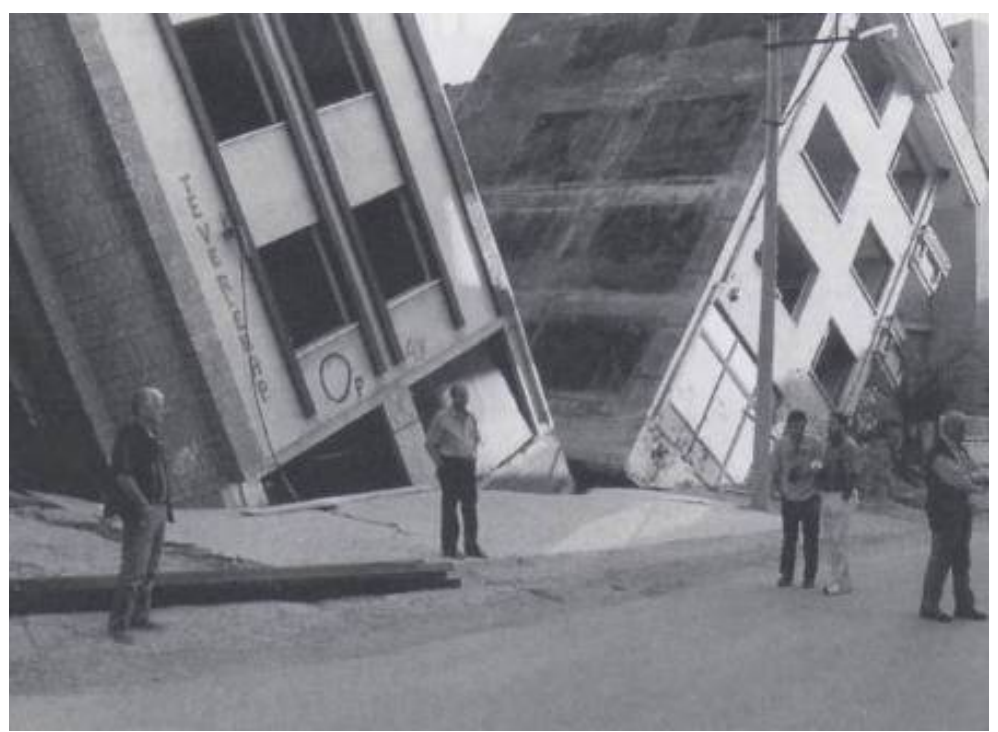

Fig. 3.1-B: Liquefaction induced bearing capacity failure (Youd et al 2002). 


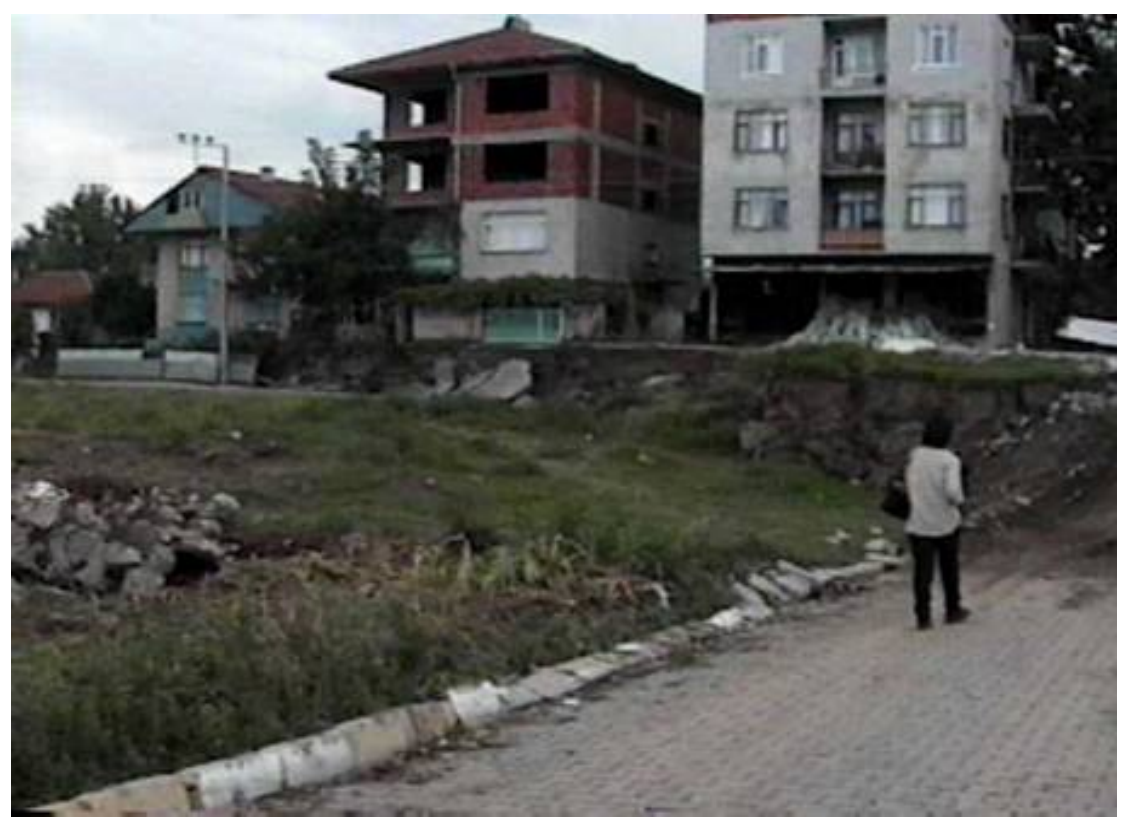

Fig. 3.1-C: Surface fault rupture; vertical offset (GEER).

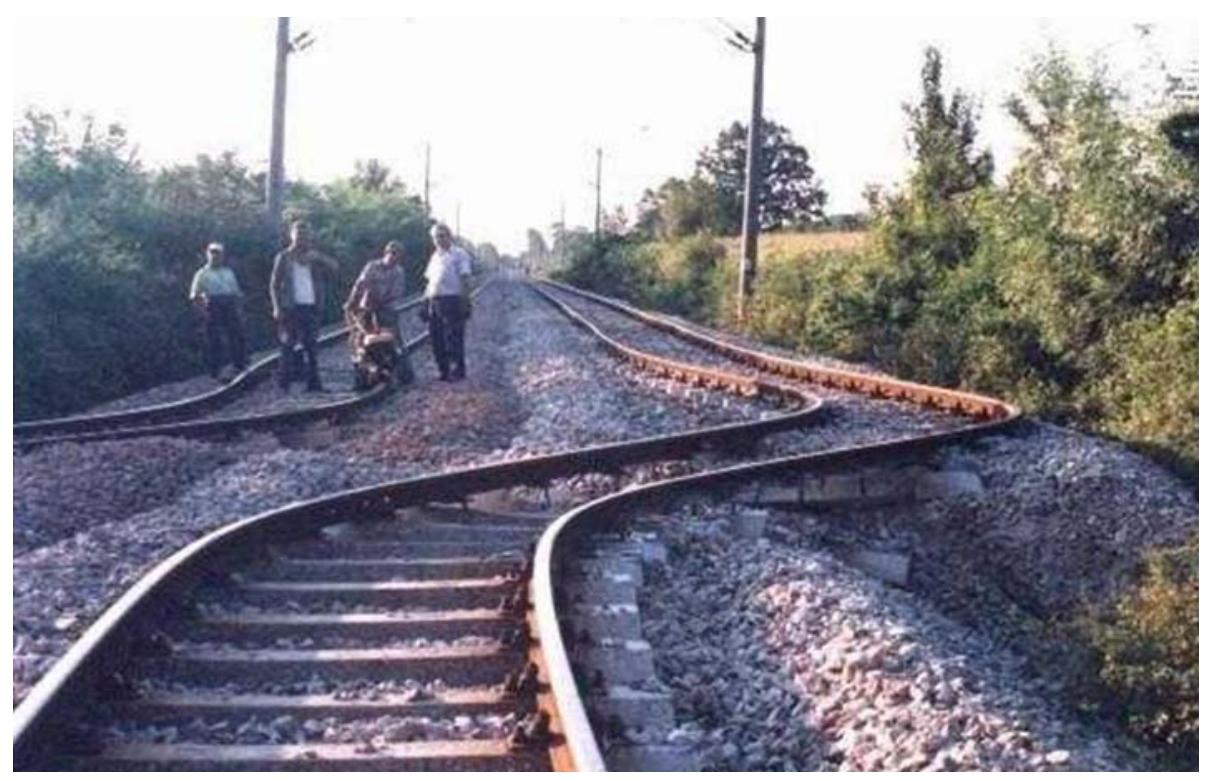

Fig. 3.1-D: Surface fault rupture; horizontal offset. 
Another form of ground deformation caused by earthquakes is surface fault

rupture (Fig. 3.1-C \& Fig. 3.1-D, shown on the previous page). Surface rupture is seen when the initial ground rupture propagates up through overlying soils. The amount and direction of surface fault rupture is dependent on the magnitude, faulting mechanism, and soil conditions. Large magnitude earthquakes generally produce larger surface offsets as more energy is present to generate greater dislocation. Regression plots below in Fig. 1.1-E, relate moment magnitude to maximum surface rupture displacements, and reveal the trend of increasing displacement as magnitude increase for all mechanisms.
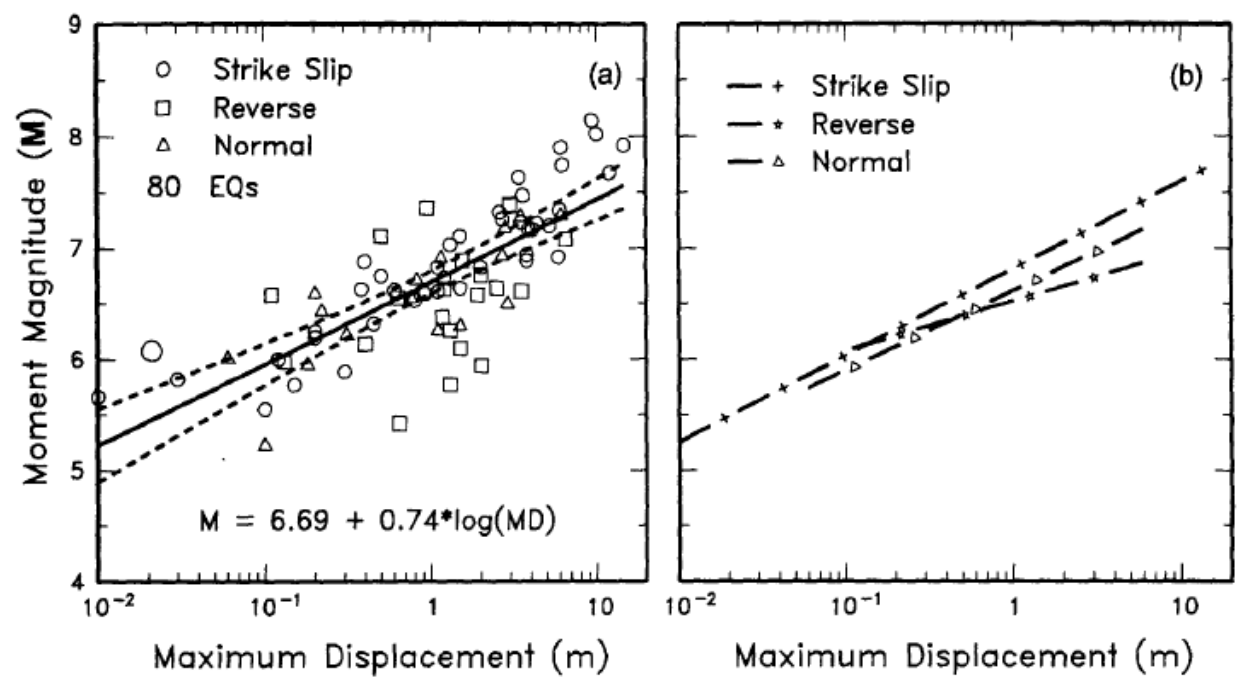

Fig. 1.1-E: Regression plots (Wells and Coppersmith 1994).

The faulting mechanism influences the primary direction of movement. Basic mechanisms include strike-slip, normal, and reverse faults as shown in Fig. 3.1-F, shown in order of decreasing seismic energy, left to right. Combined directional offset is referred to as an oblique mechanism. The differentiating factor between mechanisms is direction of primary offset. Strike-slip faults are characterized by a lateral displacement where both normal and reverse faults exhibit vertical displacements, the difference being the direction of hangingwall movement. Normal faulting is characterized by the 
hangingwall sliding down the fault - creating lateral spread as the top soils are stretched apart. Where reverse faulting is characterized by the hangingwall sliding up the faultgenerating scarps or regions where the top soils are compressed.

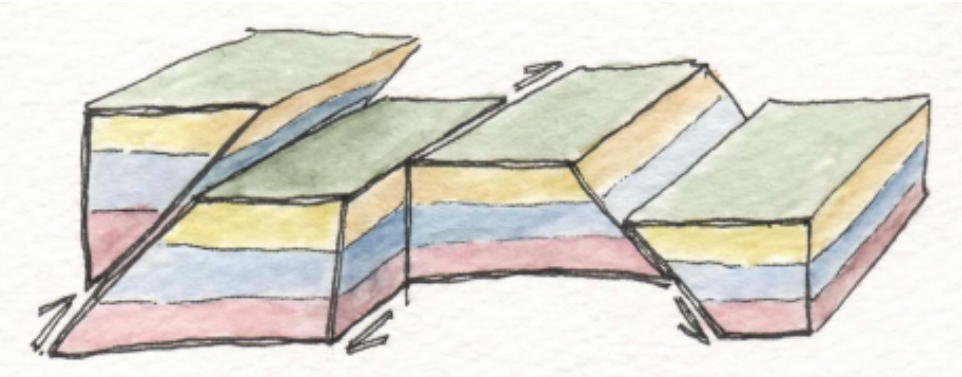

Fig. 3.1-F: Faulting mechanisms: reverse, strike-slip, and normal.

The overlying soil composition additionally plays a role in altering the characteristics of surface rupture observed. Ductile soils accommodate higher levels of stress thus producing a flexible and less distinct definition at the surface. In stiff soils, the response is more brittle and offsets are more clearly defined. Fig. 3.1-G and Fig. 3.1-H illustrate the difference in response for a normal fault. 


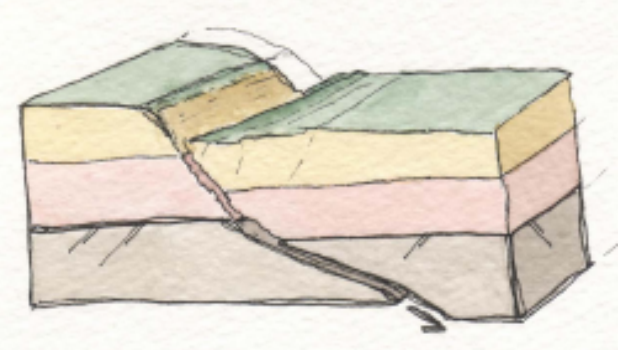

Fig. 3.1-G: Stiff soil response to normal faulting (Modified from Bray 1989).

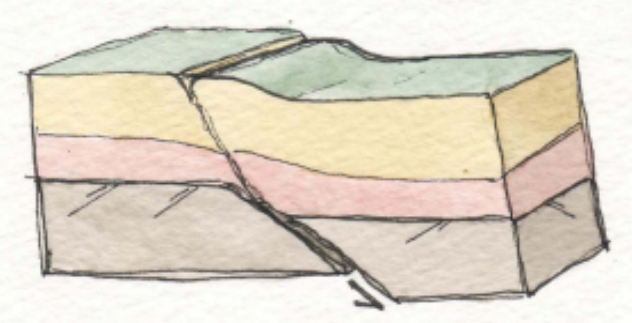

Fig. 3.1-H: Ductile soil response to normal faulting (Modified from Bray 1989).

Structural damage related to surface rupture is more difficult to estimate than that of shaking due to the complexity of variables involved. Structural designers are able to bracket a reasonable range of expected ground accelerations to determine design forces for the structure when designing for shaking. With surface rupture there are a greater number of unknowns so a probabilistic analysis is currently the best approach the development of a range of expected displacements. However, the actual displacement that occurs with surface rupture can vary drastically from the expected values. In comparison, accelerations due to shaking are likely to fall within a standard deviation of those predicted.

The amount of damage evident in structures near the main fault trace directly correlates to the amount of surface offset. Total collapse is a common fate of buildings directly atop large offsetting faults. If offset exceeds several meters, mitigation is limited 
to prevent excessive damage to structures located on the rupture. However, there have been several recorded cases where the ground displacement has been dictated by the structure spanning the rupture. This implies tailored building techniques combined with proper knowledge of surface fault rupture can lead to successful engineering of structures spanning fault traces with potential for surface rupture.

\section{Alquist-PrioloAct}

The current state of practice in California relies on the Alquist-Priolo Earthquake Faulting Zones Act (AP Act) of 1972 to address the hazard of fault rupture to structures. This Act was implemented in response to the 1971 San Fernando Earthquake which exhibited large amounts of surface fault rupture and resulted in damage to several commercial and residential structures. "The purpose of the Alquist-Priolo Earthquake Fault Zoning Act is to regulate development near active faults so as to mitigate the hazard of surface fault rupture" (CA Geological Survey).

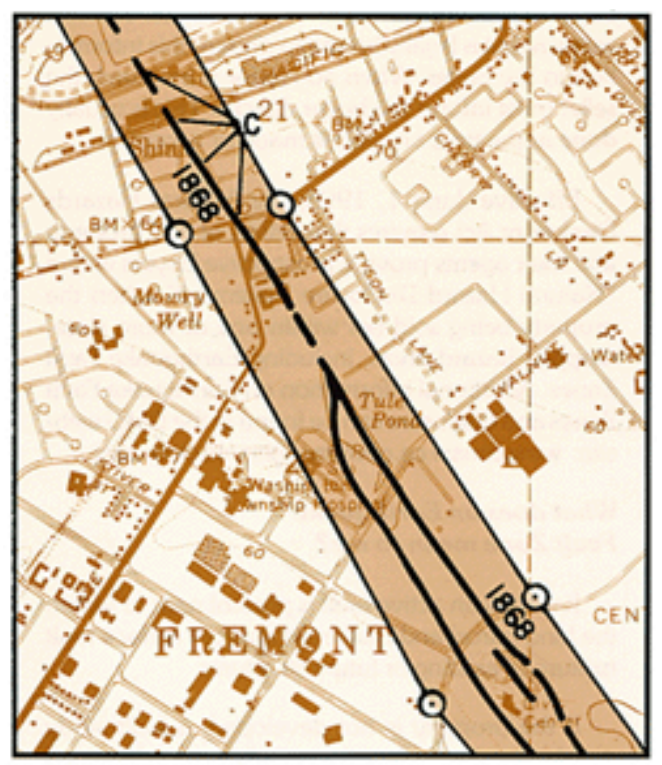

Fig. 3.1-I: A regulatory fault zone established by AP Act (USGS). 
State geologists are required to establish regulatory zones around mapped fault traces which regulate certain project development within the zones. Mapped faults are defined by their activity and are categorized as: sufficiently active or well-defined. Sufficiently active faults have exhibited surface displacement along one or more of their segments and branches within Holocene time (Table 1-A). Well-defined faults are those where their trace is clearly detectable by a trained geologist as a physical feature at or just below the ground surface. Fig. 3.1-J shows active mapped faults in California and Nevada.

As defined by the Act, typically the required setback zone is 50 feet from the mapped trace. To acquire a permit to build in the zones, potential projects must perform geologic investigations to demonstrate that the site is not threatened by surface displacement from future faulting. Essentially, the AP Act uses the mitigation procedure known as "avoidance" for new structures.

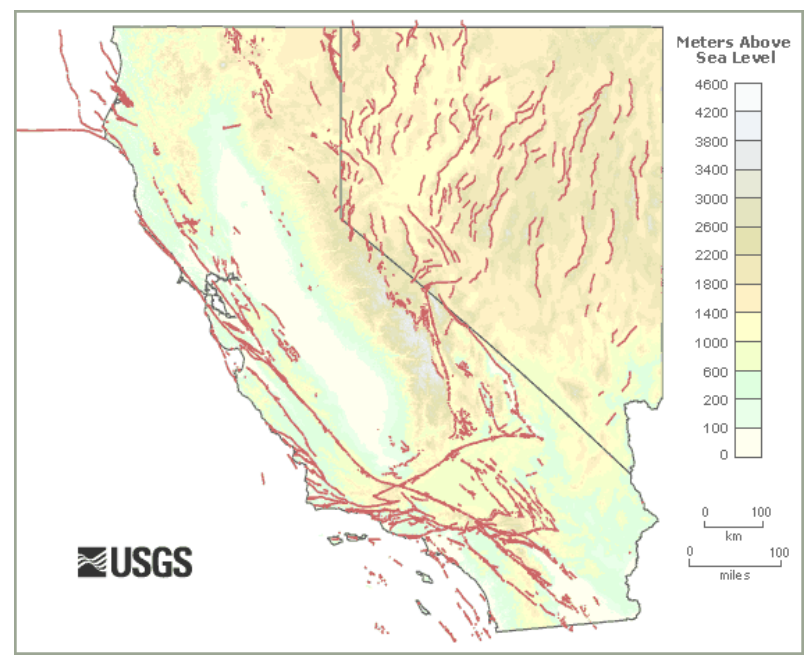

Fig. 3.1-J: Active faults mapped in California and Nevada (USGS). 
Table 1-A: Geologic age of faults characterized by AP Act (CGS).

\begin{tabular}{|c|c|c|c|}
\hline \multicolumn{3}{|c|}{ GEOLOGIC AGE } & \multirow{2}{*}{$\begin{array}{c}\text { Years Before } \\
\text { Present }\end{array}$} \\
\hline & Period & Epoch & \\
\hline \multirow{4}{*}{ 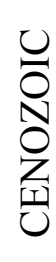 } & \multirow{4}{*}{ 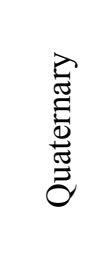 } & Historic & 200 \\
\hline & & Holocene & 11,000 \\
\hline & & Pleistocene & \\
\hline & & & $1,600,00$ \\
\hline
\end{tabular}




\subsection{STATEMENT OF THE PROBLEM}

The state of California sees an average of 0.85 fault-rupture events per year with ruptures ranging from minor offsets up to several feet of displacement (CGS). While it is a common belief amongst professionals that the best way to mitigate the hazards associated with surface rupture is to avoid potentially prone locations, it is impossible to identify and zone all active faults. Furthermore, many earthquakes in California occur on faults that are not yet mapped. While the fault evaluation and zoning program serves as a good resource to identify known places where fault rupture may be hazardous to buildings, the AP Act has its limitations and thus requires an on-going effort to revise zones as new data becomes available.

One limitation the AP Act has is that application is restricted to new structures with no language addressing existing buildings. In California, a number of structures were built atop active fault traces prior to the delineation of hazard zones. As a result, questions arise as to how to deal with existing structures atop fault traces. In these cases, it is important to ask should mitigation require strengthening through retrofit or is no action needed? What is that criteria that should be applied in these decisions?

Although there are documents available that discuss rehabilitation and retrofit for existing buildings, such as ASCE 41-06, Seismic Rehabilitation of Existing Buildings, and ASCE 31-03, Seismic Evaluation of Existing Structure, these documents do not provide adequate guidance for evaluation of existing structures. 
For example, ASCE 41-06 §C4.2.21 provides the following guidance:

Buildings found to straddle active faults should be assessed to determine if any rehabilitation is warranted, possibly to reduce the collapse potential or the structure given the likely amount and direction of fault displacement.

Likewise, ASCE 31-03 $\S 4.7 .1 .3$ provides the following Tier 2 evaluation procedure:

The proximity of the building to known active faults shall be determined. The potential for surface fault rupture and magnitude of rupture shall be determined. An analysis of the building in accordance with procedures in Section 4.2 shall be performed. The adequacy of the structure shall be evaluated for all gravity and seismic forces in combination with the forces induced by the potential for differential movement in the foundation.

Both documents suggest that existing buildings situated over a fault with the potential for offset will require retrofit if assessment finds it necessary. This becomes the hot button issue as standards as to how to conduct an assessment or determine induced forces are lacking. In addition, Section 4.2 of ASCE 31-03 is limited to an analysis procedure for seismic loading. The analysis does not consider forces generated on a structure due to fault offset, how they are applied, or how the structure should resist the loading through a reasonable load path.

To add a more robust solution to current codes guidance for buildings atop fault traces, the purpose of this project is threefold: identify parameters that influence structural performance during fault rupture, create a procedure to evaluate structures located on active fault traces, and develop code language that may be applied in the strength assessment of structures. 


\subsection{LITERATURE REVIEW}

Existing research on fault rupture interaction with structures is limited in part because of the complexity of the phenomenon and the difficulty of estimating the location and amount of fault displacements. Additionally, many structures spanning faults typically are not standing after the earthquake, either because the shaking was intense or the rupture led to collapse. Much of the published literature includes case studies from major earthquakes, which are reviewed in the sections following. Laboratory research has explored how rupture of bedrock at depth propagates through various types of overlying soils. More recently, finite element models of soil bands and soil columns are being calibrated to replicate laboratory tests and behavior observed in case studies. Researchers are now making strides to include case study structures to see how the presence of a structure influence a fault's rupture path. Summarized below are six relevant references.

\subsection{Paper by Bray (2001): Developing Mitigation Measures for the Hazards Associated with Earthquake Surface Fault Rupture}

Bray (Bray 2001) reviews the permanent ground displacement resulting from fault offset in the Landers, Duzce, Chi-Chi, and Kocaeli earthquakes, and techniques that mitigate potential hazard from surface fault rupture.

The Landers earthquake exhibited few instances where surface fault rupture interacted with structures. Through examination of the Lannom Residence's foundation, Bray concluded that polyethylene sheeting (Visqueen), used as a vapor barrier between a newer foundation slab and the ground, decreased the amount of cracking the slab was subjected to. The layer acted as a decoupling agent that separated the slab from direct 
contact with the soil that experienced strain and movement from surface faulting. Refer to Section 4.1 for further explanation and diagrams of this case study.

The 1999 Kocaeli and Duzce earthquakes in Turkey produced ground deformation from fault offset of nearly 3 meters vertical and 4 meters horizontal at the maximums. The ruptures occurred in a number of urban areas and consequently there were a handful structures affected. A bunker at the Gölcük Naval Base (See Section 4.2.2) spanned a main trace of the fault and diverted the rupture around it. The strength and solidity of the bunker disrupted the propagation path and caused the structure to rotate slightly. A two-story home with a shallow 1 meter by 1 meter reinforced concrete grid foundation was in line with a main fault trace that ruptured with an offset of 3 meters; however, the rupture displaced around the walls and underneath the foundation, taking with it a concrete sidewalk that previously abutted the structure. Refer to Section 4.2.1 for details of this structure and the fault displacement. Another area with a governing dip-slip fault mechanism demonstrated varied response of apartment buildings: some were severely damaged while others suffered only minimal impacts despite 2-3 meter offsets (Section 4.2.6).

Ninety kilometers of surface rupture propagated along a fault on the western side of Taiwan in the 1999 Chi-Chi earthquake. Shihkang dam experienced approximately nine meters of vertical offset, which severely damaged the structure and cut off water supplies to dependent towns (Section 4.4.1). A number of highway bridge systems-- $\mathrm{Wu}$ Hsi Bridge, Highway 13 and an 11-span Bridge east of Shihkang dam-- were impacted by fault movement and suffered collapse caused by detachment of the deck from piers as well as shear failures in several piers traversing the ruptures. Sections 4.4.1 and 4.4.2 
provide images and information for these structures. At a major surface rupture feature observed in Chi-Chi, Bray notes that in the region on the footwall block closest to rupture less building damage was observed, whereas on the hangingwall block more damage was seen due to scarping in the immediate area just off the rupture.

As Alquist-Priolo Earthquake Fault Zones is considered mitigation for surface rupture by avoiding the fault zone and prohibiting building within mapped zones, Bray suggests a second method for new structures through geotechnical engineering techniques such as ductile compacted fill or reinforced fill, reducing differential settlement. Structural engineering of foundation elements with increased ductility can better resist tilt. To reduce cracks in floor slabs Bray recommends sheets of polyethylene be placed between coarse sand and gravel to limit the transfer of horizontal strain. Post-tensioning of the slab is advised as it will allow the structure to accommodate irregular ground deformation. Results from finite element modeling methods suggest hazards can be reduced by increasing the height and ductility of the compacted fill and installing soilreinforcement within the compacted fill.

\subsection{Paper by Bray and Kelson (2006): Observations of Surface Fault Rupture from the 1906 Earthquake in the Context of Current Practice}

In this article Bray and Kelson discuss the 1906 earthquake that produced fault rupture over a length of 370 kilometers along the San Andreas Fault. Measurements of rupture were taken from broken pipelines and offset roads and fences. Following the earthquake, engineers recommended that new construction should avoid fault traces when possible. This has remained the common thought in where to locate structures with respect to known faults. It is recognized that while prudent, avoidance in fault zones is 
not always possible and Bray and Kelson suggest rational design strategies and retrofit measures be developed to address the main hazards associated with fault offset. Though faults are mapped and represented as a line on a map, their rupture zone can be meters wide. Therefore understanding the morphology of the region is essential to making good engineering decisions regarding the possibility of fault rupture in a specific region.

Based on the 1906 Earthquake and other notable earthquakes with surface rupture, Bray and Kelson conclude that structural performance depends on the following variables:

- Sufficiently strong facilities to withstand ground movement

- Sufficient ductility to avoid complete collapse

- Isolation from the majority of ground displacement results in rotation of the structure and less damage within the structure.

Shallow foundations are also recommended by the authors because they potentially allow the superstructure rotate as a rigid body, rather than being tied to the ground through a deep pile foundation system, for example. However, a deep rigid foundation was not problematic for the Banco Central in Managua, Nicaragua. In 1972, the Managua earthquake had a primary fault trace that ruptured through the basement of the bank, but was diverted by the vault. This was similar behavior observed at the bunkers at the Gölcük Naval Base, where the bunkers' massiveness and inherent stiffness diverted the fault and only caused mild rotation to the structure. Bray and Kelson conlcude that these two structures, located across strike-slip faults, indicate that tying the structure to each side of an active fault generally not prudent and should be avoided as a mitigation/retrofit technique. 


\subsection{Paper by Anastasopoulos and Gazetas (2007): Foundation-structure systems over a rupturing normal fault: Part I. Observations after the Kocaeli 1999 earthquake}

Although the overall mechanism of the North Anatolian fault is strike-slip, in the 1999 Kocaeli earthquake, localized regions of the fault behaved as a normal fault, as was the case in the pull-apart regions of Gölcük. Anastasopoulos' and Gazetas' paper records several case studies in the region of Denizevler: 5 residential buildings, a mosque, a basketball stadium, the Ford automobile factory, and a high-voltage electricity pylon. These structures were crossed by a fault trace outcropping. Despite vertical fault offsets of 2 meters, none of these structures completely collapsed. Anastasopoulos and Gazetas describe each of the structures, modes of failure, ground displacement, and soil types and use this information for modeling the soil structure interaction. Some of these structures are included in Section 4.2 with specifics regarding performance.

The term "Fault Rupture-Soil-Foundation-Structure Interaction," (FR-SFSI) is coined by Anastasopoulos and Gazetas to designate the modeling process and identify relevant factors. The first task in this process includes identifying if, where, and how large the rupture path in the soil will be. Fault rupture propagation will follow a rupture path along the weakest planes in the soil layers above initial bedrock rupture; this is referred to as "free-field" rupture. "Free-field" rupture can be influenced, however, by the presence of a structure as seen in previous examples with fault diversion. In addition to contact diversion where the rupture diverts at a specific structure boundary, "freefield" rupture can be interrupted at deeper soil levels through increased stress from the weight of a structure above. Manipulation to the "free-field" path can also be attributed 
to the foundation depth; a deep pile foundation at the basketball court caused more damage as it forced the fault offset and structure to displace into each other.

The case studies outlined in this paper provide solid evidence as to how foundations can impact the relationship of fault propagation, the soil stresses, and overall structural performance of a structure located on a fault. Rigid and continuous foundations appear to perform the best, even when the superstructure is moderately reinforced. Box type and mat foundations outperform flexible and isolated foundations and can aid in diverting the fault rupture. Shallow foundations appear to respond better than deep piles, because the piles can cause the superstructure to deform and displace with the fault.

\subsection{Paper by Anastasopoulos and Gazetas (2007): Foundation-structure systems over a rupturing normal fault: Part II. Analysis of the Kocaeli case histories}

In part II of their analysis, Anastasopoulos and Gazetas use finite-element modeling to study FR-SFSI. The goal of the analysis is to identify how the presence of a structure influences rupture path. A control finite element model of the soil band was created to test how the rupture propagated in the "free-field." A second model modeled the structures from the Denizevler region of Turkey, referred to in part I, imposed the fault offset, and recorded any alteration in the rupture path. For one of the structures, the two models are shown in Fig. 3.4-A where (a) shows "Free-field" deformation and (b) shows rupture propagation altered by presence of structure. 

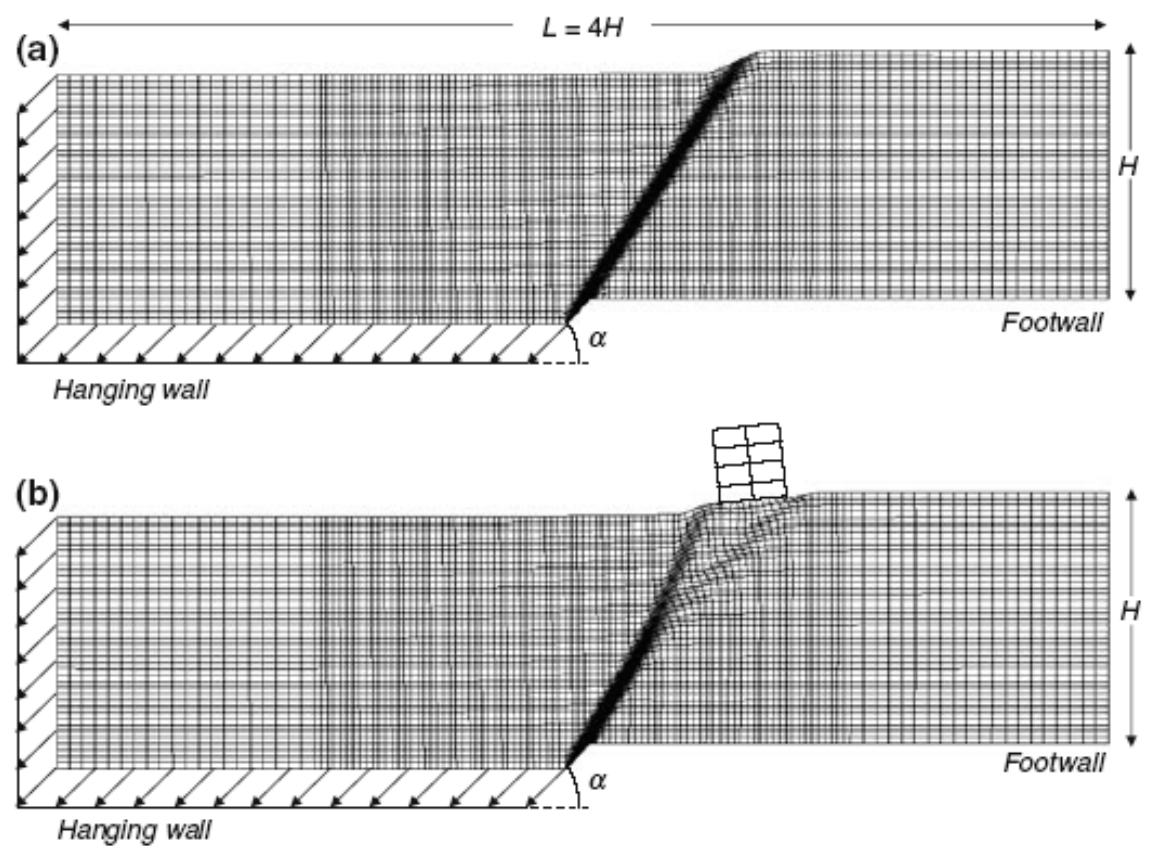

Fig. 3.4-A: Finite element model of soil band. (Anastasopoulos and Gazetas 2007).

The main factors of FR-SFSI are outlined as:

1. Type and continuity of the foundation system

2. Flexural and axial rigidity of the foundation system

3. Load of the superstructure

4. Stiffness of the superstructure

5. The soil stiffness and strength.

Rigid foundations in the case studies not only managed to divert the rupture, but also allowed the building to rotate as a rigid body, without stressing its superstructure. In the case of isolated footings, the rupture was diverted very locally and in general followed the "free-field" path undeterred. Adjusting the weight of the structure in the FE models revealed that increased weight caused stresses in the soil at a greater depth. As a result, the rupture path was altered at a deeper level. A trend was noticed in both the 
isolated and rigid foundations such that the depth at which the rupture deviated from the "free-field" path tended to be equal to the width of the foundation element.

\subsection{Paper by Duncan and Lefebvre (1973): Earth Pressures on Structure Due to Fault Movement}

If a structure is to be designed to resist loads imposed by fault offset, then it is essential that the loads be known. To develop these loads, an experiment performed by Bechtel in 1973 evaluated the earth pressures on an embedded circular structure with $50 \%$ of the structure on either side of the fault. The results determined the how pressure loads induced by the faulting acted on periphery of the structure. Finite element testing of the same structure was used to compare the variation in stress and strain at the edges of the structure.

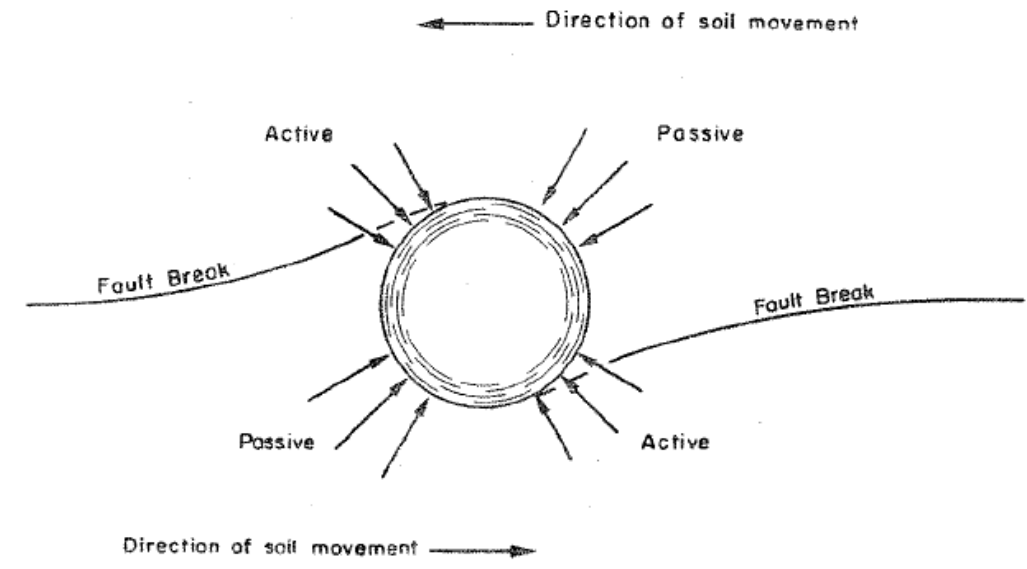

Fig. 3.5-A: Pressure wedges from fault offset (Duncan \& Lefebvre 1973).

The structure tested was a solid cylinder embedded into the soil. The experiment showed that strong structures divert the faulting around it. Weak structures that are unable to resist the loads will experience a high rate of deformation and rip apart with the fault break passing through the structure. Fig. 3.5-A idealizes how 4 pressure wedges 
form as the fault offsets - 2 passive wedges and 2 active wedges. The highest areas of pressure occur in the passive region as the earth presses into the structure. As failure in the soil occurs, the ground surface bulges up at the face of the structure. In the active regions, the ground is moving away from the structure resulting in decreased pressure regions. The reduction in the passive regions occurs simultaneous with increased pressure in the active regions.

A finite element analysis of the structure simulated the fault rupture by applying loads at the locations of passive pressure wedges. The results verified the physical test, and changes in pressure of the surrounding soil occurred at the back, the bottom, and at the front of the structure. Active pressure at the back of the structure decreased from at rest values as the structure moved relative to the ground. A minimum active pressure was held constant in this region. At the base of the structure, the underlying movement of the soil developed shear stresses along the base to resist movements. The stresses increased steadily until the imposed displacement exceeded the strength of the soil and the structure was mobilized. The shear stress value for at failure due to shear is calculated as:

$$
\tau_{\mathrm{f}}=\mathrm{p} \tan \varphi
$$

where:

$$
\begin{aligned}
& p=\text { vertical stress due to weight of the structure and the soil } \\
& \varphi=\text { friction angle of soil. }
\end{aligned}
$$

The analysis further revealed that the most critically stressed planes are not horizontal because failure occurs on other planes before the strength of the horizontal plane is fully developed. Added strength based on position with respect to the direction of fault rupture showed that the shear failure would only develop following active failures. Soil 
elements that piled up as active failure occurred helped to strengthen the soil in critical shear regions.

Complete passive failure was the last to occur as the structure moved against the soil. Although surface passive failure occurred, a large relative displacement between the structure and the soil was needed before total passive failure could occur.

\subsection{Paper by Murbach, Rockwell, and Bray (1999): The Relationship of Foundation Deformation to Surface and Near-Surface Faulting Resulting from the 1992 Landers Earthquake}

The surface rupture in seen in the 1992 Landers earthquake caused damage to various structures. Extensive faulting was recorded given the area's little to no vegetation. Studying the effects on the Lannom residence foundation's revealed the role of a decoupling layer to reduce deformation in the structure as mentioned in Section 4.1. Broad shear zones were mapped in areas outside indicated potential hazard region, bringing to light the effectiveness of the Alquist-Priolo act. 


\subsection{CASE STUDIES OF STRUCTURES}

This chapter presents major earthquakes where surface fault rupture was prevalent and heavily impacted areas populated with buildings, various other structure types, and major lifelines. Table 4-A identifies the earthquakes investigated and lists the corresponding relevant information. The case histories provided in the following sections document structural response to surface offset. They identify the parameters that influence performance and are explained in Section 6.2.

Table 4-A: Summary of Case Study Earthquakes

\begin{tabular}{cccccc}
\hline Earthquake & Date & Fault Type & Epicenter & $\mathbf{M}_{\mathbf{w}}$ & Casualties \\
\hline Landers & Jun 28, 1992 & Strike-Slip & California & 7.3 & 3 \\
Izmit(Kocaeli) & Aug 17, 1999 & Strike-Slip & Turkey & 7.4 & 17,225 \\
Chi-Chi & Sep 21, 1999 & Reverse & Taiwan & 7.6 & 2,400 \\
Duzce & Nov 12, 1999 & Strike-Slip & Turkey & 7.1 & 894 \\
Denali Fault & Nov 3, 2002 & Strike-Slip & Alaska & 7.9 & 0 \\
\hline
\end{tabular}




\subsection{Landers, California Earthquake, 28 June 1992}

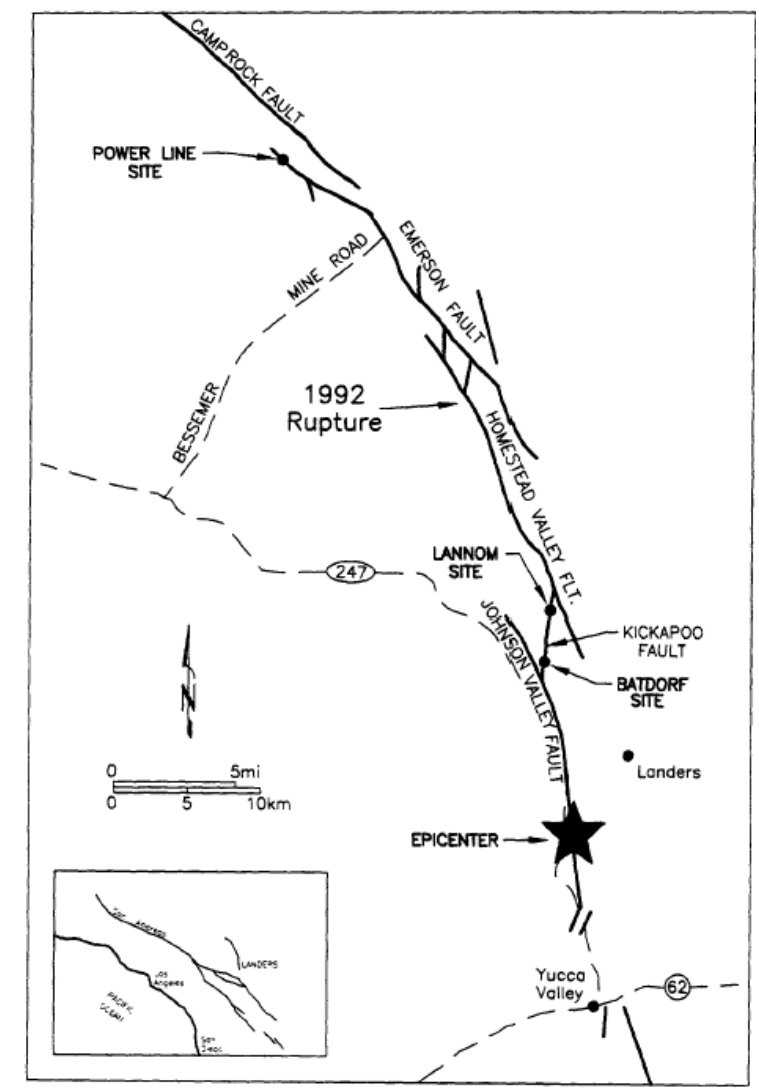

Fig. 4.1-A: Fault traces in '92 Landers earthquake (Murbach 1999).

The 1992 Landers earthquake shook a region in southeastern California with a moment magnitude of 7.3. The earthquake rupture occurred across three fault segments with a total rupture length of 70 kilometers with a broad shear zone of approximately 80 kilometers wide. The rupture lasted for a total of 24 seconds, less than 4 seconds at any one location (Yeats 1997). Extensive surface fracture characterized the quake and had maximum displacement of 6.3 meters along the Emerson fault (Murbach 1999). The area is sparsely populated and very few structures were affected by the numerous surface ruptures. The fatalities from the quake totaled three; two of which resulted from heart attacks. 


\subsubsection{Lannom Residence}

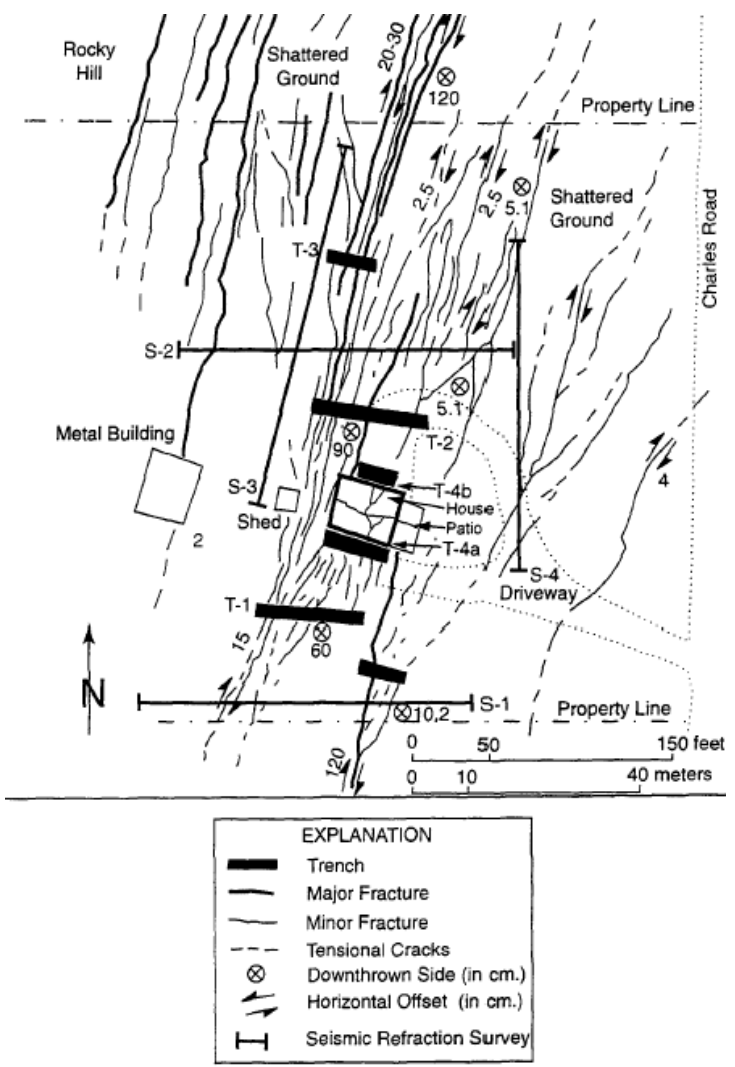

Fig. 4.1-B: Mapped shear zone near Lannom home (Murbach 1999).

\begin{tabular}{ll}
\hline Local Fault Behavior & Right Lateral \\
\hline Surface Offset & $\begin{array}{l}1.2 \mathrm{~m} \text { Horiz } \\
\text { Slight Vert }\end{array}$ \\
\hline $\begin{array}{l}\text { Percentage of } \\
\text { Structure on each side } \\
\text { of the fault }\end{array}$ & $\begin{array}{l}100 \text { (On a Broad } \\
\text { Shear Zone) }\end{array}$ \\
\hline Structure & Wood Frame \\
\hline Foundation Type & Slab-on-Grade \\
\hline
\end{tabular}

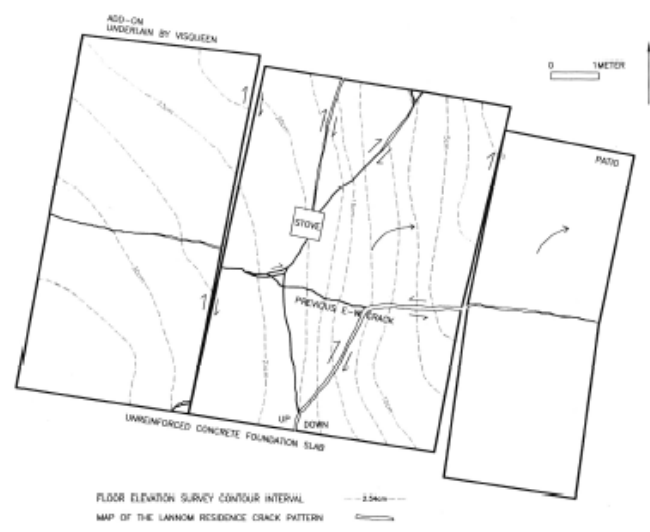

Fig. 4.1-C: Slab Plan (Bray 2001).

The Lannom residence was located along a newly active portion of the Kickapoo fault trace (Fig. 4.1-A) that ruptured in the 1992 Landers earthquake. The single story home was situated directly above a broad shear region where the ground displacement along several parallel cracks. The structure was approximately 30 years old and was a single-story wood frame house with an unreinforced slab-on-grade foundation. "The footing depth was generally placed to 30 centimeters below grade with a 10 centimeter thick interior slab" (Murbach 1999). The western slab portion was constructed during an addition to the house and underlain with a layer of polyethylene sheeting (Visqueen) used as a vapor barrier. 
Damage to the two slabs was examined in a field investigation, revealing that the presence of the barrier layer under the western slab reduced the extent of cracking. This layer decoupled the slab from the ground, thereby reducing the shear strain and thus the tension cracks seen by the slab. Many of the new cracks to the main slab developed from existing shrinkage and joint cracks. Fig. 4.1-C shows the difference in tension cracks in the two slabs. The central slab is unreinforced and displayed more cracking. Leftmost slab was newer and decoupled from the ground with a sheet of Visqueen. 


\subsection{Izmit (Kocaeli), Turkey Earthquake, 17 August 1999}

On August 17, 1999 a magnitude 7.4 earthquake ruptured the North Anatolian Fault with an epicenter located 90 kilometers east of Istanbul near Izmit. More than 17,000 people lost their lives with thousands more injured. The economic toll was estimated to total more than 6 billion dollars (US). The fault mechanism is right-lateral strike slip with an average slip rate of $25 \mathrm{~mm} / \mathrm{yr}$. The Izmit earthquake is of interest to California researchers as the mechanism and slip rate are similar to that of the San Andreas Fault, which has a slip rate of 22-24 mm/yr (USGS). Ground failure due to liquefaction and surface rupture were common in this earthquake, including in densely populated regions where hundreds of thousands homes and businesses badly damaged. Surface rupture extended $110 \mathrm{~km}$ with an average vertical offset of $5.5 \mathrm{~m}$ and an average horizontal offsets of $2.3 \mathrm{~m}$. Though the fault mechanism is categorized as strike-slip, localized areas experienced offsets where the vertical component was a dominant feature.

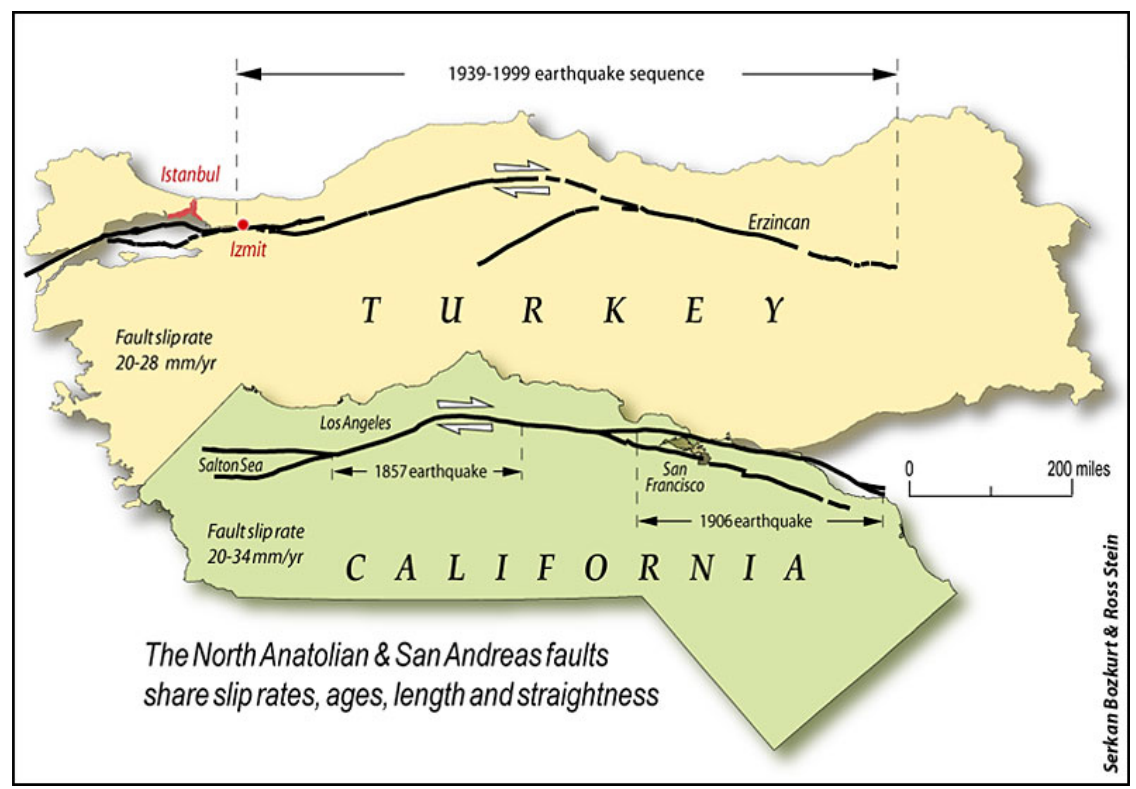

Fig. 4.2-A: North Anatolian Fault versus the San Andreas Fault (USGS). 


\subsubsection{Residence in Arifiye}

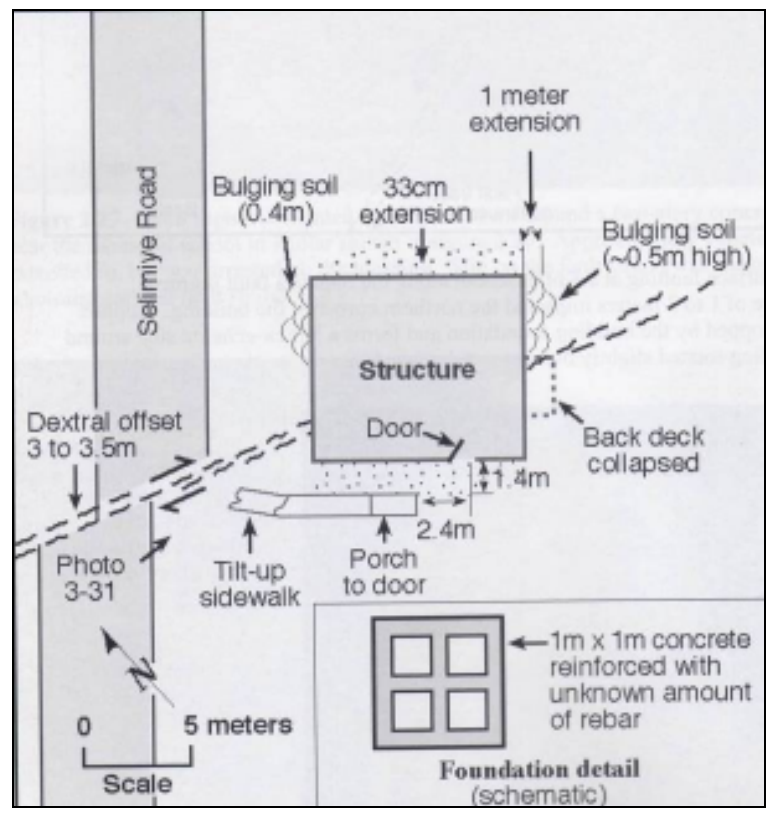

Fig. 4.2-B: Plan of Arifiye Residence (Lettis et al.2000).

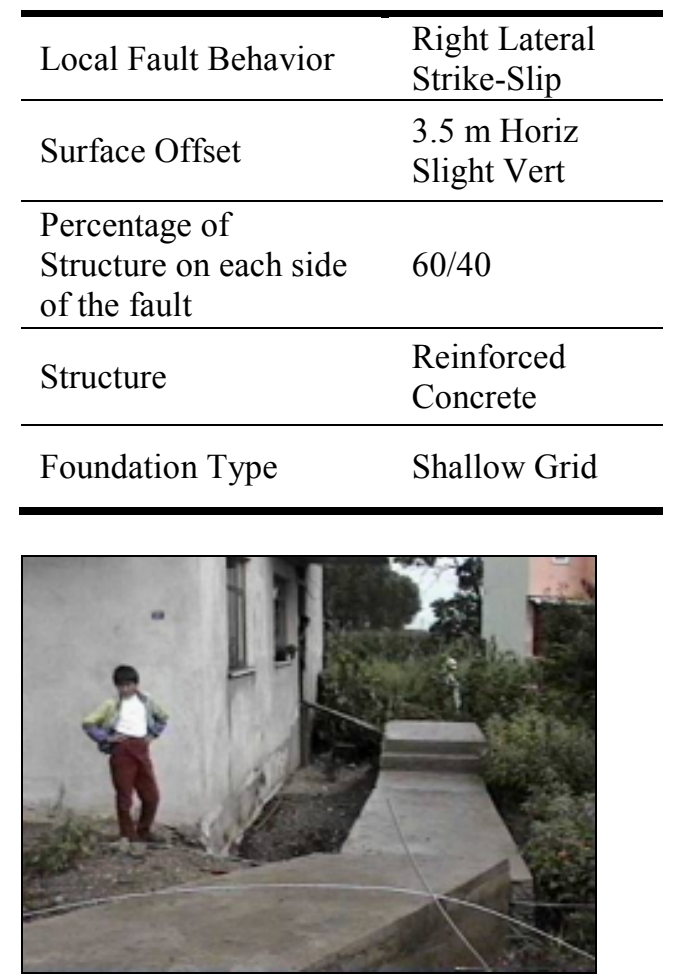

Fig. 4.2-C: Sidewalk Displaced (GEER).

The two story residence is located on the Sakarya Fault Segment of the North Anatolian fault. The main fault trace ruptured directly through the structure as seen in Fig. $4.2-\mathrm{B}$, about $60 \%$ of the floor plan on the north side of the fault and $40 \%$ of the floor plan on the south side of the fault. The fault ruptured approximately 3.5 meters at the surface and caused little damage to the structure. The sidewalk originally abutted the structure until it was displaced 3.2 meters eastward by the fault displacement, see Fig. 4.2-C. The 1 meter by 1 meter shallow reinforced concrete grid foundation appeared to be sufficiently stiff as to decouple the house from the passing soil. Patches of bulging soil were found along the northwestern and northeastern walls of the house. 


\subsubsection{Gölcük Naval Base Bunker}

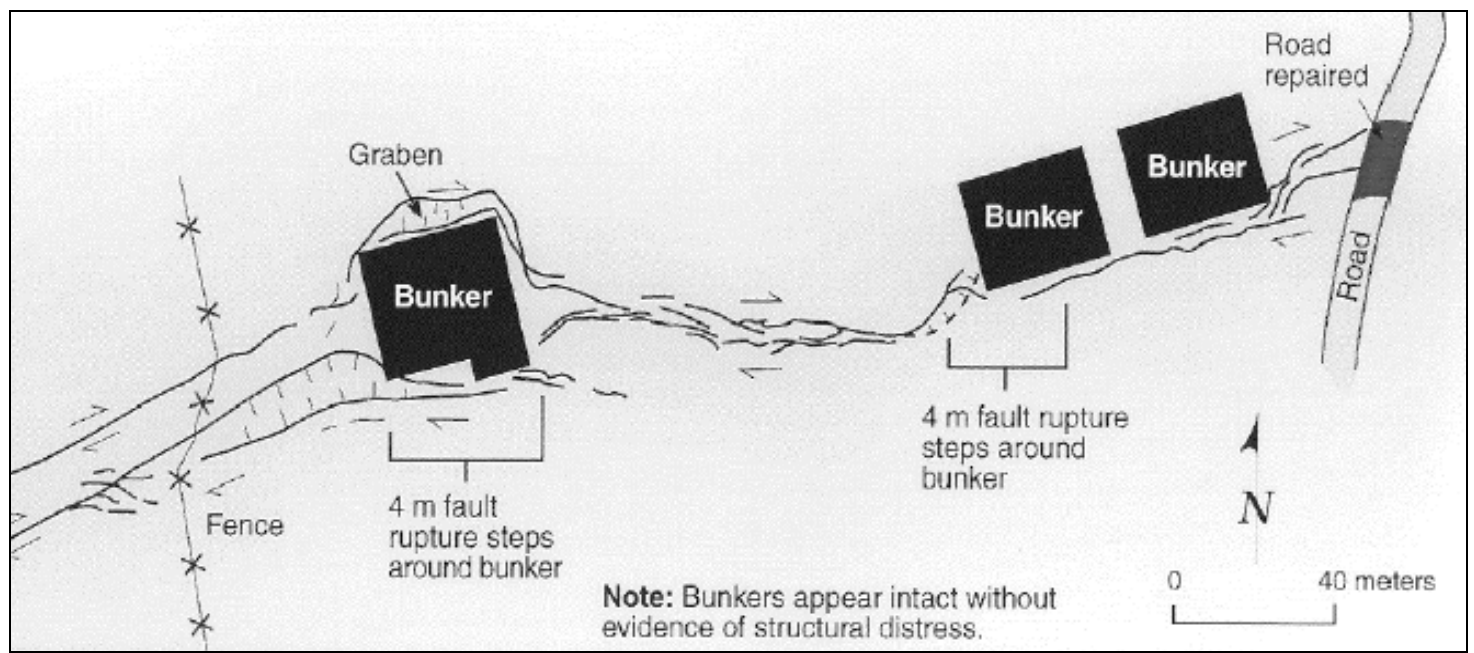

Fig. 4.2-D: Fault rupture at bunkers on the Gölcük Naval Base (Lettis et al. 2000).

\begin{tabular}{ll}
\hline Local Fault Behavior & Strike-Slip \\
\hline Surface Offset & $\begin{array}{l}3-4 \mathrm{~m} \text { Horiz } \\
\text { Slight Vert }\end{array}$ \\
\hline $\begin{array}{l}\text { Percentage of } \\
\begin{array}{l}\text { Structure on each side } \\
\text { of the fault }\end{array}\end{array}$ & $50 / 50$ \\
\hline Structure & $\begin{array}{l}\text { Heavily Reinforced } \\
\text { Concrete Bunker }\end{array}$ \\
\hline Foundation Type & Not Indicated \\
\hline
\end{tabular}

A bunker at the Gölcük Naval

Base spanned the main fault trace of

Gölcük segment on the North Anatolian

fault. The fault laterally displaced

approximately 4 meters in a right-lateral

behavior, rotating the bunker. No

apparent structural damage to the bunker was recorded due its heavy construction of

reinforced concrete. The massive concrete bunkers caused the surface rupture to divert around the bunkers (Bray 2001). 


\subsubsection{Koran School}

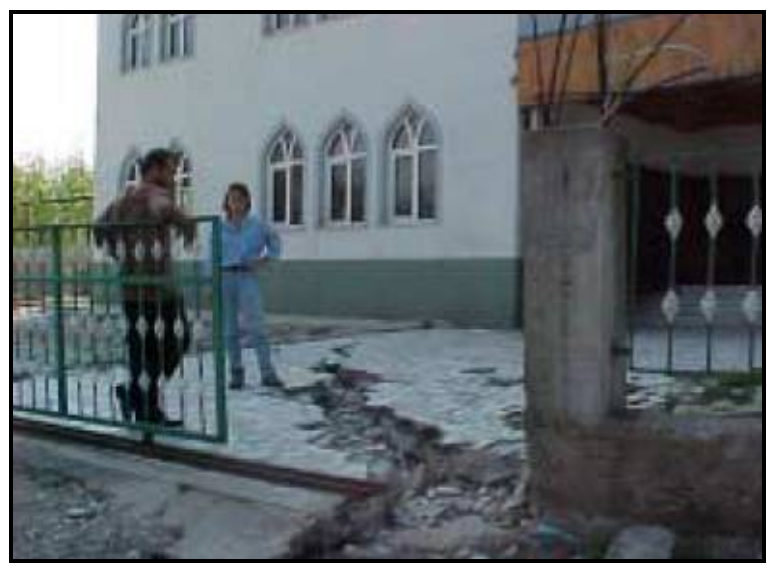

\begin{tabular}{ll}
\hline Local Fault Behavior & Strike-Slip \\
\hline Surface Offset & $\begin{array}{l}\text { 1-2 m Horiz } \\
\text { Slight Vert }\end{array}$ \\
\hline $\begin{array}{l}\text { Percentage of } \\
\text { Structure on each side } \\
\text { of the fault }\end{array}$ & $5 / 95$ \\
\hline Structure & Unknown \\
\hline Foundation Type & Unknown \\
\hline
\end{tabular}

Fig. 4.2-E: Fault passing under Koran school (Bray 2001).

A segment of the Sapanca fault trace of the North Anatolian fault directly ruptured under the corner of a school building, shearing approximately 1-2 meters. Only a small portion of the building was situated over the displaced fault. The fault passed under the left corner of the Koran school, see Fig 4.2-E showing visible surface rupture heading toward building. No damage to the walls or foundation was evident; however, the buildings presence resulted in en-echelon stepping in the surrounding soil. This case study indicates that if smaller portions of the structure overly the offsetting fault, it is likely that it will be anchored and less likely to be damaged. 


\subsubsection{Concrete MRF Building Under Construction East of Gölcük}

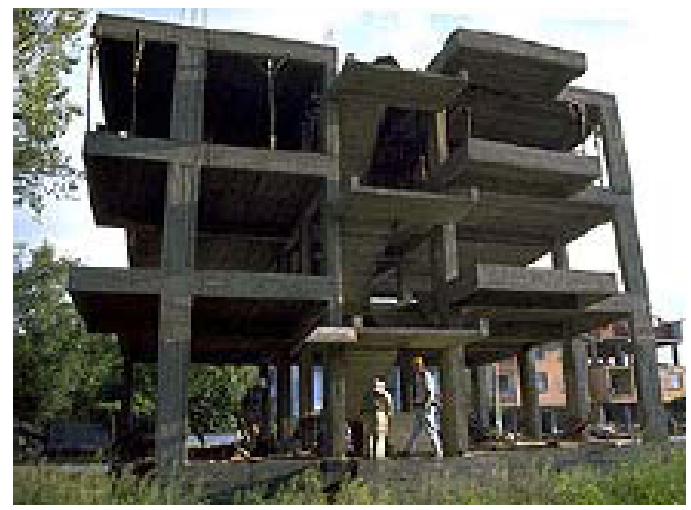

\begin{tabular}{ll}
\hline Local Fault Behavior & Strike-Slip \\
\hline Surface Offset & $\begin{array}{c}\text { 1m Horiz } \\
\text { Slight Vert }\end{array}$ \\
\hline $\begin{array}{l}\text { Percentage of } \\
\text { Structure on each side } \\
\text { of the fault }\end{array}$ & $15 / 85$ \\
\hline Structure & $\begin{array}{l}\text { Reinforced Concrete } \\
\text { MRF }\end{array}$ \\
\hline Foundation Type & 1m Deep Raft \\
\hline
\end{tabular}

Fig. 4.2-F: Concrete MRF under construction (Sezen 2000).

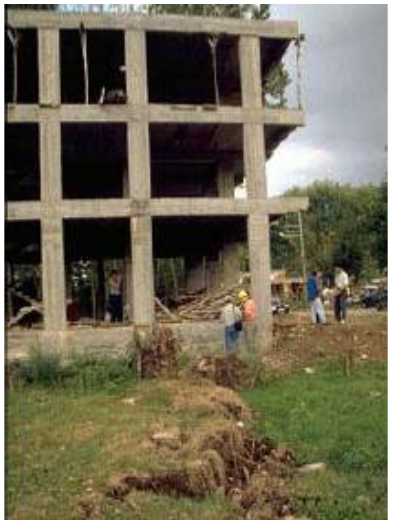

Fig. 4.2-G: Scarp at foundation (Sezen 2000).

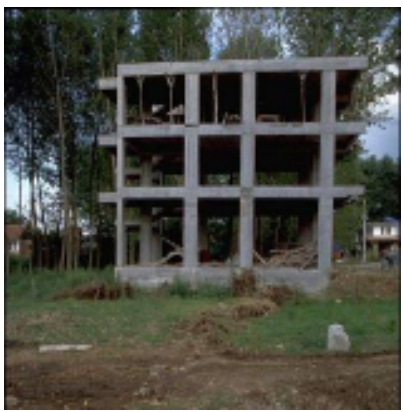

Fig. 4.2-H: Fault at corner of building (EERC).

\section{A 3-story reinforced concrete moment}

resisting frame structure was under construction at the time of the earthquake. Located directly atop a Gölcük fault segment the proportional relationship of building overlaying the fault was roughly 15$85 \%$ (Fig. 4.2-I). The fault offset horizontally a distance of 1 meter in a strike-slip mechanism. Fig. 4.2-F shows an undamaged north-south elevation and Fig. 4.2-G zooms into the resulting fault scarp. The good performance of the frame structure is attributed to the rigid 1 meter deep raft foundation on which it was constructed.

This structure demonstrates how the rigidity of the structure rooted in the soil is more resistant to the shear strain. Maximum force from the earth passive pressure on the raft can only exert a shear force equal to that of the passing soil strength. Thus, it can be 
concluded from this structure that the strength of the raft in shear was sufficient in resisting the forces imposed by the soil displacement.

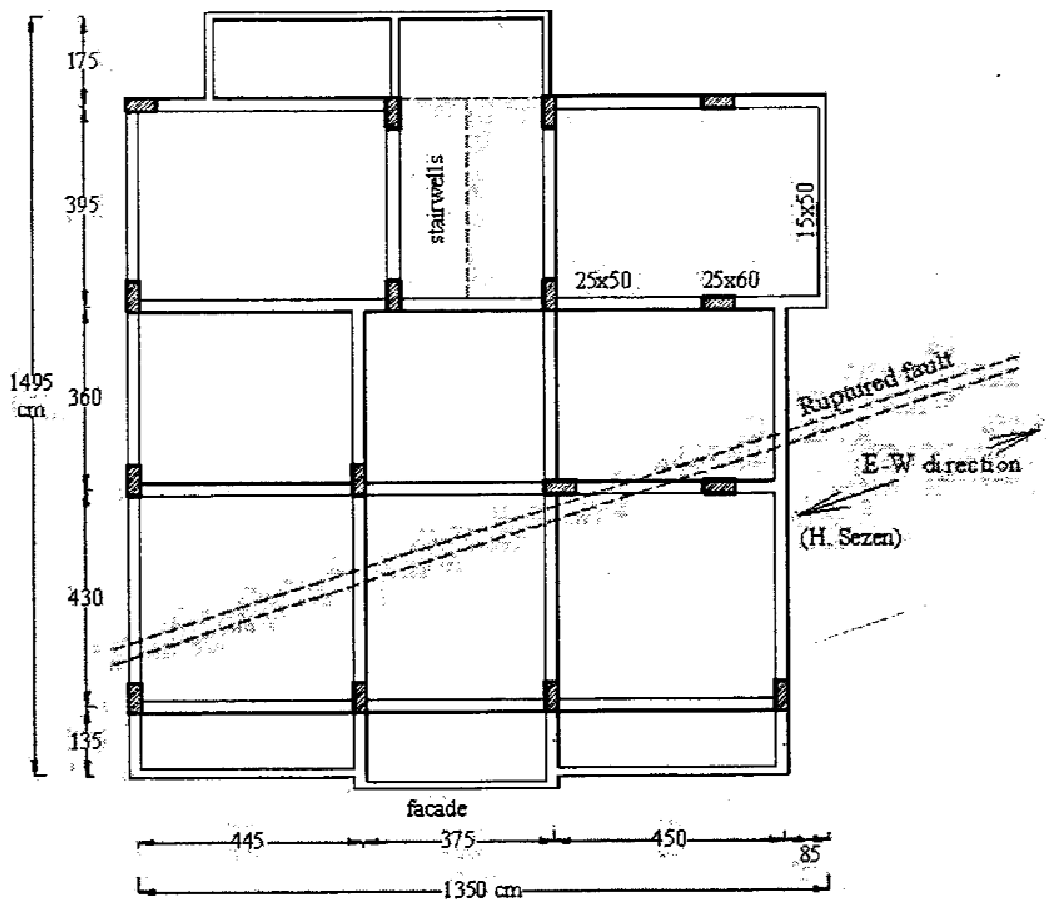

Fig. 4.2-I: Plan view of structure with fault trace under foundation (Sezen 2000). 


\subsubsection{Single Story Building in Gölcük}

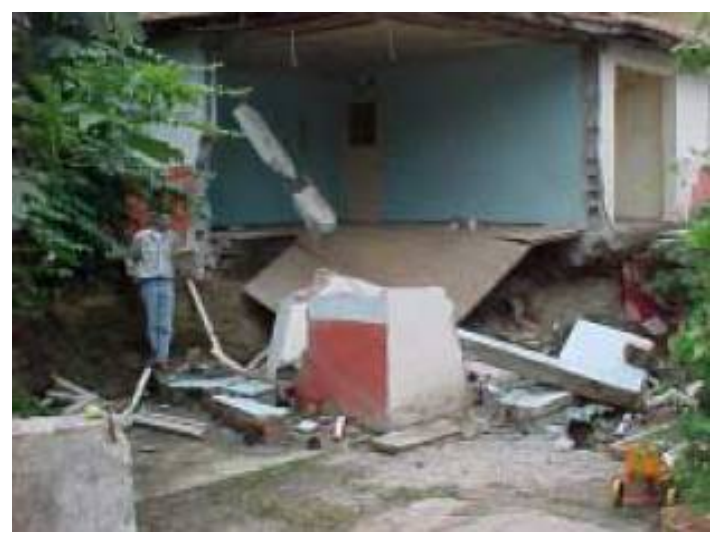

\begin{tabular}{ll}
\hline Local Fault Behavior & Dip-Slip \\
\hline Surface Offset & $\begin{array}{l}1.5 \mathrm{~m} \text { Vert } \\
0.5 \mathrm{~m} \text { Horiz }\end{array}$ \\
\hline $\begin{array}{l}\text { Percentage of } \\
\text { Structure on each side } \\
\text { of the fault }\end{array}$ & $10 / 90$ \\
\hline Structure & $\begin{array}{l}\text { Cinder Block Walls } \\
\text { with Concrete Tie } \\
\text { Beams }\end{array}$ \\
\hline Foundation Type & Shallow Grid \\
\hline
\end{tabular}

Fig. 4.2-J: Golcuk building destroyed by fault (Bray 2000)
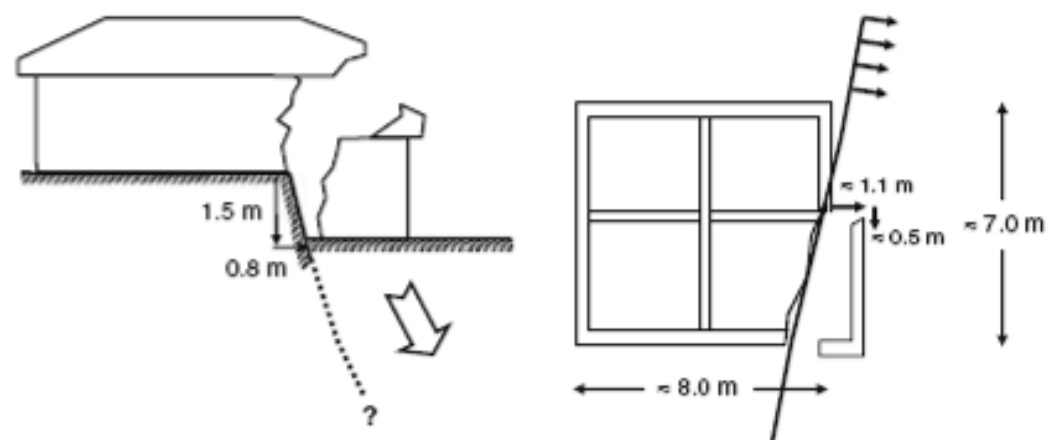

Fig. 4.2-K: Plan \& elevation of fault damage (Anastasopoulos and Gazetas 2007)

This single story building had corner overlying a primarily dip-slip segment of rupture. The corner of the structure displaced 1.5 meters down as the hanging wall receded. Poor construction techniques are attributed to preventing total collapse given the magnitude of displacement under the corner of the structure. The walls were constructed of cinder block units with concrete beams to tie the walls together (Anastasopoulos and Gazetas 2007). The roof structure was wood with tile covering. Relatively low tensile strength in the masonry units allowed the corner to shear vertically without complete collapse. This building system can be considered flexible given the construction of the house in response to the direct fault scarp offset. The foundation 
lacked rigidity in the vertical direction. Had the motion been primarily horizontal, the grid foundation would have likely been sufficiently strong in resisting offset as seen in the Arifiye Residence (Section 4.2.1). 


\subsubsection{5-Story Building in Gölcük}

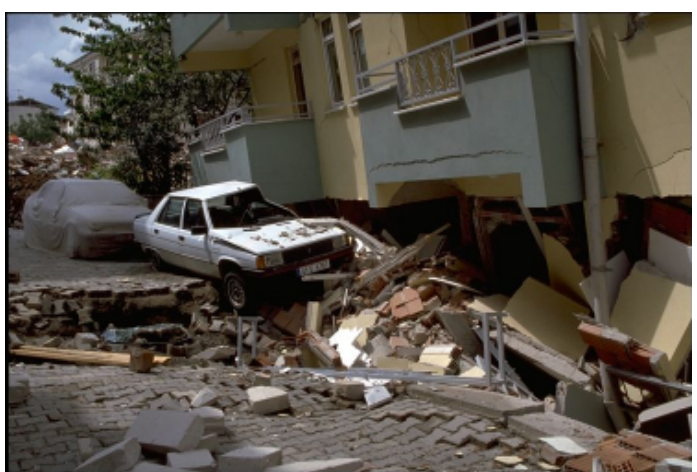

\begin{tabular}{ll}
\hline Local Fault Behavior & Strike-Slip \\
\hline Surface Offset & $\begin{array}{l}\text { 4m Horiz } \\
\text { Some Vert }\end{array}$ \\
\hline $\begin{array}{l}\text { Percentage of } \\
\text { Structure on each side } \\
\text { of the fault }\end{array}$ & $50 / 50$ \\
\hline Structure & Concrete Frame \\
\hline Foundation Type & Unknown \\
\hline
\end{tabular}

Fig. 4.2-L: Damaged building in Golcuk(EERI)

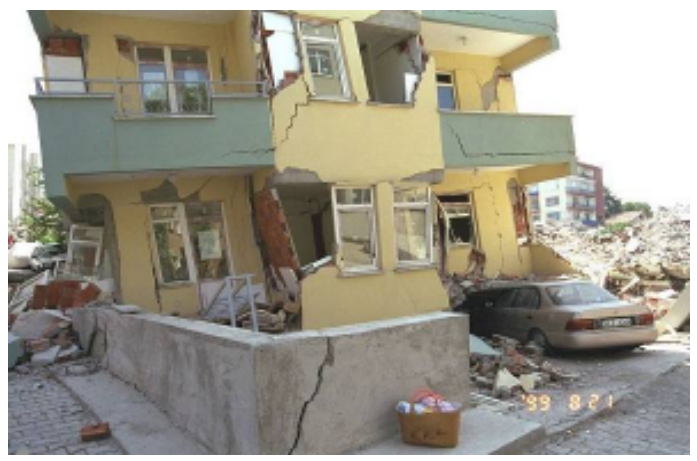

Fig. 4.2-M: Another View of damage to building (EERI)

This 5-story buildling straddling the fault collapsed due to 4meters of horizontal offset in addition to some vertical. The structure is assumed to be concrete frame with masonry infill walls. The large offset coupled with shaking triggered collapse of structural elements in the first level. 


\subsubsection{Primary School in Kullar}

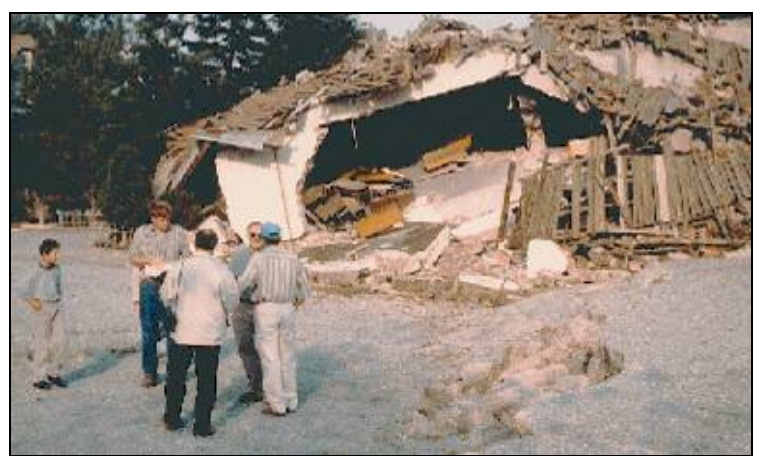

Fig. 4.2-N: Damaged school in Kullar (Lettis et al. 2000).

\begin{tabular}{ll}
\hline Local Fault Behavior & Dip-Slip \\
\hline $\begin{array}{l}\text { Length of Surface } \\
\text { Rupture }\end{array}$ & $\begin{array}{l}\sim 1 \mathrm{~m} \text { Vert } \\
\sim 1 \mathrm{~m} \text { Horiz }\end{array}$ \\
\hline $\begin{array}{l}\text { Percentage of } \\
\text { Structure on each side } \\
\text { of the fault }\end{array}$ & $50 / 50$ \\
\hline Structure & Concrete Frame \\
\hline Foundation Type & Unknown \\
\hline
\end{tabular}

This primary school in Kullar straddled the fault with $50 \%$ of the structure on each side of the fault. The structure is a concrete moment resisting frame with infill walls. From the pictures it is clear that the structure suffered complete collapse. 


\subsubsection{Mosque}

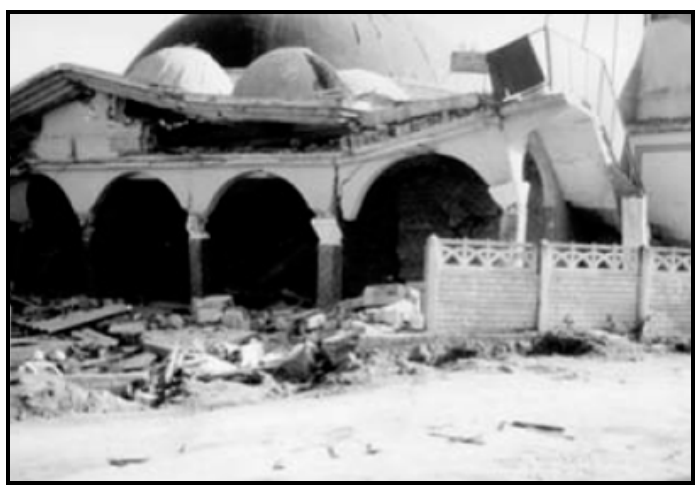

\begin{tabular}{ll}
\hline Local Fault Behavior & Dip-Slip \\
\hline Surface Offset & $1.3 \mathrm{~m}$ Vert \\
\hline $\begin{array}{l}\text { Percentage of } \\
\text { Structure on each side } \\
\text { of the fault }\end{array}$ & $10 / 90$ \\
\hline Structure & Reinforced Concrete \\
\hline Foundation Type & Isolated Footings \\
\hline
\end{tabular}

Fig. 4.2-O: Partially collapsed mosque (Anastasopoulos and Gazetas 2007).

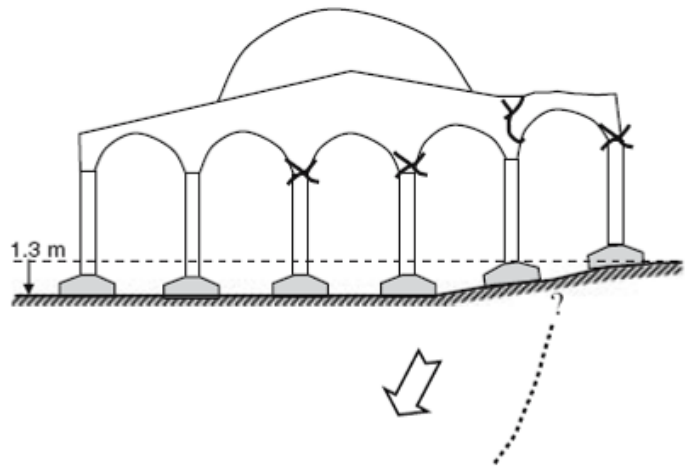

Fig. 4.2-P: Isolated column footings (Anastasopoulos and Gazetas 2007).

The mosque was constructed of reinforced concrete and the heavy domed ceilings supported on columns at their adjoining points. The columns bore on isolated footings with no ties between them, see Fig 4.2-P, creating an extremely flexible foundation system. No shear walls or tie beams were used within the superstructure, thus creating a flexible superstructure. About $90 \%$ of the structure displaced downward 1.3 meters. This concentrated stresses at the column roof connection marked in Fig. 4.2-P. High stresses at critical column joints caused failure in the connection and resulted in partial structural collapse. 


\subsection{Duzce, Turkey Earthquake, 12 November 1999}

On November 12, 1999, the Duzce fault ruptured with a moment magnitude of

7.2. The earthquake closely tailed two other large earthquakes with record surface ruptures, Kocaeli and Chi-Chi. Rupture of the Duzce Fault came as no surprise since the North Anatolian Fault (NAF) ruptured only 3 months earlier in the Kocaeli earthquake. Due to the proximity of the faults as seen in Fig. 4.3-A, it is likely the rupture of the NAF transferred strain onto the Duzce Fault inducing subsequent rupture. A maximum surface rupture of 5 meters of horizontal offset was observed near the epicenter of the Duzce earthquake.

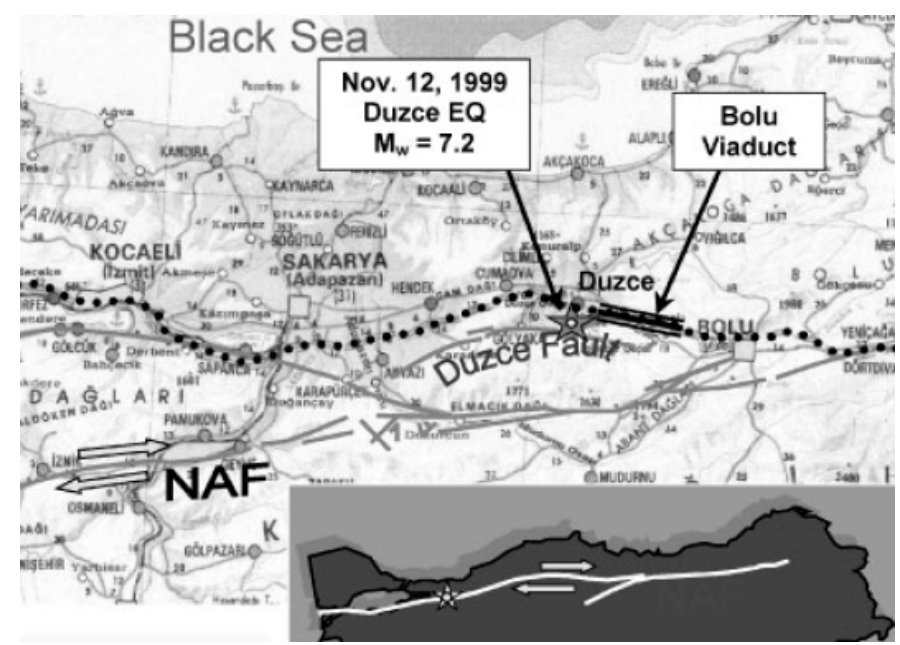

Fig. 4.3-A: The Duzce Fault (Park et al. 2004). 


\subsubsection{Bolu Viaduct}

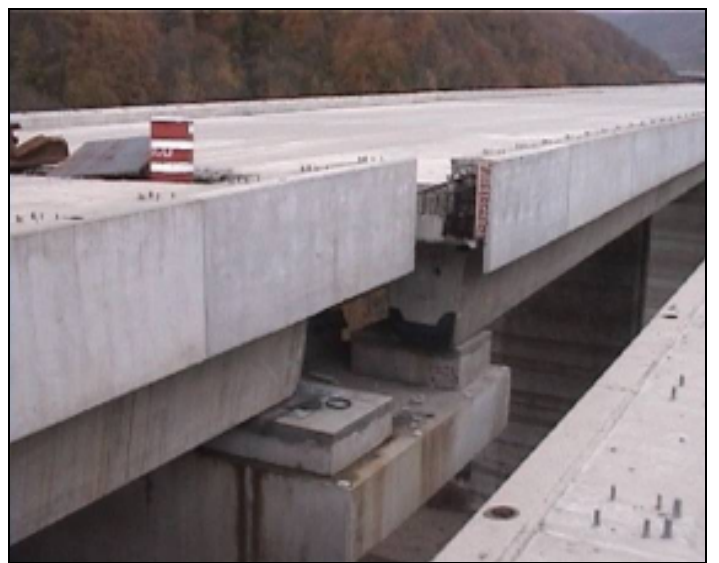

\begin{tabular}{ll}
\hline Local Fault Behavior & Strike-Slip \\
\hline Surface Offset & $1.5 \mathrm{~m}$ Horiz \\
\hline $\begin{array}{l}\text { Percentage of } \\
\text { Structure on each side } \\
\text { of the fault }\end{array}$ & $10 / 90$ \\
\hline Structure & Reinforced Concrete \\
\hline Foundation Type & $\begin{array}{l}12-1.8 \mathrm{~m} \Phi \text { Piles per } \\
\text { Pier }\end{array}$ \\
\hline
\end{tabular}

Fig. 4.3-B: Horizontal offset at Viaduct (Park et al 2004)..

The Bolu Viaduct is constructed as two parallel bridges carrying east and west bound traffic on opposite sides. The eastbound side is a 58-span system and the westbound side is a 59-span system, each span is 39.2 meters in length. The total structure is 2.3 kilometers. The decks are supported on 4.5 meter by 8 meter columns with heights varying from 4-10 meters (S.W. Park et. al. 2004). The decks were installed on a seismic isolation system of steel yielding devices in conjunction with sliding pot bearings (Fig. 4.3-C). The foundation of each column consists of 12-1.8 meter diameter drilled piles that extend an average of 30 meters into the ground.

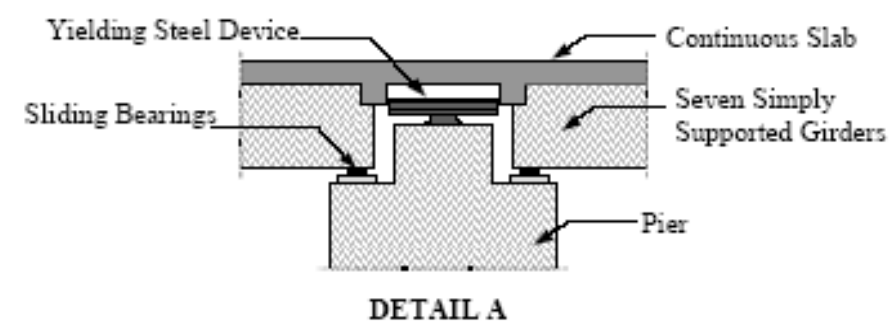

Fig. 4.3-C: Detail at pier connection to deck (Roussi 2003). 
At the time of the earthquake, the viaduct construction was almost complete. The fault rupture intersected the viaduct at piers 45 and 47 lending to a 10-90 structure to fault ratio. The isolation system had a displacement capacity of 2.1 meter; however, the imposed ground motion displacements in addition to the 1.5 meter static ground offset exceeded the isolator capacity early on in the ground shaking. With the failure of the seismic isolation system, failure of the deck joints at the top of the columns ensued and the decks displaced to a more precarious support on the edge of column piers.

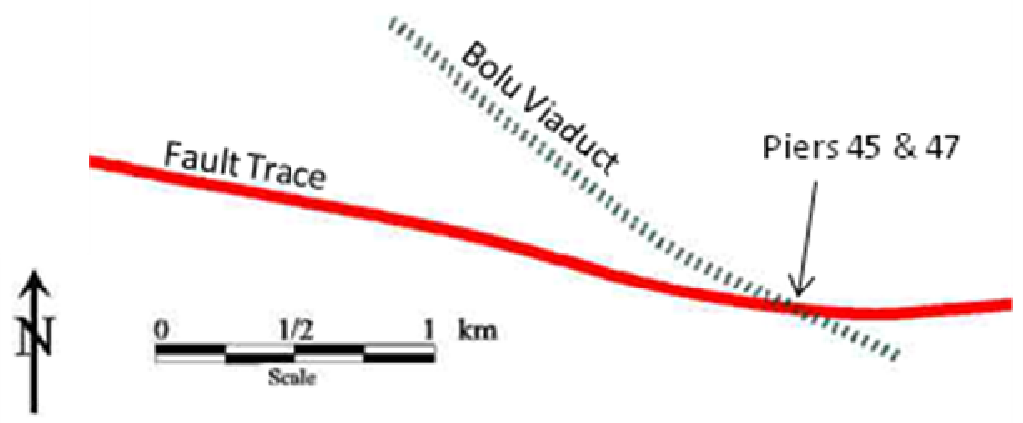

Fig. 4.3-D: Duzce Fault Trace intersects Bolu Viaduct (Roussi 2003).

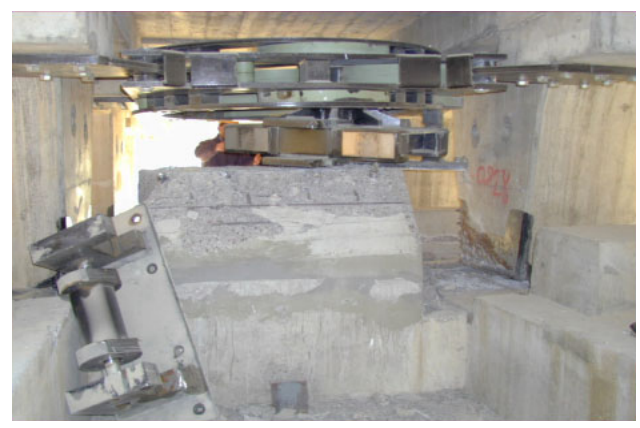

Fig. 4.3-E: Seismic isolator displaced (Park et al 2004). 


\subsection{Chi-Chi, Taiwan Earthquake, 21 September 1999}

The 1999 Chi-Chi earthquake hit Taiwan at 1:47am September 21, 1999. The Chelungpu fault ruptured at a depth of $7 \mathrm{~km}$ and produced over 90 kilometers of surface rupture. The thrust fault passed through several densely populated areas resulting in approximately twenty to thirty million dollars (US) in damage. Chi-Chi earthquake is associated with some of the largest ground offsets ever observed with vertical offsets ranging from 4-8m and horizontal offsets as great as 2-3 meters. The location, width, and style of fault-related rupture damaged determined the severity of the earthquake damage and can be seen in the following sections (Uzarski \& Arnold 2001). Damage patterns tended to be higher in the areas located on the hanging wall that offset up. Many of the structures on the footwall had little to no damage relative to those on or just off the folding scarp.

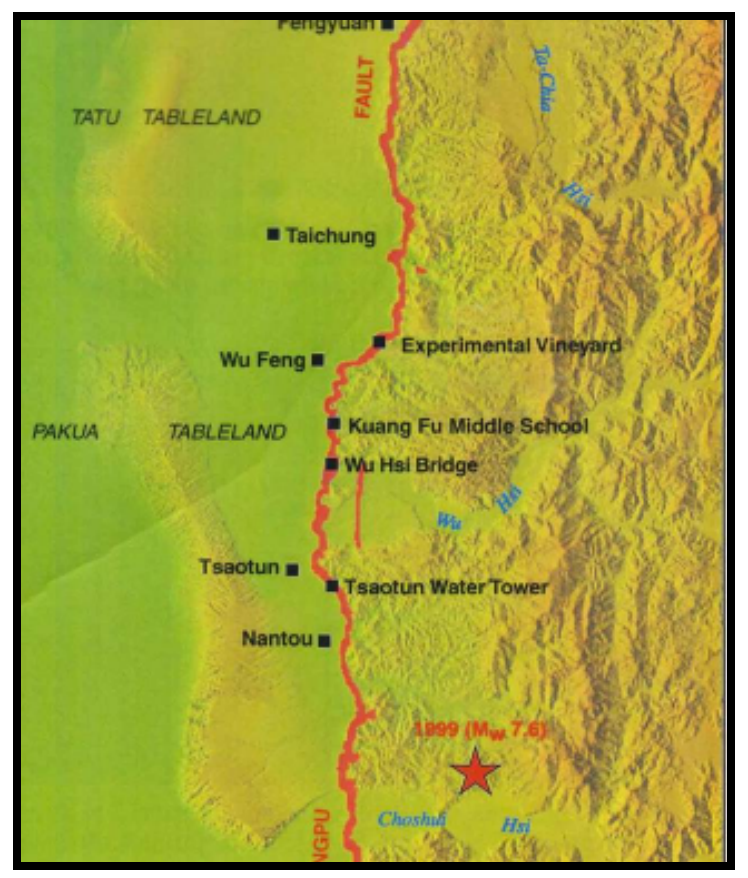

Fig. 4.4-A: Chelungpu fault trace in Taiwan (Lettis \& Associates 2003). 


\subsubsection{Shihkang Dam}

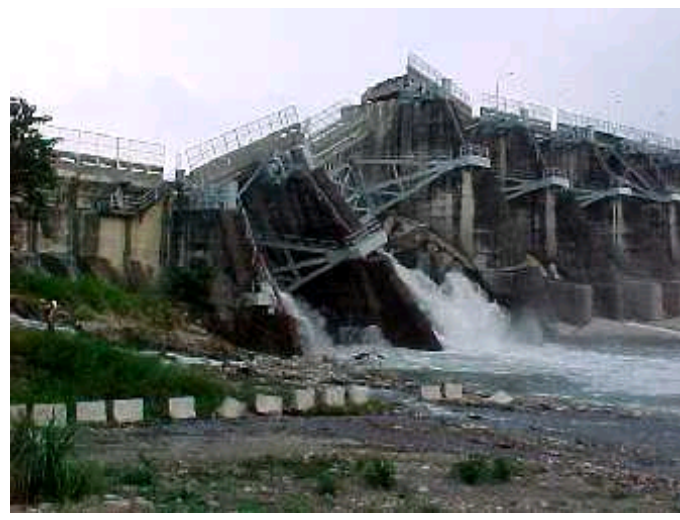

\begin{tabular}{ll}
\hline Local Fault Behavior & Dip-Slip \\
\hline Surface Offset & $\begin{array}{l}\text { 8m Vert } \\
\text { Slight Horiz. }\end{array}$ \\
\hline $\begin{array}{l}\text { Percentage of } \\
\begin{array}{l}\text { Structure on each side } \\
\text { of the fault }\end{array}\end{array}$ & $10 / 90$ \\
\hline Structure & Reinforced Concrete \\
\hline Foundation Type & Unknown \\
\hline
\end{tabular}

Fig. 4.4-B: Warped Shihking Dam Spillways (GEER).

Shihkang damn provided a substantial proportion of water to the surrounding areas. Approximately 90 percent of the dam sits on the south side of the Chelungpu fault. The dam consists of 20-spillways and gates; the two northernmost spillways were severely damaged by $8 \mathrm{~m}$ of uplift as see in Fig. 4.4-B. Mild horizontal offset was recorded as the structure was subject to mainly compressional warping and uplift of the south side's anticlinal folding. 


\subsubsection{Wu Shi Bridge}

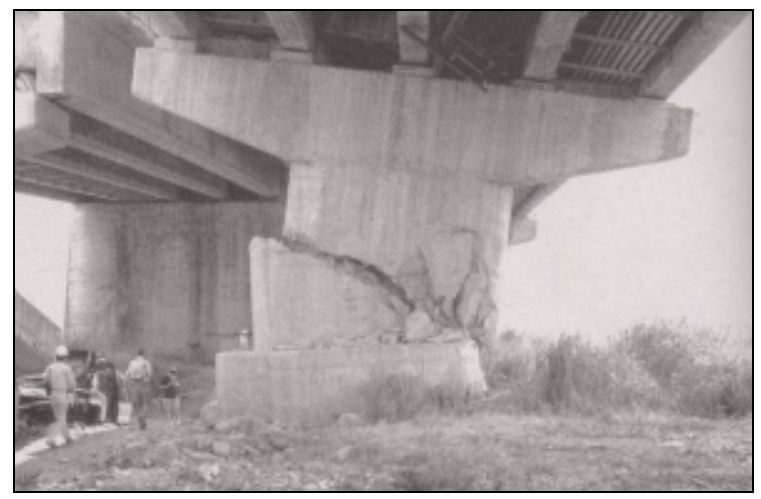

\begin{tabular}{ll}
\hline Local Fault Behavior & Dip-Slip \\
\hline Surface Offset & $1.5-2 \mathrm{~m}$ Vert \\
\hline $\begin{array}{l}\text { Percentage of } \\
\text { Structure on each side } \\
\text { of the fault }\end{array}$ & $10 / 90$ \\
\hline $\begin{array}{l}\text { Structure } \\
\text { Foundation Type }\end{array}$ & Caisson \\
\hline
\end{tabular}

Fig. 4.4-C: Shear failure in southbound pier (Lettis \& Associates 2003).

The Wu-Shi bridge consists of two parallel systems: one for southbound commute and the other for northbound. Constructed within two years of each other, the bridges are supported on two different pier systems. The southbound (west side) decks are supported on piers which are circular in plan where the northbound (east side) decks are supported by pier walls (Fig. 4.4-D). Each bridge has 18 spans, each 40 meters in length (Lettis \& Associates 2003). A caisson foundation supports the piers of both the northbound and southbound bridge decks (Lettis \& Associates 2003).

Traversed by the surface fault rupture at the northern end of the structure, the fault rupture lifted the east side of the fault approximately $1.5-2 \mathrm{~m}$ at the bridge pier locations. Failures in the structure occurred at the deck connection to the pier on the northbound bridge causing the two northernmost spans to fall (Fig. 4.4-E). On the southbound side, failure was observed as shear in the pier, but the deck did not collapse (Fig. 4.4-C). The fault rupture appears to have been influenced by the massive piers. A main fault scarp splays off at the intersection with the piers and their caissons and rejoins just on the other side of the river (Fig. 4.4-D). 


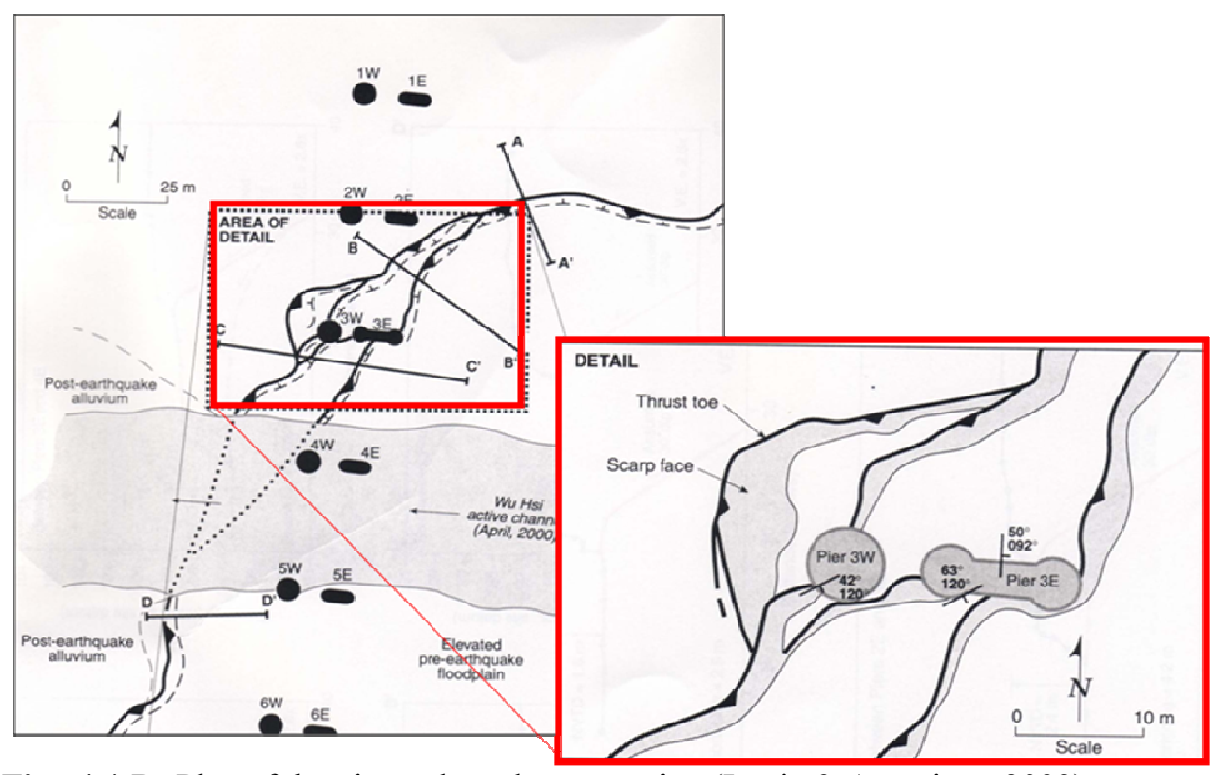

Fig. 4.4-D: Plan of the pier style and construction (Lettis \& Associates 2003).

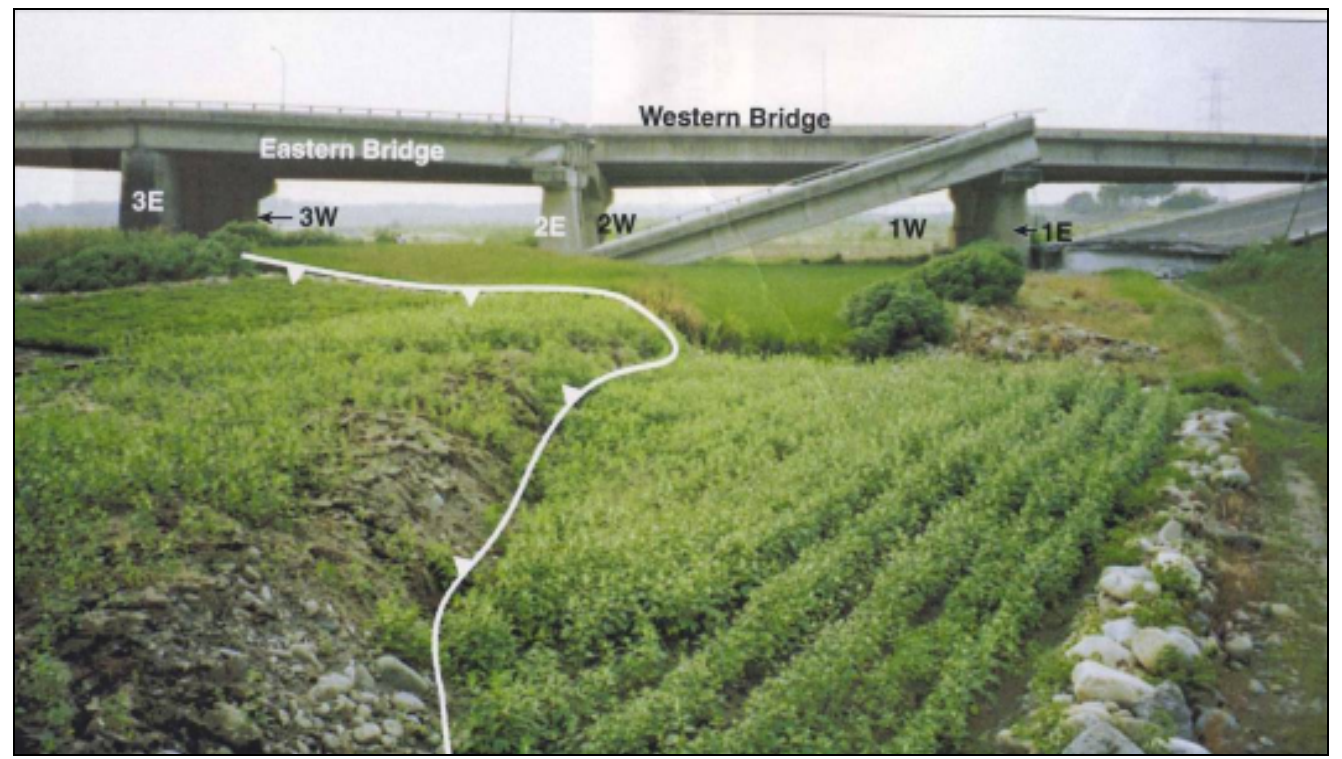

Fig. 4.4-E: Northbound decks collapses (Lettis \& Associates 2003). 


\subsubsection{Multi-story Building in Fengyuan}

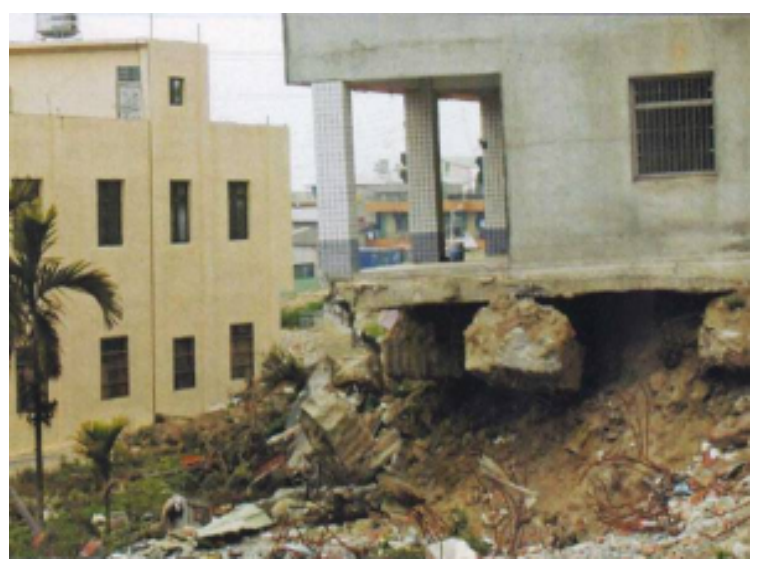

\begin{tabular}{ll}
\hline Local Fault Behavior & Dip-Slip \\
\hline Surface Offset & $4 \mathrm{~m}$ Vert \\
\hline $\begin{array}{l}\text { Percentage of } \\
\begin{array}{l}\text { Structure on each side } \\
\text { of the fault }\end{array}\end{array}$ & $10 / 90$ \\
\hline Structure & Reinforced Concrete \\
\hline Foundation Type & Unknown \\
\hline
\end{tabular}

Fig. 4.4-F: Chelungpu fault scarp near Fengyuan (Lettis \& Associates 2003).

This multi-story reinforced concrete building was positioned with $90 \%$ of the structure on the uplifting hanging wall. Despite loss of bearing under the corner, see Fig. 4.4-F, the building withstood collapse. Large grade beams allowed the structure to redistribute load in the absence of bearing at the corner the structure. This indicates that the structure was sufficiently reinforced to carry the weight of the corner through vertical shear in the walls and the beams in the foundation. This type of success can be compared to the single story building in Gölcük (Section 4.2.5) where the grid foundation was not useful in providing a secondary load path nor were the walls capable of supporting the weight of the structure. The corner sheared off the structure and localized damaged to the portion corner experiencing loss of bearing. 


\subsubsection{Wu Feng Apartment Building}

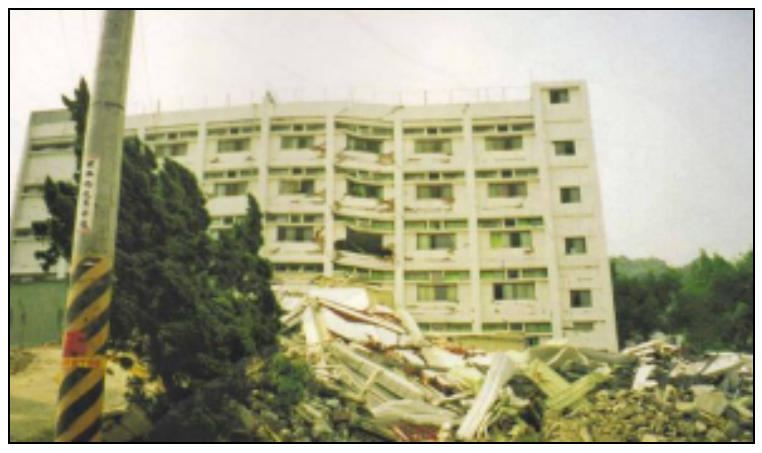

Fig. 4.4-G: Damage to multi-story apartment building (Lettis \& Associates 2003).

\begin{tabular}{ll}
\hline Local Fault Behavior & Dip-Slip \\
\hline Surface Offset & 2m Vert \\
\hline $\begin{array}{l}\text { Percentage of } \\
\text { Structure on each side } \\
\text { of the fault }\end{array}$ & $50 / 50$ \\
\hline Structure & $\begin{array}{l}\text { Reinforced Concrete } \\
\text { Frame w/ Masonry } \\
\text { Infill }\end{array}$ \\
\hline Foundation Type & Unknown \\
\hline
\end{tabular}

This apartment building in Wu-Feng straddled the 2 meters of vertical fault offset with approximately equal portions located on either side of the fault. Structural damage appears to have been isolated to the center of the building. Limited information on this building was available however, it can be postulated that adequate ductility in the damaged spandrel joints allowed for load redistribution to prevent total catastrophic collapse. Collapsed buildings are seen in the foreground. 


\subsubsection{Kuangfu Middle School}

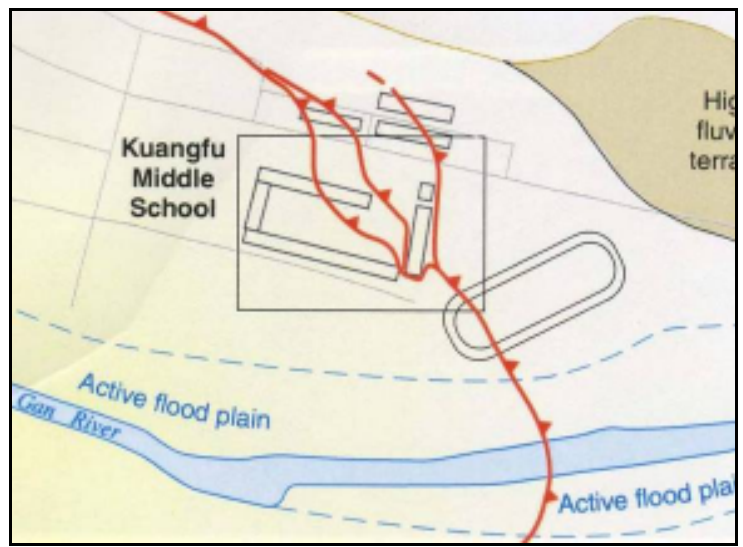

\begin{tabular}{ll}
\hline Local Fault Behavior & Dip-Slip \\
\hline Surface Offset & $2.4-3.2 \mathrm{~m} \mathrm{Vert}$ \\
\hline $\begin{array}{l}\text { Percentage of } \\
\text { Structure on each side } \\
\text { of the fault }\end{array}$ & $10 / 90$ \\
\hline Structure & Reinforced Concrete \\
\hline Foundation Type & Isolated Footings \\
\hline
\end{tabular}

Fig. 4.4-H: Fault trace through the middle school (Lettis \& Associates 2003).

The Chelungpu thrust fault rupture propagated through the center of Kuangfu Middle school. Structures that were $40 \mathrm{~m}$ or further from the scarp on the hanging wall experienced minor or no damage (Lettis \& Associates 2003). Three localized faults appear to have branched off the main fault trace as it approached the campus and coincided with the eastern classroom building. The splaying of the fault can be seen in Fig. 4.4-H.

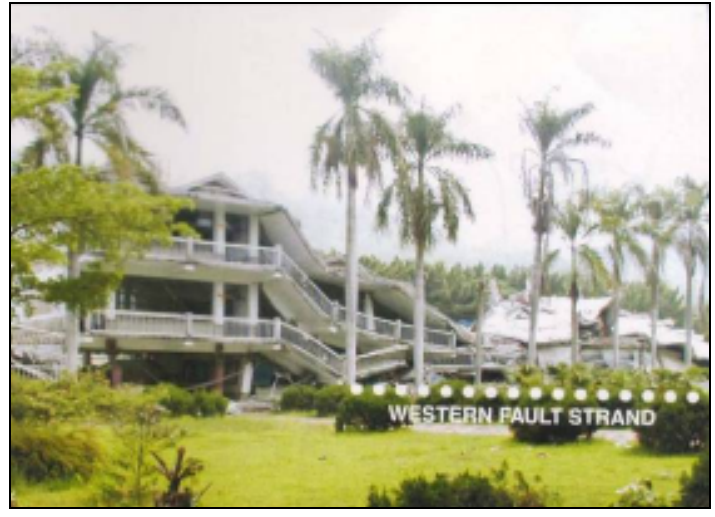

Fig. 4.4-I: The Northern Classroom Building collapse (Lettis \& Associates 2003).

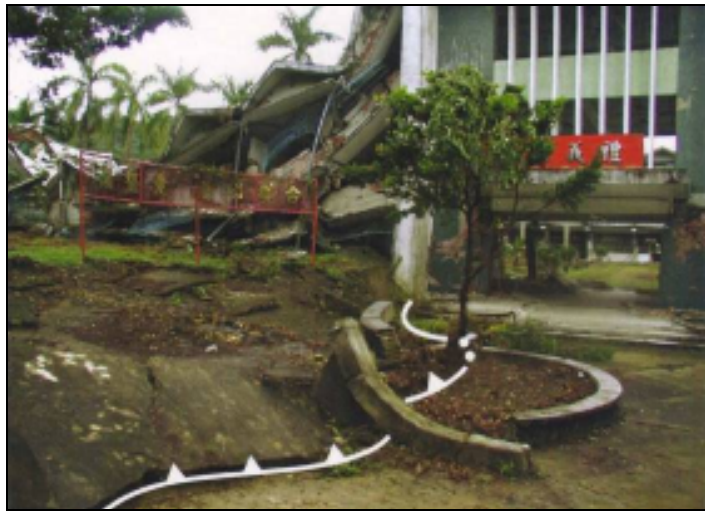

Fig. 4.4-J: West View, Northern Classroom Building (Lettis \& Associates 2003).

The fault rupture buckled the sports track with approximately 2.8 meters of vertical offset. Prior to the earthquake the sports track was level, thus providing a good 
example of the magnitude of ground distortion. As the fault rupture propagated north towards the Eastern Classroom Building, three branches splay off the main trace. A basement at the south end of the eastern classroom building is believed to have caused the fault to diverge providing stiffness at a sub grade level. Stress cracking on the south wall show the force exerted on the structure from surface rupture (Fig. 4.4-K).

A subsequent branch of the fault passed directly through the Northern Classroom building. At the location where the fault bisected the Northern Classroom Building the structure is very flexible with gravity columns along the exterior combined with an open hallway in the first story. The loss of these columns due to fault offset resulted in collapse (Fig. 4.4-I \& Fig. 4.4-J).

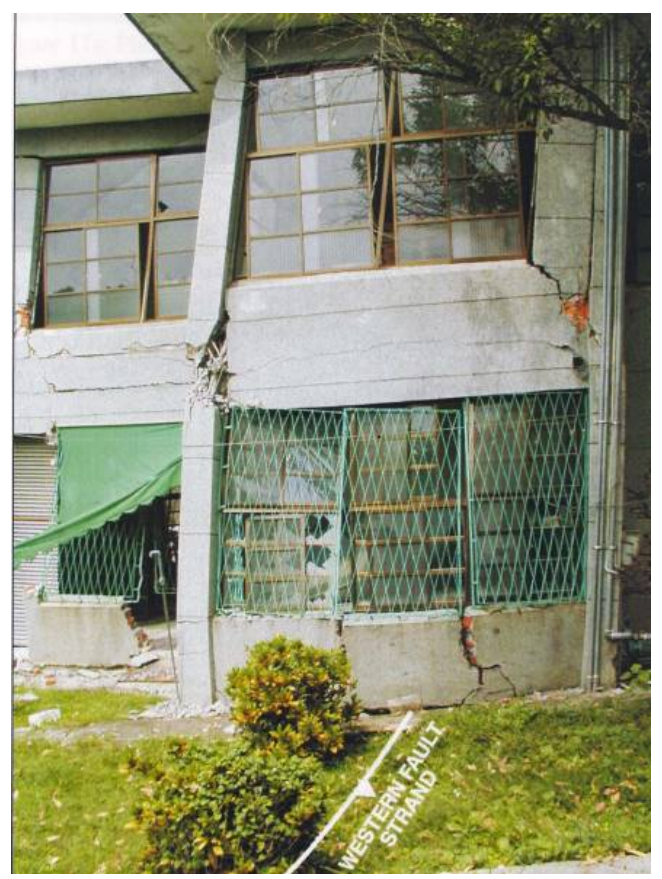

Fig. 4.4-K: Wall cracks in Eastern Classroom Building (Lettis \& Associates2003). 


\subsection{Denali Fault, Alaska Earthquake, 3 November 2002}

The Denali Fault Earthquake was the strongest earthquake ever recorded in the interior of Alaska. There was little structural damage that resulted from 8.0 magnitude earthquake and there were no deaths reported, however, the earthquake caused thousands of landslides throughout the surrounding steep mountainous topography. The earthquake generated seismic waves that were felt in a lake near Seattle, where houseboats were knocked off their moorings, and as far away as Louisiana where several seiches were observed (CGS). The overall mechanism of the fault is a right lateral strike slip, similar to the San Andreas Fault that runs the length of California. 


\subsubsection{Trans Alaska Pipeline (TAPS)}

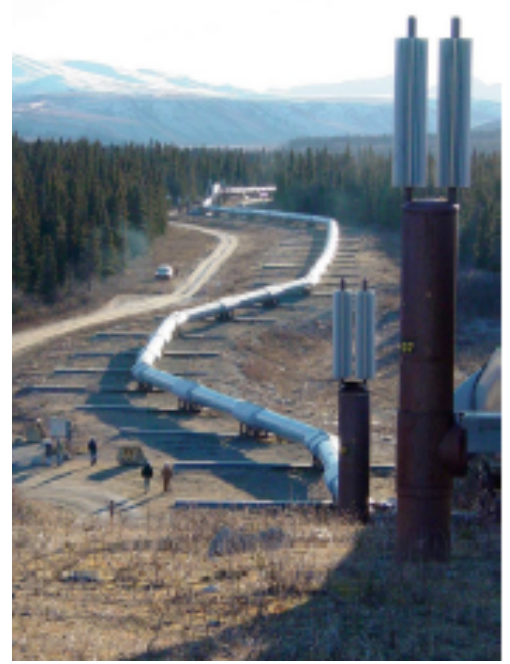

\begin{tabular}{ll}
\hline Local Fault Behavior & Strike-Slip \\
\hline Surface Offset & $\begin{array}{l}5.5-6 \mathrm{~m} \text { Horiz } \\
1.5 \mathrm{~m} \text { Vert }\end{array}$ \\
\hline $\begin{array}{l}\text { Percentage of } \\
\text { Structure on each side } \\
\text { of the fault }\end{array}$ & $50 / 50$ \\
\hline & $\begin{array}{l}\text { Reinforced concrete } \\
\text { beams with Teflon } \\
\text { shoes supporting } \\
\text { steel oil pipe }\end{array}$ \\
Structure & $\begin{array}{l}\text { Reinforced concrete } \\
\text { slider beams }\end{array}$ \\
\hline Foundation Type & \\
\hline
\end{tabular}

Fig. 4.5-A: Pipeline crossing Denali Fault (Honnegar2004).

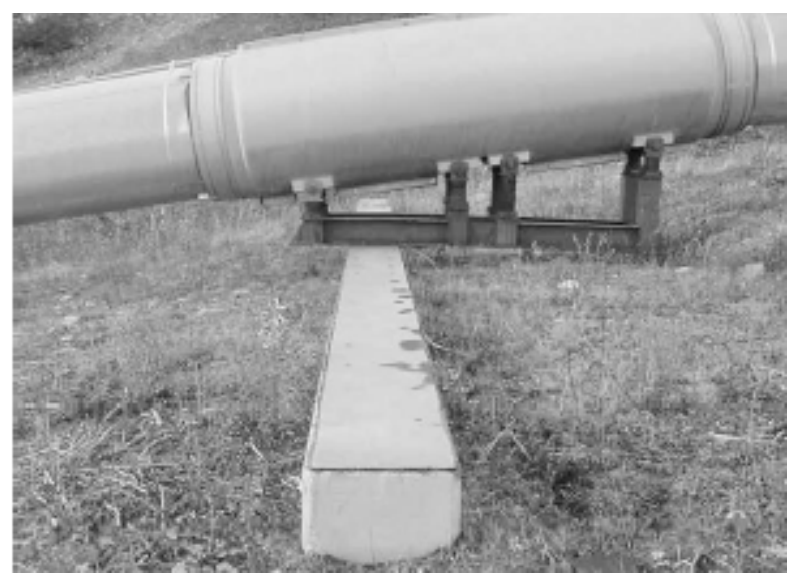

Fig. 4.5-B: Concrete slider beam and teflon shoe (Honnegar 2004).
At the time of design and construction in the early 1970's indentifying and classifying active faults was a relatively new field. The proposed Trans Alaskan Pipeline System (TAPS) was expected to transport nearly $20 \%$ of the United State's oil supply. The route, however, to the United States included passing directly through the Denali Fault. An in depth investigation into the fault was conducted in an effort to reduce the possible dollar loss and environmental hazard TAPS would experience due to earthquake damage. TAPS became the first load tested structure specifically designed for seismic hazards. 
The geotechnical study revealed that the Denali Fault was capable of producing an 8.0 magnitude earthquake and experience surface offsets as large as 9.1 meters horizontal and 2.1 meters vertical. A 76.2 meter wide hazard zone was established for the section where TAPS crossed over the fault.

Engineers designed the structure across the fault in plan view to zig zag to accommodate movement and reduce potential damage at the section. Additionally, supports at the fault zone were brought closer to the ground where the pipe was supported on a steel beam and Teflon slider shoe configuration (Fig. 4.5-B). The shoe support system rested on a long concrete beam that would allow for the pipeline to be continuously supported even during offset. Although average surface displacement along a fault is typically half of the maximum value recorded, the engineers conservatively used expected design displacements equal to $2 / 3$ the maximum potential.

After the earthquake, the structure was inspected for damage and only minor improvements, such as re-centering on the concrete sliders, were required. Fig. 4.5-C shows one support that require repair. All repairs needed were exterior and no leaks or direct damage to the pipeline were reported.

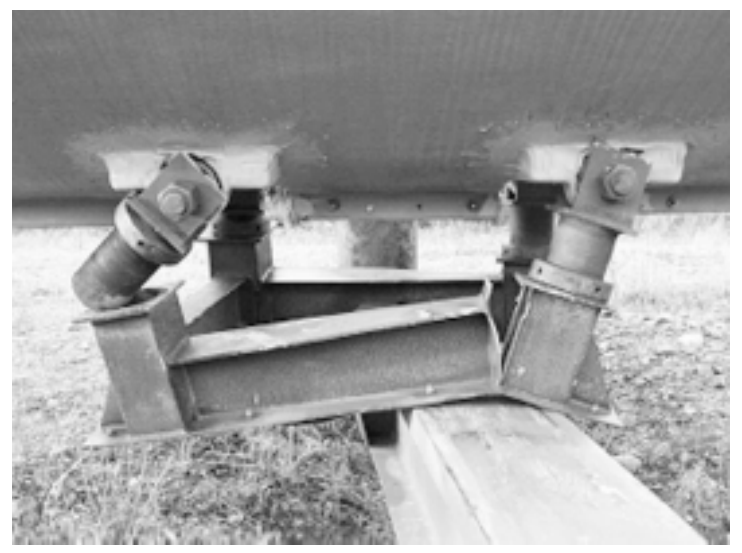

Fig. 4.5-C: Damaged slider shoe following the earthquake (Honnegar 2004). 


\subsubsection{Tree Trunk Fracture}

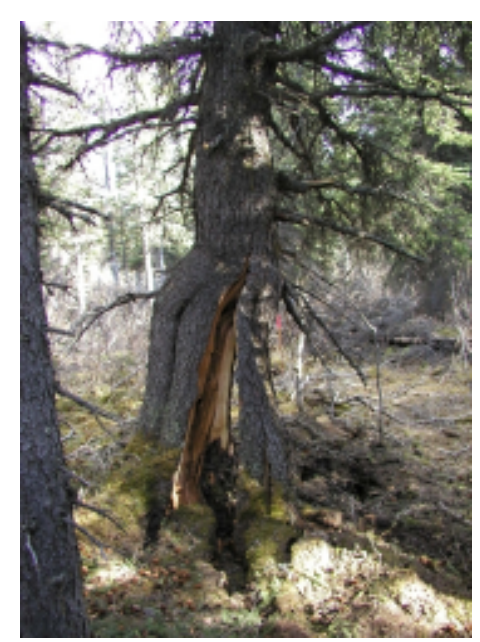

\begin{tabular}{ll}
\hline Local Fault Behavior & Strike-Slip \\
\hline Surface Offset & $0.5 \mathrm{~m} \mathrm{Horiz}$ \\
\hline $\begin{array}{l}\text { Percentage of } \\
\text { Structure on each side } \\
\text { of the fault }\end{array}$ & $50 / 50$ \\
\hline Structure & Spruce Tree \\
\hline Foundation Type & Root System \\
\hline
\end{tabular}

Fig. 4.5-D: Spruce tree split by fault (DGGS).

The root system of a tree serves several purposes: anchor the tree to the ground and capture nutrients from the soil. The roots spread out through the surrounding soil, maximizing the area in which to absorb nutrients. Additionally, the finger-like system "grabs" onto the soil providing sufficient anchorage through soil confinement. In this instance, the Denali fault trace ruptured through the root system of a spruce tree. As the soil offset sheared through the center of the roots, the roots confined on the offsetting side induced a splitting action in the trunk. The tree cracked and separated as the stresses generated perpendicular to grain exceeded the wood's capacity. This simple structure is analogous to the basketball court pile system discussed by Anastasopoulos and Gazetas in their paper (reviewed in Section 3.3). Although the roots are effective in preventing overturning, they can be hazardous in fault offset situations. 


\subsection{EXAMPLE EVALUATION AND MITIGATION OF A STRUCTURE FOR FAULT OFFSET: BOWLES HALL, UC BERKELEY}

This section illustrates how earthquakes exhibiting fault rupture can provide insight into how to successfully mitigate the effects of surface ruptures on existing structures. Exploring the case studies of the previous chapter, a mitigation technique was recommended for Bowles Hall in the report UC Berkeley Bowles Hall: Seismic Evaluation and Conceptual Retrofit Design, by Rutherford \& Chekene(Maffei et al. 2008). The report focused on the associated hazards to Bowles Hall due to the proximity of the structure to the Hayward fault. The sections below explain the possible risks to the structure due to anticipated ground displacements and commentary of the capacity analysis performed. Analysis regarding the shaking and the response of the structure were additionally performed; however, for the purpose of this project commentary on the shaking analysis will not be provided.

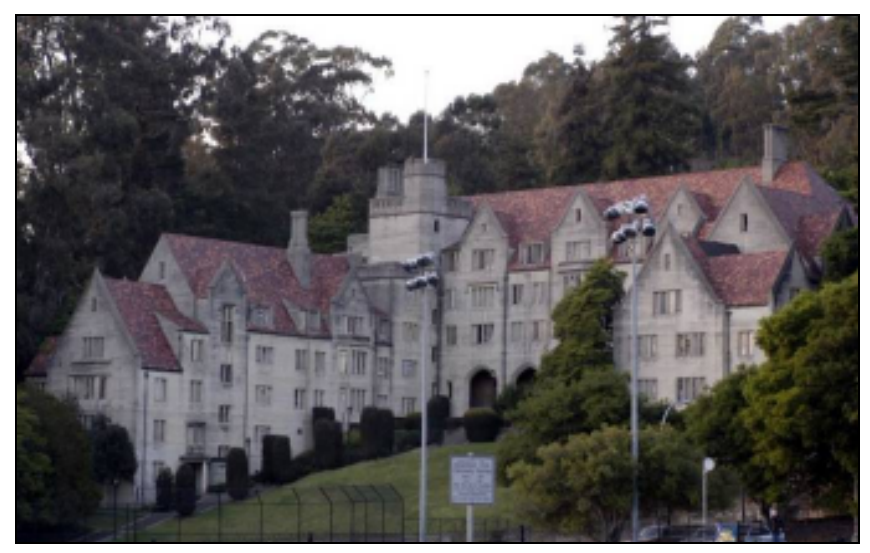

Fig. 5.0-A: Bowles Hall South Elevation. 


\subsection{Description of the Structure}

Bowles Hall is the oldest dormitory at the University of California, Berkeley (UCB). Built in 1927, the building is a tudor style mansion that steps up the slopes of the Berkeley hills eight floors. Constructed from reinforced concrete, the building has a oneway slab system, with gravity beams, girders, and columns and load bearing exterior and interior walls. The walls serve a dual purpose; in addition to gravity loads, they resist lateral forces from wind earthquakes.

Several renovations have modified the current structure in the years following initial construction. In 1938, Hart library - a rectangular single story building, approximately 20 feet by 30 feet -- was added on to the back of the main hall (Fig. 5.1-A). In 1947, the recreation/weight room space in the eastern corner of the main hall was excavated and finished with a slab-on-grade floor. In 1977, improvements to the building's seismic force resisting system were made: discontinuities in concrete walls

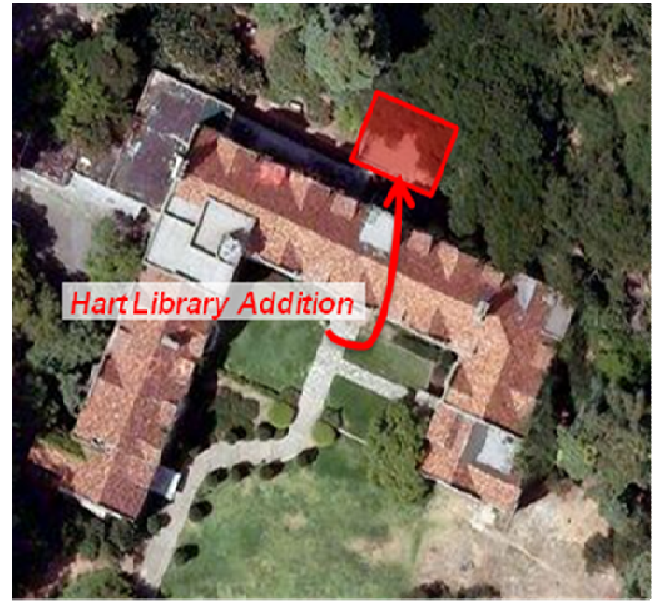

Fig. 5.1-A: Aerial View of Bowles with library addition highlighted. were remedied and window openings at the bottom level were in-filled. A seismic evaluation of the structure preformed in 1997 , deemed Bowles Hall to be 'Good' by the campus rating system and although some deficiencies were noted, no further retrofit work was recommended. 


\subsection{Fault Displacement Hazard}

In 2007, concerns were raised regarding the building's proximity to the Hayward fault. To examine this issue more closely, a fault displacement hazard analysis was commissioned by the University to identify the potential fault displacement hazards to the structure [Lettis \& Associates 2007]. The report concluded that two corners of the structure, the east corner of the main building and the east corner of Hart library, sit directly atop a potentially active western fault trace of the Hayward fault. Fig. 5.2-B and Fig. 5.2-C show the fault zone passing under the two eastern corners of Bowles Hall. The identified zone of potential fault offset is 18 feet wide at the weight room (Fig. 5.2-B) and 16 feet wide at Hart library (Fig. 5.2-C).

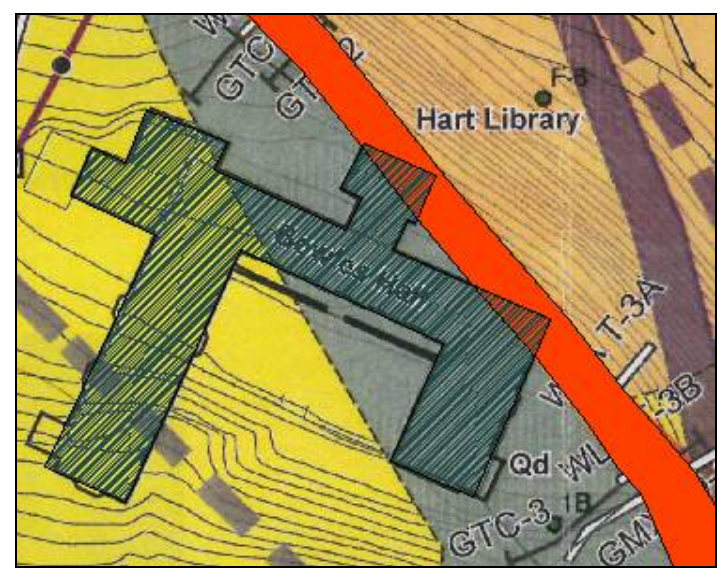

Fig. 5.2-A: Western fault trace at Bowles Hall (Lettis \& Associates 2007).

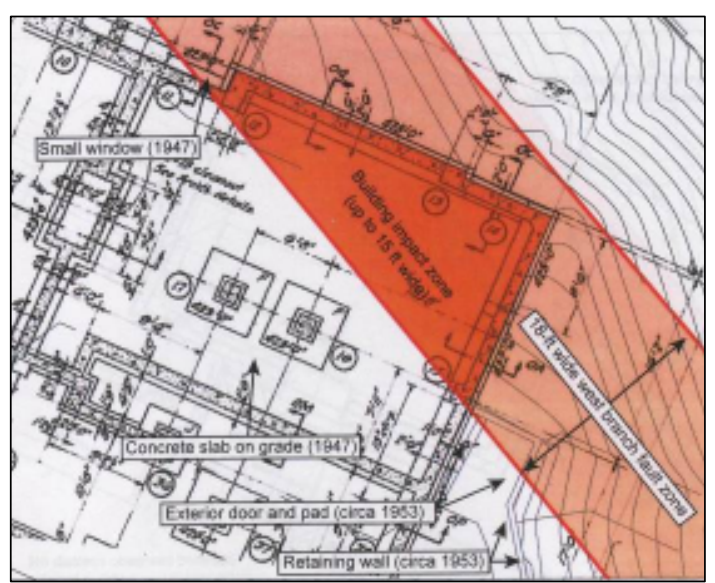

Fig. 5.2-B: Fault Zone Under Weight Room (Lettis \& Associates 2007).

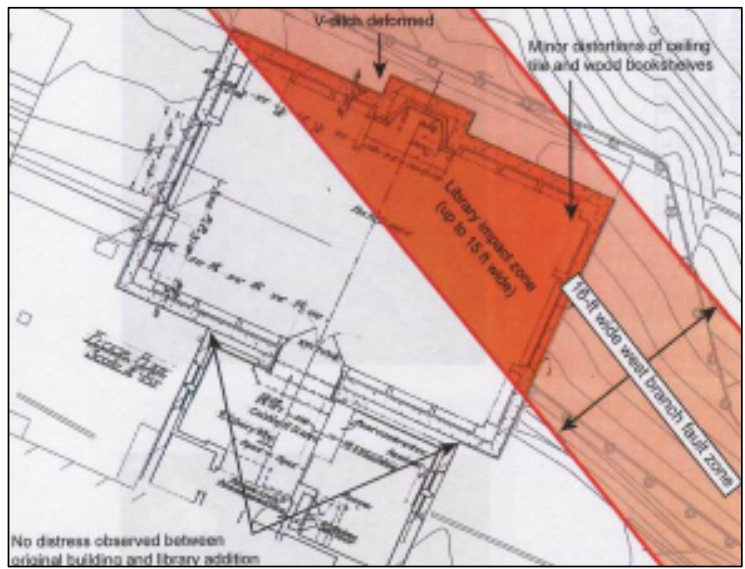

Fig. 5.2-C: Fault Zone Under Hart Library(Lettis \& Associates 2007). 
Table 5-A: Historic Earthquake Data (Lettis \&Associates 2007) Predicted and Recorded Displacement

\begin{tabular}{|c|c|c|c|c|c|c|}
\hline Year & Event & $\begin{array}{l}\text { Slip } \\
\text { Type }\end{array}$ & M & $\begin{array}{c}\text { Avg } \\
\text { Displacement } \\
\text { (meters) }\end{array}$ & $\begin{array}{c}\text { Predicted } \\
\text { Avg } \\
\text { (meters) }\end{array}$ & $\begin{array}{c}\text { Predicted Average } \\
+ \text { Std Dev of } 0.39 \\
\text { (meters) }\end{array}$ \\
\hline 1930 & North Izu, Japan & LL-R & 6.89 & 2.9 & 0.8 & 1.9 \\
\hline 1940 & Imperial Valley, USA & RL & 6.92 & 1.5 & 0.8 & 2.0 \\
\hline 1953 & Camakkale, Turkey & RL & 7.22 & 2.1 & 1.5 & 3.7 \\
\hline 1954 & Dixie Valley, USA & RL-N & 6.94 & 2.1 & 0.8 & 2.1 \\
\hline 1954 & Fairview Peak, USA & RL-N & 7.17 & 2.45 & 1.4 & 3.3 \\
\hline 1966 & Varto, Turkey & RL & 6.88 & 0.15 & 0.7 & 1.8 \\
\hline 1968 & Dasht-e-Bayaz, Iran & LL & 7.23 & 2.3 & 1.5 & 3.8 \\
\hline 1970 & Tonghai, China & RL & 7.26 & 2.1 & 1.6 & 4.0 \\
\hline 1976 & Caldiran, Turkey & RL & 7.23 & 2.05 & 1.6 & 3.8 \\
\hline 1979 & Koli, Iran & LL-R & 7.17 & 1.2 & 1.4 & 3.3 \\
\hline 1988 & Gangma, Yunnan, China & RL & 6.83 & 0.6 & 0.7 & 1.6 \\
\hline 1988 & Lancang-Gengma, China & RL & 7.13 & 0.7 & 1.3 & 3.1 \\
\hline 1999 & Duzce, Turkey* & RL & 7.1 & 2 & 1.2 & 2.9 \\
\hline 1999 & Hector Mine, USA** & RL & 7.1 & 2.5 & 1.2 & 2.9 \\
\hline
\end{tabular}

The Hayward fault is categorized as a right-lateral strike-slip fault system and transverses part the UC Berkeley campus. The eastern side of the fault will move southeast with respect to the western side of the fault. The report concluded that at the site, the expected ratio of offset displacements is approximately 7 inches horizontal for linch of vertical offset. The expected vertical is 2 inches. For a 475 -year return period, the expected horizontal displacement is 14 inches. At lower probability of recurrence, horizontal deformations could be as great as 9 feet as previously seen along other strikeslip fault systems (Table 5-A). 


\subsubsection{Weight Room Fault Offset Hazard}

At the eastern corner of the main hall, the fault passes beneath the weight room.

The foundation system in that region consists of concrete walls with perimeter footings at the exterior and two isolated footings supporting columns. In this corner of the building, the structure extends up six levels to the roof. Heavy damage or loss of structural integrity at the weight room level would potentially cause collapse of the five levels above that are dependent on this corner. For this area of the building, it is critical that the capacity of the structure be greater than the demand exerted by earthquake shaking or fault displacement. See Fig 5.2-D for a plan view of the weight room showing the extent of the fault zone where positive soil pressure is expected (in red) and where it is expected the soil will move away from the structure as the rupture propagates (in blue). Fig 5.2-E shows the expected failure mode of the stem walls without retrofit.

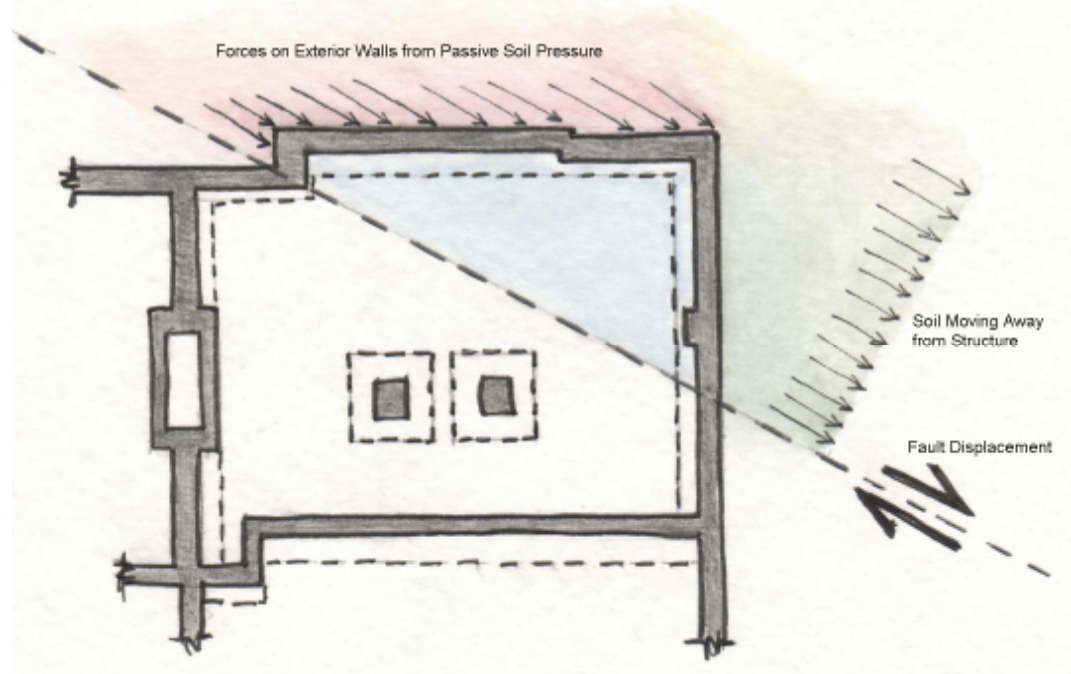

Fig. 5.2-D: Plan view of the Weight Room. 


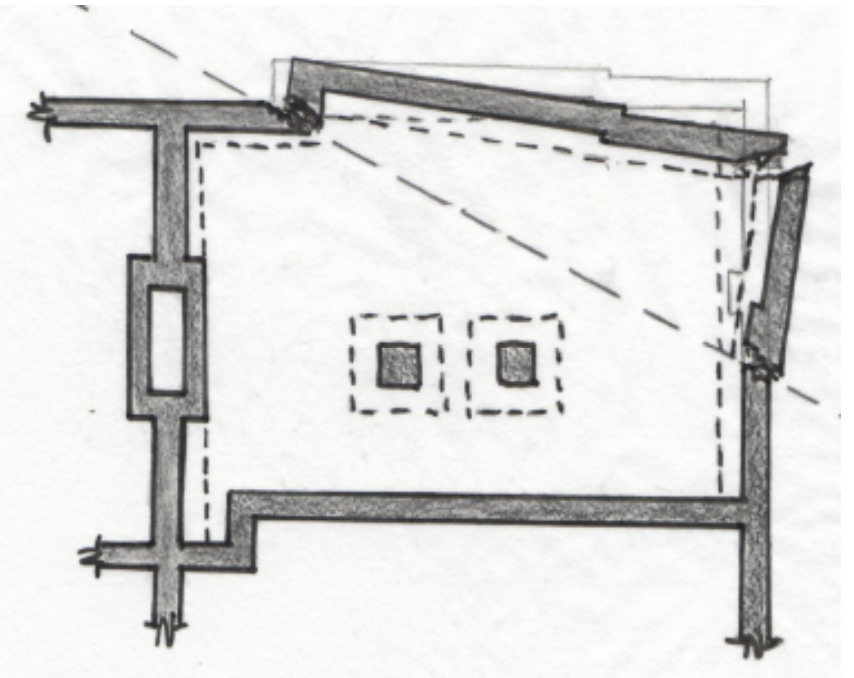

Fig. 5.2-E: Plan view of the Weight Room post surface rupture.

\subsubsection{Hart Library Fault Offset Hazard}

In the case of Hart library, the box-like structure is an addition not attached to the main hall. Instead of being constructed integrally or tied to the main hall, it was built against the existing exterior walls. A perimeter continuous footing supports separate stepped stem wall foundation system isolates the structure. The footing abuts the main structure, but neither the foundation nor the walls of Hart Library are dowled into the main building structure. The consequence of this construction decision potentially alleviates some problems associated with the expected fault displacements. Decoupled from the main hall, the library structure could displace independent of its counterpart as the ground displaces. Thus damage resulting from the fault displacing beneath the library will be concentrated at the library and cause separation and rotation from the main hall. Such movement of Hart Library may cause localized and repairable damage, see Fig 5.2F. This localized damaged is not expected to be hazardous to the building's occupants. 

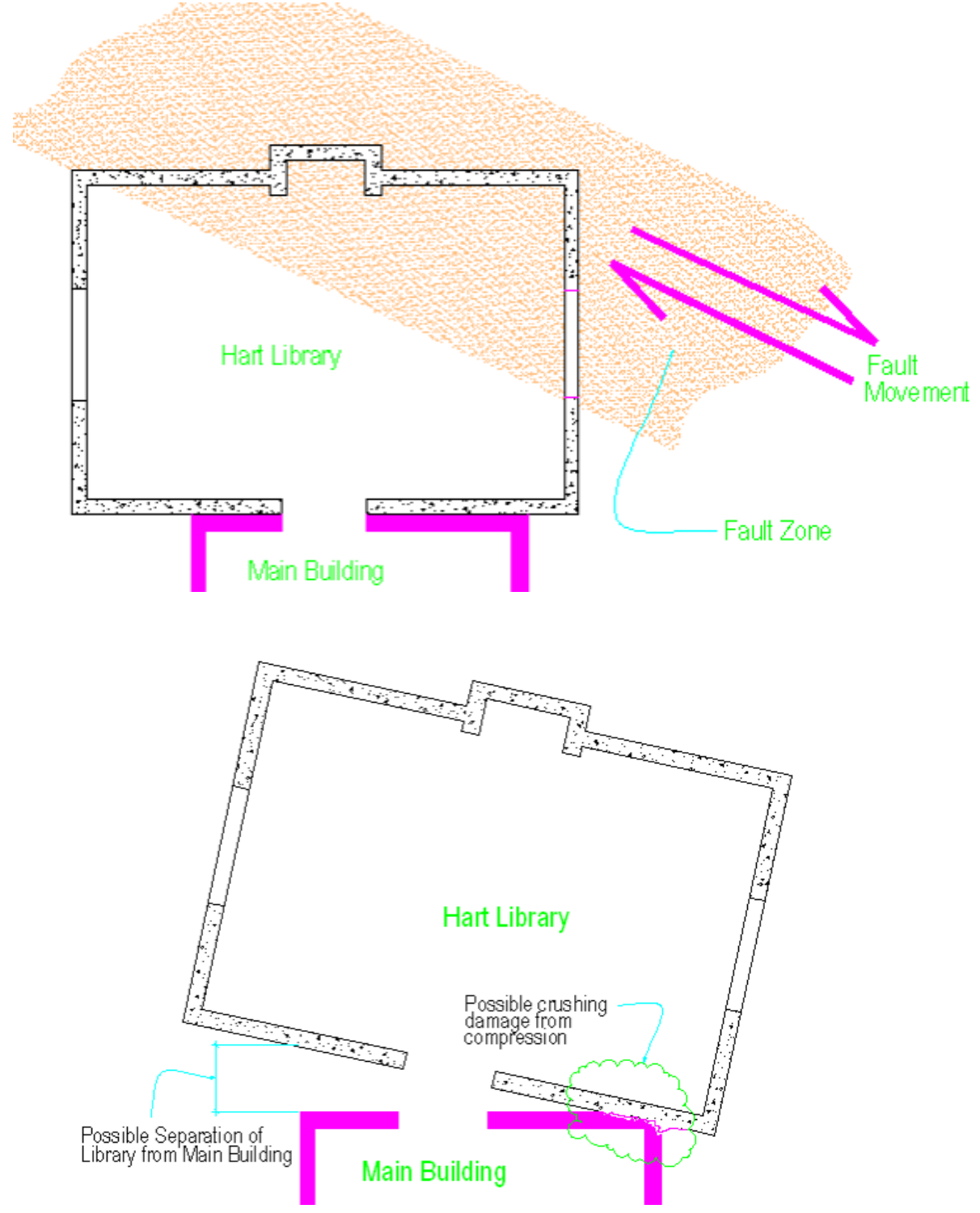

Figure 5.2.F: Expected performance of Hart Library.

\subsubsection{Applicable Examples Used for Mitigation Methodology}

To evaluate the potential for damage resulting from fault offset at the weight room and Hart Library, it is useful to consider similar building fault rupture interactions seen in past earthquakes. Case studies examined in previous chapters help determine likely damage and appropriate mitigation. The Kocaeli earthquake in Turkey is applicable because the North Anatolian fault acts as a strike-slip system, similar to the 
Hayward fault. The case studies of the Arifiye Residence (Fig. 4.2-B), the concrete moment frame under construction (Fig. 4.2-F), and the Gölcük Naval Base Bunker (Fig. 4.2-D) demonstrate how a sufficiently strong and rigid foundation system can deflect the fault propagation away from the structure and prevent rupture through the structure. If the fault is re-directed, a reduced strain is felt by the structure, and limits the damage. The Lannom Residence case study (Fig. 4.1-C), in the Landers earthquake, indicates that a decoupling layer between the foundation and the soil lowers the strain transfer and consequently lessens cracking in the foundation and structure above.

The following sections discuss the analysis and capacity design approach used to determine a reasonable mitigation solution, both in safety and economy.

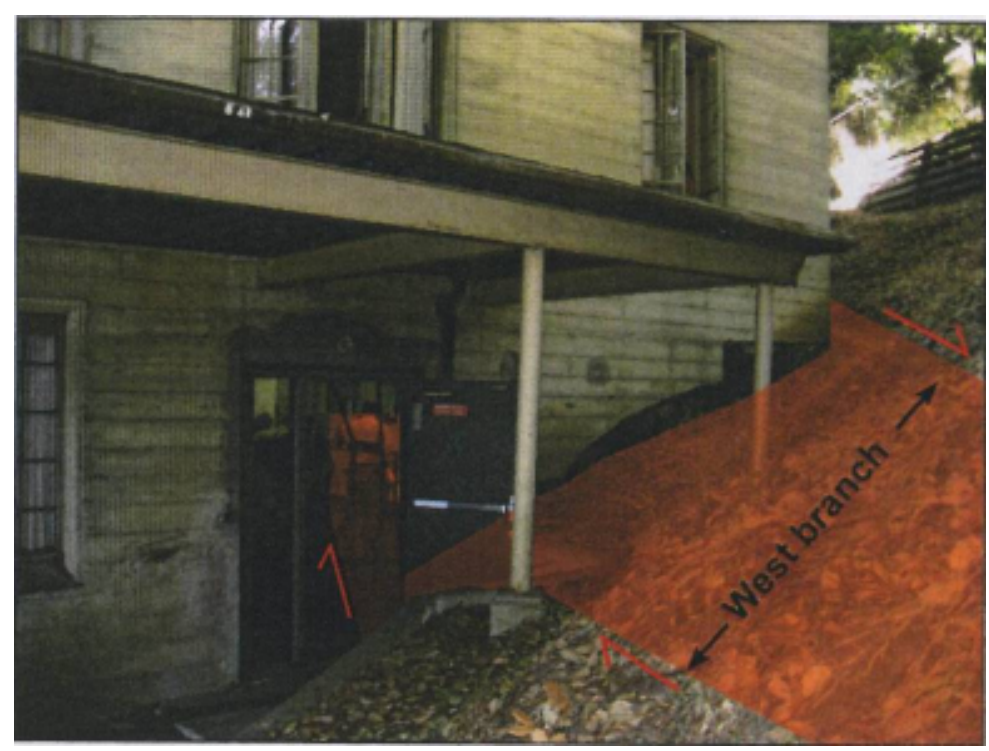

Fig. 5.2-G: View Northeast showing depth of soil at weight room. 


\subsection{Evaluation of Structure for Horizontal Fault Offset}

\section{Demands Imposed by Fault Offset}

When a fault ruptures in a strike-slip mechanism, the horizontal fault offset exerts horizontal forces on the structure. The forces are imparted to the structure through frictional resistance of soil passing under the foundation. If the structure is embedded in the soil, horizontal forces are also imparted against vertical surfaces of the structure, being imposed by passive pressures of the fault offsetting the earth into the structure. The applied horizontal forces cause internal forces and bending moments in the structure. The maximum amount of force exerted on structure is limited by the maximum strength of the soil. The goal of this approach is to ensure that failure will occur in the soil such that the structure is sufficiently strong to resist maximum imposed soil forces.

\section{Potential Structural Failure Modes \& Capacities}

Evaluation of demands on the structure due to horizontal fault offset reveals several possible failure modes: out-of-plane bending or shearing through critical wall sections, and shearing through the proposed mat foundation.

Out-of-plane bending caused by passive soil pressure acting on exterior walls was shown to be the critical mode of failure. At both Hart Library and the weight room, a depth of up to 10 feet of soil is retained against the exterior walls (Fig. 5.2-G). An initial mitigation approach was developed to excavate all soil from the face of the wall to the bottom of footing. This solution was shown to be disruptive to the potential landscape uses behind the building, when the steep site conditions and amount of soil removal required were considered. To address this, various depths of soil were considered in 
analysis to determine a reasonable depth of excavation. Out-of-plane shear demand and the subsequent moment imparted on the exterior walls were evaluated for varied depths ranging from 3-5feet of soil at the weight room and 4-7feet of soil at the library. Fig. 5.3-A shows the loading condition used to determine the bending moment and shear demand on the exterior walls due to passive soil pressure.

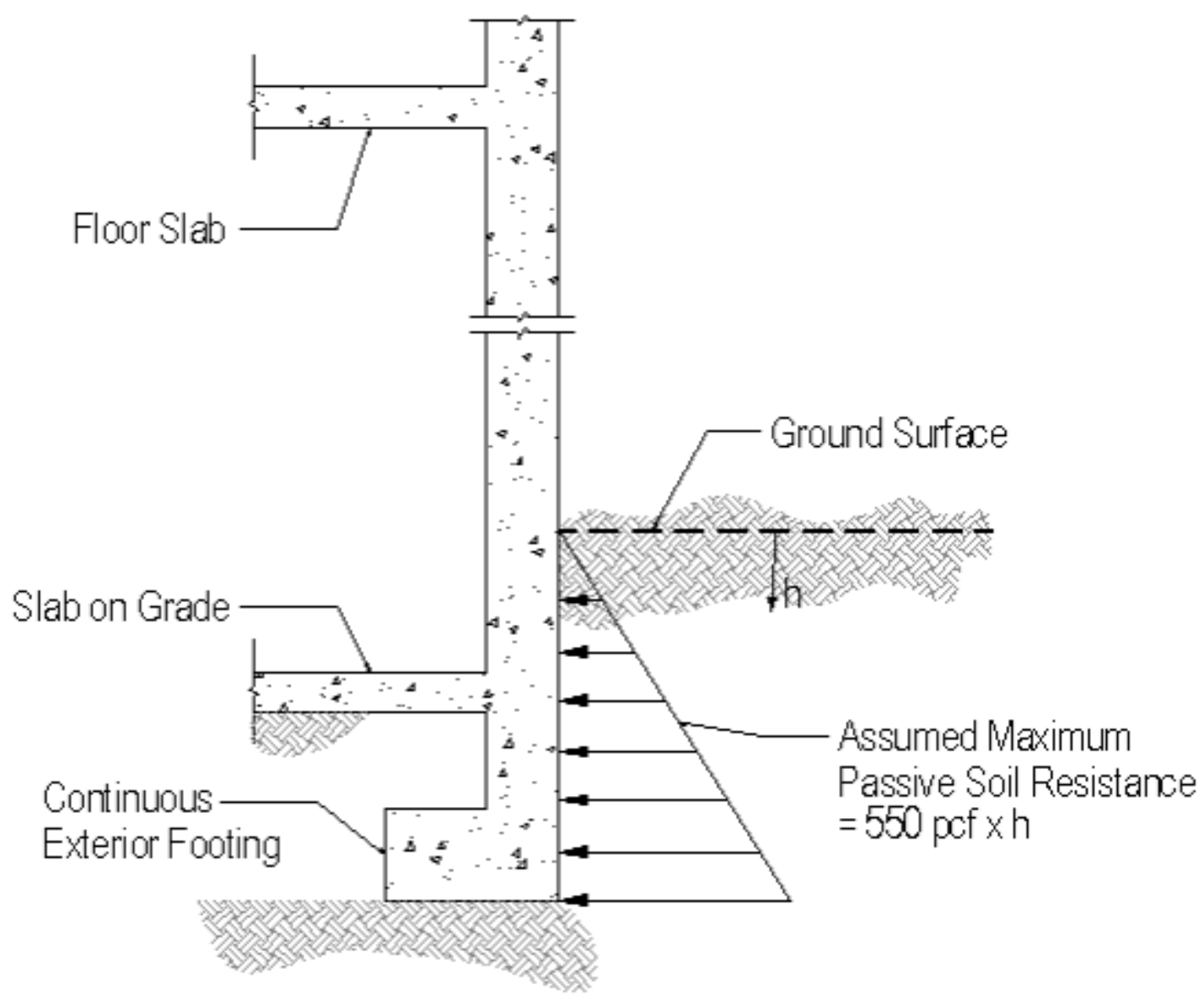

Fig. 5.3-A: Lateral Pressure Diagram.

The computer structural analysis program, RISA-2D, was used to model the wall and determine the moment and shear demands. Considering both pinned-pinned and fixed assumptions for the wall end conditions, this model enveloped the maximum positive and negative bending the wall would likely experience during fault offset in 
addition to the maximum shear force at the base of the wall just above the mat

foundation. Bending and shear capacities of the reinforced concrete sections were calculated using customary assumptions. Shear friction capacities at the base of the wall were determined using ACI 318-08, Eq. 11-25, with $V_{n}=A_{v f} f_{y} \mu$. Assumptions for all calculations may be referenced in Table 5-E. The demand and capacities were calculated on a per foot basis along the length of the wall. Table 5-B thru Table 5-D, summarize wall type, moment and shear capacity, and expected demand. Calculations shown in the tables indicate that approximately 3 to 4 feet of soil can be retained at the weight room north wall and 6 to 7 feet of soil can be retained against the library north wall without causing failure of the walls. From this depth, a 64 degree soil failure plane is extended from the bottom of foundation to determine the appropriate distance away from the building at which site retaining walls can be built.

Table 5-B: Bending Moment \& Shear Capacity

\begin{tabular}{|c|c|c|c|}
\hline Location & Wall Type & Moment Capacity & Shear Capacity \\
\hline Weight Room & $\begin{array}{c}\text { 8" Concrete Wall } \\
\text { Single Curtain } \\
1 / 2 \text { "square bars @ 12"o.c. ea. way }\end{array}$ & $3.9 \mathrm{k}-\mathrm{ft} / \mathrm{ft}$ & $14.4 \mathrm{k} / \mathrm{ft}$ \\
\hline Hart Library & $\begin{array}{c}\text { 12" Concrete Wall } \\
\text { Double Curtain } \\
\text { 1/2" round bars@12"o.c. ea. way }\end{array}$ & $10.2 \mathrm{k}-\mathrm{ft} / \mathrm{ft}$ & $28 \mathrm{k} / \mathrm{ft}$ \\
\hline
\end{tabular}


Table 5-C: Weight Room Passive Soil Pressure Moment \& Shear Demand

\begin{tabular}{c|c|c}
\hline Weight Room & $\begin{array}{c}\text { Moment Demand } \\
\mathbf{k}-\mathbf{f t} / \mathbf{f t}\end{array}$ & $\begin{array}{c}\text { Shear Demand } \\
\mathbf{k} / \mathbf{f t}\end{array}$ \\
\hline 3ft of Soil & 1.9 & 2.3 \\
\hline 4ft of Soil & 4.2 & 3.8 \\
\hline 5 ft of Soil & 7.5 & 5.8 \\
\hline
\end{tabular}

Table 5-D: Hart Library Passive Soil Pressure Moment \& Shear Demand

\begin{tabular}{c|c|c}
\hline Hart Library & $\begin{array}{c}\text { Moment Demand } \\
\mathbf{k - f t} / \mathbf{f t}\end{array}$ & $\begin{array}{c}\text { Shear Demand } \\
\mathbf{k} / \mathbf{f t}\end{array}$ \\
\hline $4 \mathrm{ft}$ of Soil & 4.5 & 3.8 \\
\hline $5 \mathrm{ft}$ of Soil & 8.3 & 5.8 \\
\hline $6 \mathrm{ft}$ of Soil & 13.5 & 8.4 \\
\hline $7 \mathrm{ft}$ of Soil & 20 & 11.2 \\
\hline
\end{tabular}

Table 5-E: Shear Friction

Table 5-E: Shear Friction
\begin{tabular}{c|c|c}
\multicolumn{3}{c}{ Calculation Assumptions } \\
\hline $\mathrm{f}^{\prime}{ }_{\mathrm{c}}=3,000 \mathrm{psi}$ & $\mu=1.4 \lambda$ & $\rho=1 \%$ \\
\hline $\mathrm{f}_{\mathrm{y}}=50 \mathrm{ksi}$ & $\lambda=1.0$ & $\mu_{\mathrm{soil}}=0.55$ \\
\hline
\end{tabular}

Table 5-F: Shear Demand at Foundation

\begin{tabular}{c|c|c|c|c}
\hline Location & $\begin{array}{c}\text { Frictional Force } \\
\text { Demand } \\
\text { Wt } \mathbf{x} \boldsymbol{\mu}_{\text {soil }}\end{array}$ & $\begin{array}{c}\text { Passive Soil } \\
\text { Pressure }\end{array}$ & $\begin{array}{c}\text { Total Shear } \\
\text { Demand @ } \\
\text { Critical Section }\end{array}$ & $\begin{array}{c}\text { Capacity } \\
\text { 12\% R.C. Mat }\end{array}$ \\
\hline Weight Room & $566 \mathrm{kips}$ & $348 \mathrm{kips}$ & $914 \mathrm{kips}$ & $2,879 \mathrm{kips}$ \\
\hline Hart Library & $259 \mathrm{kips}$ & $383 \mathrm{kips}$ & $642 \mathrm{kips}$ & $3,133 \mathrm{kips}$ \\
\hline
\end{tabular}




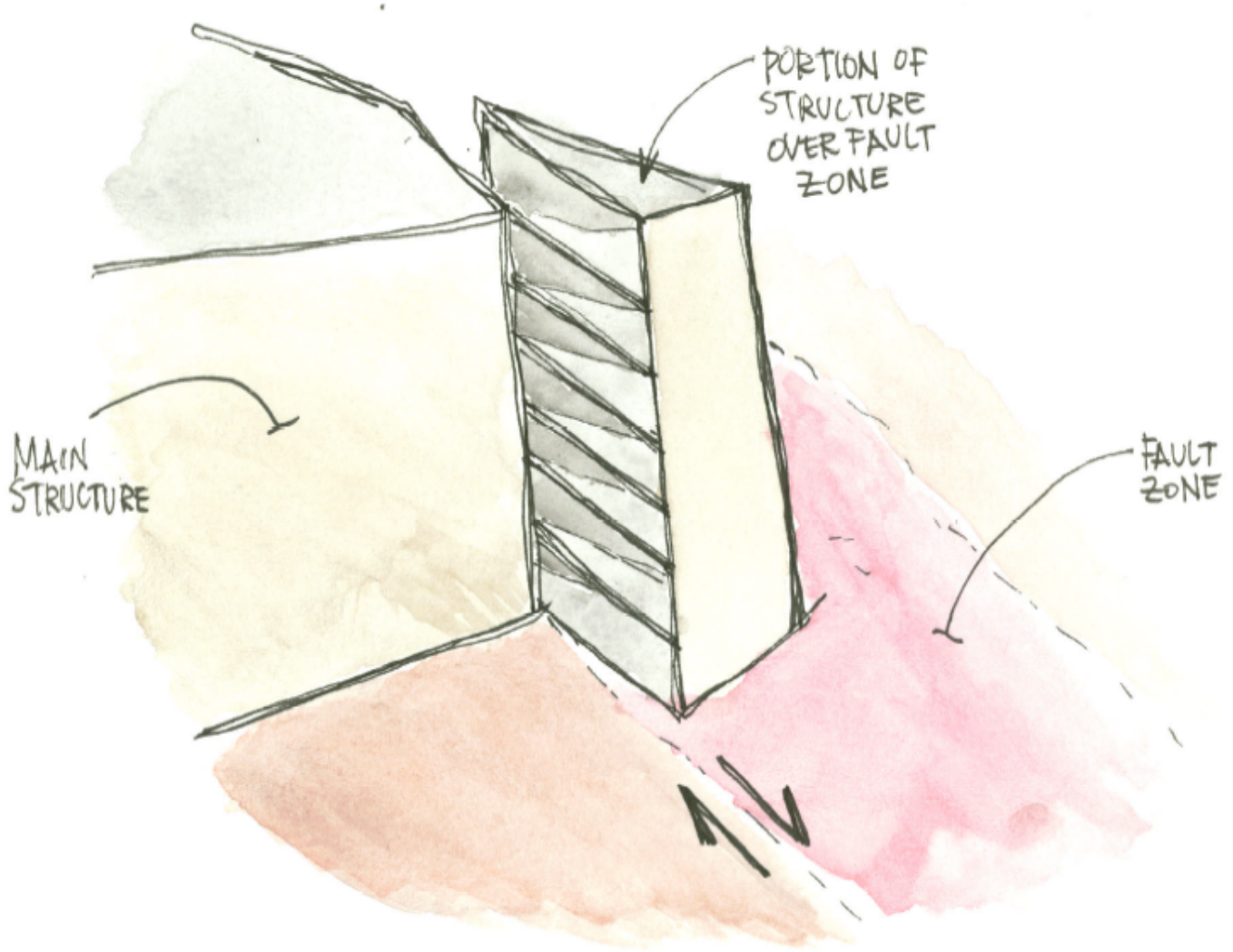

Fig. 5.3-B: Conceptual shearing damage due to horizontal offset.

In addition to bending and shear from out of plane action on the walls, shearing through the structure was evaluated. The tendency of the horizontal fault offset to cause shearing through the structure is shown in Fig. 5.3-B. A more likely mode of failure is shown in Fig. 5.2-D with damage mainly occurring at the foundation and bottom story. The horizontal force tending to cause such a shearing failure comes from two sources: (a) friction underneath the foundation, which is proportional to building weight, calculated based on the tributary area carried by the corner of the building on the fault side, and (b) passive soil pressure was calculated using the same model used for out-of-plane bending. Frictional force and passive soil pressure combined represent the total shear demand on the critical section. Ideally all of this shear demand should be received at the foundation level, to prevent damage at that level. A structural slab on grade can be used at the 
foundation level to resist the forces. The shear friction capacity of the foundation slab is evaluated using ACI 318-08, Eq. 11-25. Several designs for the foundation slab were analyzed to assess the necessary depth to resist the forces. A 12 inch thick foundation slab was shown to provide sufficient capacity to the demand. The potential critical sections at the weight room and library are shown in Fig. 5.5-C and Fig. 5.5-D respectively. The results summarized in Table 5-F indicate that the improved foundation will be sufficiently strong enough in shear by more than three times that required. It is expected that the soil will fail around the mat foundation and the fault offset will have limited effects on the structure.

\subsection{Retrofit of Structure for Horizontal Fault Offset}

The evaluation of the structure for horizontal fault offset leads to two recommended seismic retrofit measures: the addition of structural foundation slabs in the weight room and at Hart library, and excavation of retained soil from the northwest elevations of the building. At the weight room and Hart library it is recommended that reinforced concrete foundation slabs be constructed within the existing foundation boundaries to add stiffness and shear capacity (Fig. 5.4-A). Several studies on the required thickness of the mat revealed that a 12 inch reinforced concrete mat foundation would be adequate, as shown in Table 5-F. The construction of the foundation slab should avoid creating additional friction below the building between the soil and the structure. Thus the slab should be placed on a low friction layer that is even with the bottoms of the existing foundations, such as in Fig. 5.4-A. 


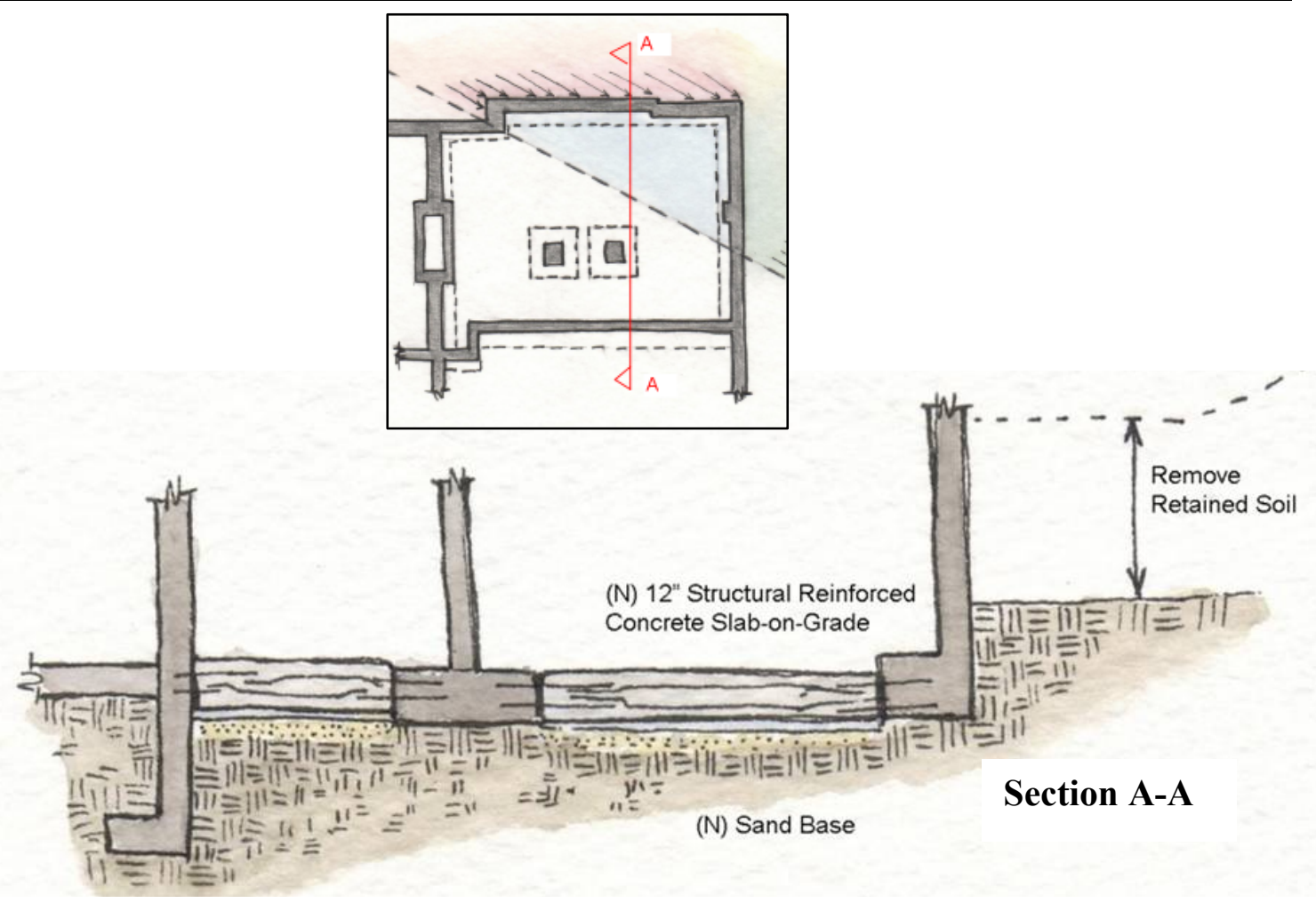

Fig. 5.4-A: Section of retrofit solution at weight room.

A retaining wall system of soldier piles and reinforced concrete walls tied into hillside to hold back hill following the excavation of soil from the face of back walls (See Fig. 5.4-B and Fig. 5.4-C). The system is flexible enough to allow deformations in the shear zone to occur first at a distance away from the structure within the retaining wall as shown in Fig. 5.4-D. In Fig 5.4-D the gray piles represent the undeformed condition and the colored piles show the deformed state. The distance set back is dependent on the angle of failure in the soil and the depth against the structure. The wall and piles will serve as a "sacrificial system" to absorb energy exerted by offset soil. The setback distance not only coincides with the angle of shear failure in the soil, but the setback distance allows the system to translate as it deforms and ultimately avoid contact with 
Bowles Hall. Rupture propagation occurring on the fault north of Bowles Hall is likely to intercept the retaining system before the building.

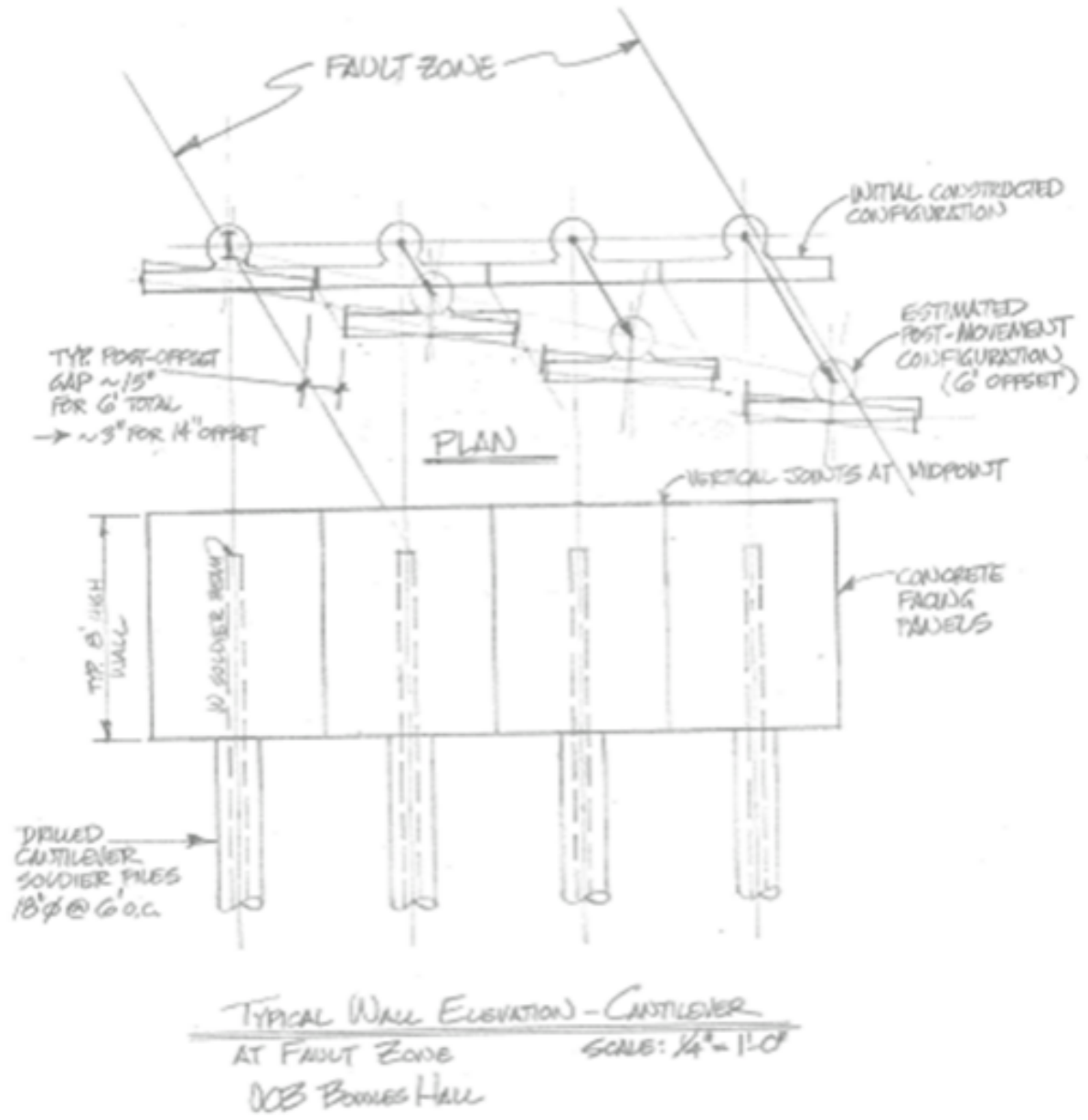

Fig. 5.4-B: Plan and elevation of retaining wall system (Image Courtesy of R\&C ). 


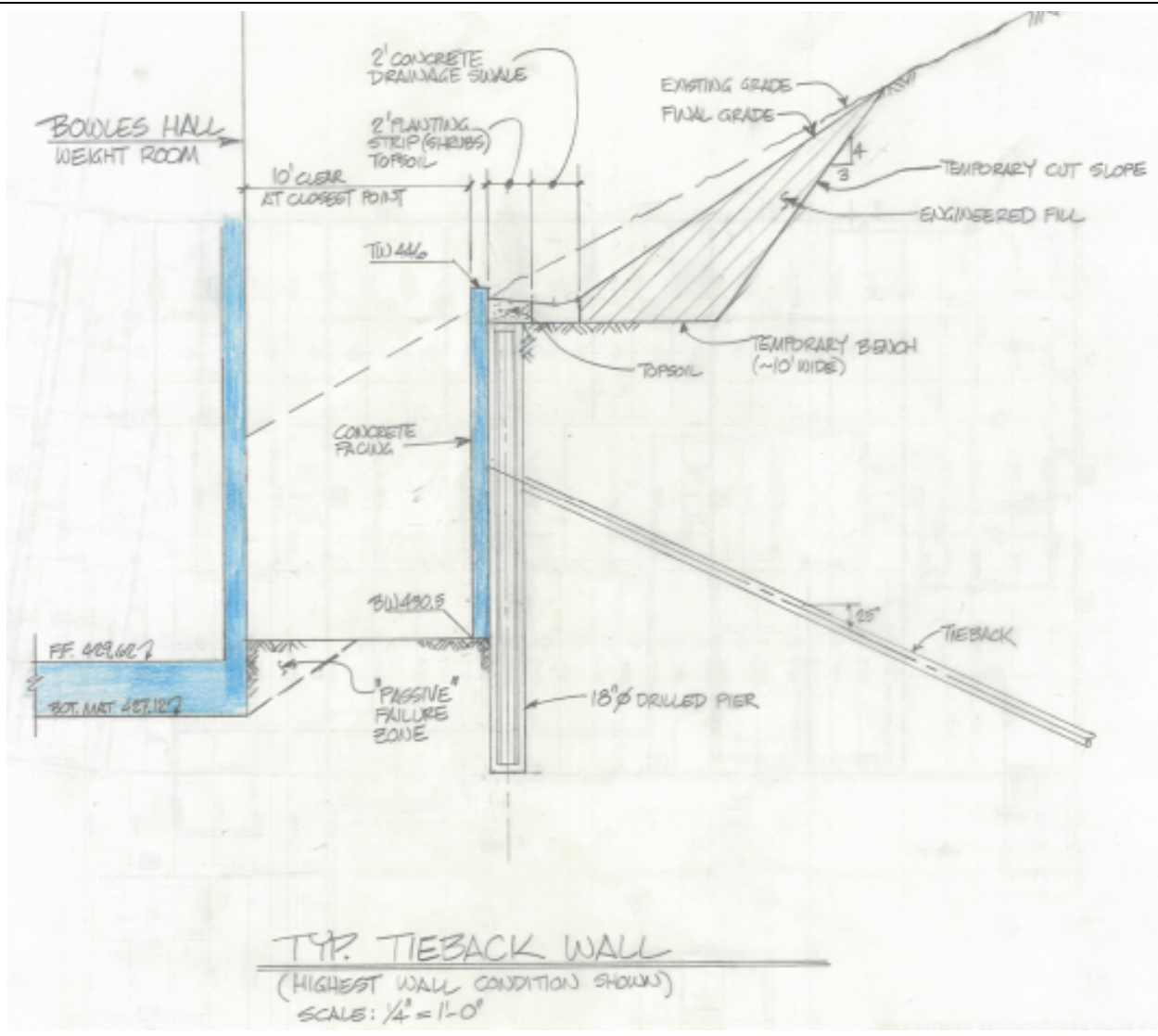

Fig. 5.4-C: Section of weight room and retaining wall (Image Courtesy of R\&C). 


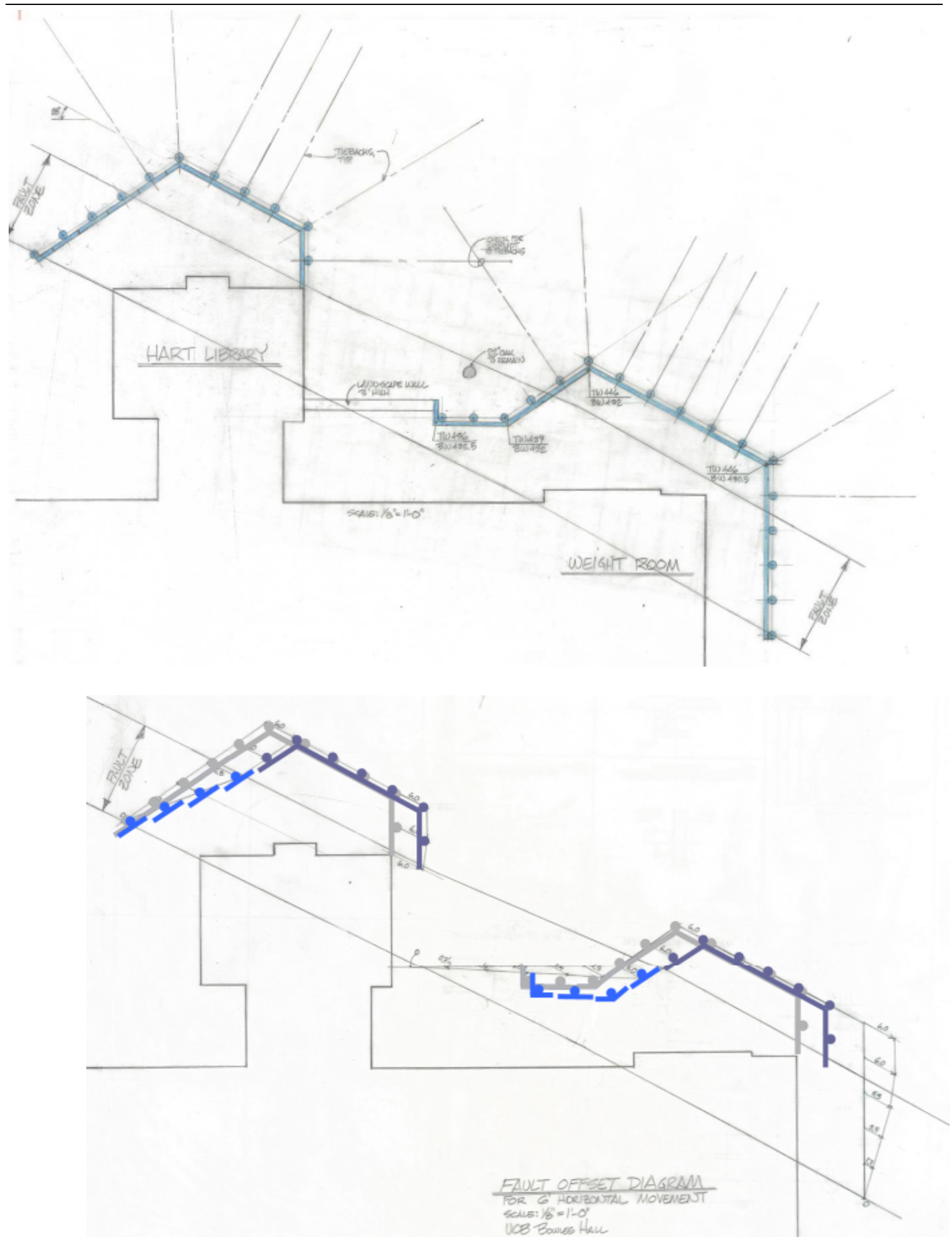

Fig. 5.4-D: Plan of soldier piles for retaining wall system. (Image Courtesy of R\&C). 


\subsection{Evaluation of Vertical Fault Offset}

\section{Demands Imposed by Fault Offset}

From the fault rupture hazards report (Lettis \& Associates 2007), the ratio of horizontal to vertical fault offset at the site is expected to be 7 to 1 . For a 475 -year return period, a 2 inch $(50 \mathrm{~mm})$ vertical offset resulting from fault rupture is expected. Referring back to historical earthquake data in Table 1-A, it is possible that the offset could be as much as one foot $(300 \mathrm{~mm})$ vertical. Vertical displacement impacts the structure through changing soil bearing pressure under the foundation. In this case, soil uplift of the east side of the fault with respect to the west side, will cause the corners over the fault zone to encounter increased bearing pressures. This movement can be considered similar to foundation settlement but in the reverse direction. In contrast, sections spanning between the soil supports will experience complete loss of bearing and necessitate resistance to shear due to gravity.

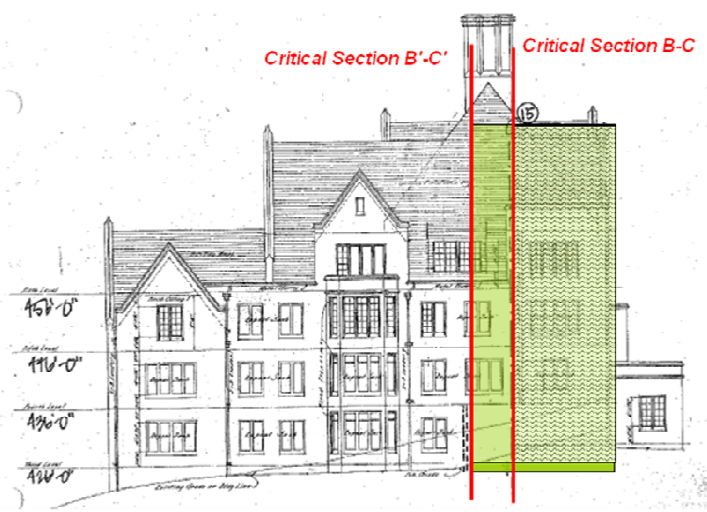

Fig. 5.5-A: Critical sections on northeast elevation. 


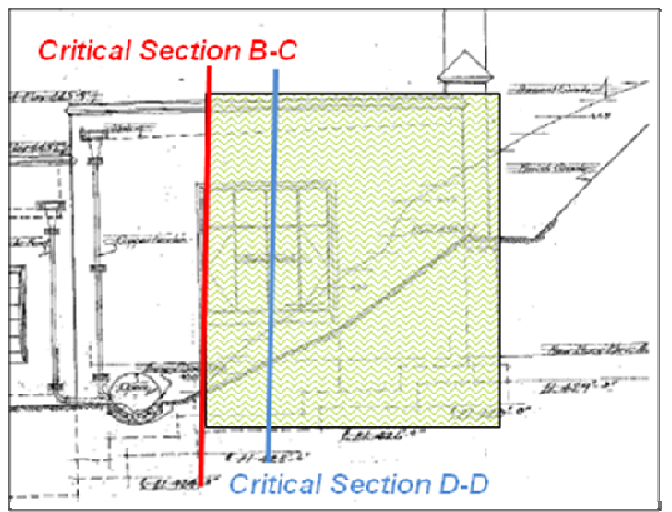

Fig. 5.5-B: Northeast Elevation of Hart Library

\section{Potential Structural Failure Modes \& Capacities}

Vertical failure planes were investigated to ensure that even the weakest sections would be able to support the tributary dead load in the absence of bearing. The vertical failure planes were selected by the fault zone line and extended the full height of the structure at a given location; this is show on Fig. 5.5-A as "Critical Section B-C." An additional critical section was examined at the edge of the new proposed mat foundation and is identified as "Critical Section B'-C"' in Fig. 5.5-A. This analysis was performed on each exterior surface where the fault intercepts the building. The shear friction capacity of a given section was evaluated using ACI Eq. 11-25.

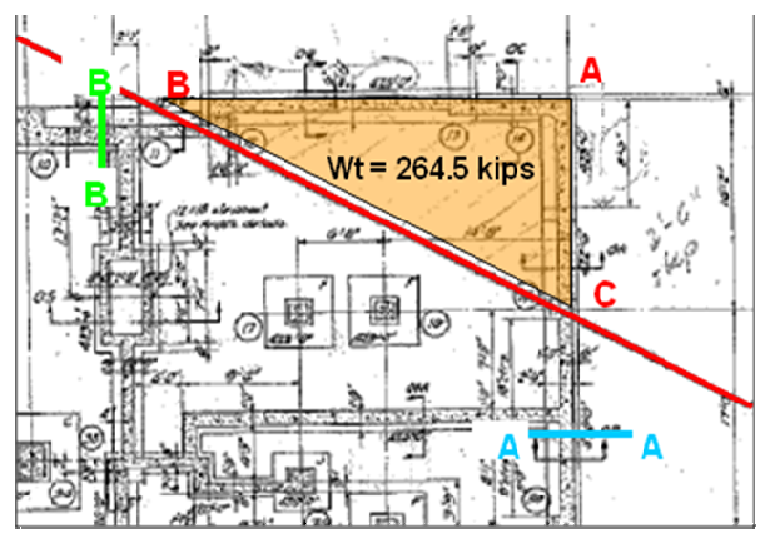

Table 5-G: Wall Shear Capacity

\begin{tabular}{c|c}
\hline Weight Room & $\begin{array}{c}\text { Shear Friction } \\
\text { Capacity }\end{array}$ \\
\hline $\begin{array}{c}\text { Section A-A } \\
\text { East Elevation }\end{array}$ & 1,138 kips \\
\hline $\begin{array}{c}\text { Section B-B } \\
\text { North Elevation }\end{array}$ & 1,867 kips \\
\hline
\end{tabular}

Fig. 5.5-C: Plan view of weight room.

Red line BC shows extent of fault zone. 


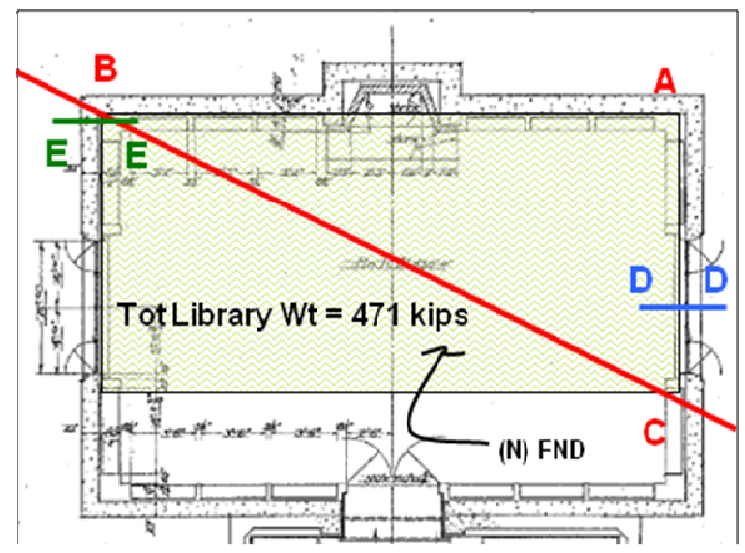

Table 5-H: Wall Shear Friction Capacity

\begin{tabular}{c|c}
\hline Hart Library & $\begin{array}{c}\text { Shear Friction } \\
\text { Capacity }\end{array}$ \\
\hline $\begin{array}{c}\text { Section D-D } \\
\text { East Elevation }\end{array}$ & $301 \mathrm{kips}$ \\
\hline $\begin{array}{c}\text { Section E-E } \\
\text { North Elevation }\end{array}$ & $469 \mathrm{kips}$ \\
\hline
\end{tabular}

Fig. 5.5-D: Plan view of library.

Red line BC is shows extent of fault zone.

\subsection{Retrofit of Structure for Vertical Fault Offset}

The calculations reveal that some cracking of the concrete may occur during fault offset, but the structure is able to carry its own weight if fault offset forces the building to span between soil supports. This suggests that the building has the ability to resist vertical offset and avoid severe damage. No additional retrofit is deemed necessary for vertical offset and recommendations made toward mitigating horizontal effects will likely alleviate vertical effects as well. 


\subsection{RECOMMENDATION FOR ADDRESSING FAULT OFFSET}

Research of surface fault rupture has relied in part on case studies to identify characteristics which determine how structures respond to fault offset. This report includes pertinent case studies that provide insight into how and why these characteristics affect a structure's resistance to fault offset. A means to evaluate a structure's resistance to fault offset is explained in Section 6.1. Section 6.2 discusses the variables that contribute to successful resistance to fault rupture and is followed by Section 0 identifying applicable retrofit and strengthening options. Section 6.3 demonstrates how code language can be applied to existing and new structures found to be situated in active fault regions to evaluate if retrofit and strengthening measures need be explored.

\subsection{Procedure for Evaluation of Existing Buildings}

This section outlines and describes an overall procedure to evaluate a structure where surface fault rupture hazard exists. The steps of the procedure are as follows:
A. Determine the earthquake fault parameters.
B. Identify the fault location and local characteristics at the site.
C. Evaluate the soil properties at the site.
D. Determine the structure geometry, properties, and details.
E. Evaluate the structure for horizontal offset.

i. Determine the force demands that can be imposed.

ii. Determine potential locations and modes of structural failure.

iii. Evaluate the capacity of the structure in each potential failure mode.

iv. Compare the demand to the available capacity. 
F. Evaluate the structure for vertical offset.

i. Determine the force demands that can be imposed.

ii. Determine potential locations and modes of structural failure.

iii. Evaluate the capacity of the structure in each potential failure mode.

iv. Compare the demand to the available capacity.

G. Recommend retrofit/ strengthening.

i. If demand exceeds capacity, propose retrofit.

ii. Return to step D to re-evaluate retrofitted structure.

Each step is discussed in detail below. While the procedure is written to be generally applicable, each structure should be considered on a case by case basis as variables associated with the site and the structure alter the applicability of recommended mitigation and retrofit procedures explored in Section 0.

\section{Step A: Determine earthquake fault parameters}

A geological assessment of the fault is required to determine the potential for fault offset. This step includes the collection of all pertinent information about the fault and local geology that does not rely on investigations at the site. Site specific investigations are used in Steps B \& C. The fault data of interest includes the following: the mechanism of the fault, likely magnitude, the potential for surface rupture, the expected amount of offset, and the recurrence interval. The fault rupture mechanism often provides insight on the expected relationship of vertical to horizontal offset. The paleoseismologist conducting the investigation determines the expected offsets as a function of the 
recurrence interval. The recurrence interval used for analysis affects the magnitude of the expected maximum offset values. This allows the expected amount of offset to be adjusted for varied return rates. The description of potential offset expected can also include a ratio of vertical and horizontal offset.

\section{Step B: Identify the fault location and local characteristics at the site}

Site specific studies provide a detailed analysis of the local fault mechanism. At the global level, faults are characterized as strike-slip, normal, reverse, or oblique. When examined at a specific location along the fault, directional behavior can vary from that of the overall faulting mechanism. For example, the San Andreas fault on a whole exemplifies strike-slip behavior but at a portion of the fault may behave as a normal fault and experience compression while the entire fault slides along in a strike-slip mechanism. A trench study near the structure may be necessary to confirm fault activity and identify the location of the fault relative to parts of the structure likely to be effected by fault rupture in some cases. Historic earthquakes on the fault can also be evaluated during trenching and allow paleoseismologists to determine the amount of offset seen in a given earthquake as well as the slip rate of the fault. This enables them to develop an expected ratio of horizontal to vertical offset and associate the fault with a recurrence interval.

\section{Step C: Evaluate the soil properties at the site}

Soil exploration at the site identifies the soil strata and properties through various means. The soil type, respective layer thicknesses surrounding the structure, and the depth to bedrock are determined through soil exploration as well. Soil samples analyzed in the laboratory provide values for the angle of internal friction, cohesion, and the shear strength of the soil. These values allow geotechnical engineers to determine appropriate 
values for equivalent passive pressure, the coefficient of friction, and other properties of interest structural engineers. The trench investigations, mentioned in step B, enable a broader area of subsoil to be surveyed and provide necessary information for the construction of a continuous soil profile.

\section{Step D: Determine the structure geometry, properties, and details}

As the potential fault location and effects are investigated, building plans can be reviewed to identify how the structure may be affected by fault offset, and the structural components at risk. Embedment of the structure into the soil is an important parameter. A deep foundation, such as driven or drilled piles, generally will attract more force during horizontal offset. Soils under greater stress and compression, usually at depth, can exert higher demands than soils at the near surface levels. Consequently, shallow foundations generally attract less force. Foundation walls and isolated footings that are tied together and connected will increase the structure's resistance to offset due to their rigidness and interconnectedness.

The geometry and construction materials of the foundation and superstructure determine the strength of the structure to resist ground offset. Corners and openings are potential regions that may experience increased stresses. Detailing at critical sections and joints additionally affects a structure's ductility and consequently its ability to redistribute forces in response to fault offset and structural deformation.

\section{Step E: Evaluate the structure for horizontal offset}

The force demands on structure from horizontal offset are imposed on vertical surfaces where soil is retained. Additional forces are generated on horizontal surfaces under the structure through soil friction. Using the passive soil pressures and friction 
coefficient established by the geotechnical engineer, the force demands may be estimated. Exterior walls experience out-of-plane loading from retained soil displacing into the structure. A triangular loading diagram (or another pattern suggested by the geotechnical engineer) imposes an out-of-plane bending moment and shear demand on the wall. Care should be taken during analysis to appropriately model the boundary conditions of a wall element as this can change the location and peak value of demand, ie fixed versus pinned. Underneath the structure, the force demand is calculated by multiplying the coefficient of friction of the soil by the weight of the structure bearing at the soil.

The engineer identifies critical sections and failure modes of the structure by evaluating the geometry, layout, and pattern of internal forces and moments imposed. Exterior walls retaining soil can fail in bending at the location of maximum moment. Construction joints at the base of the wall can fail in sliding shear. The bending, shear, and shear friction capacities at these critical sections can be calculated for comparison to the demands.

The location of the fault zone passing through the structure indicates where to analyze the foundation for in-plane shear. The shear friction strength through the structural elements of this section should be greater than the force imposed by soil displacing under the weight of the structure.

If the capacities at each of the critical sections exceed the demand, the structure is likely to resist offset with only minor damage such as cracking. However, if the capacity is less than the demand, more significant damage can be expected and retrofit of the deficient areas should be considered. 


\section{Step F: Evaluate the structure for vertical offset}

The evaluation of force demands from vertical fault offset is in some ways similar to an evaluation of a structure for differential settlement.

Vertical offset will cause the ground to push upwards under the foundation of some portion of the structure while the foundations of other portions remain the same. In the case of a weak structure this will cause an overall vertical shearing action and failure through the structure. For a stronger structure, portions of the foundation can be lifted up off the ground. The maximum demands on the structure are determined through an assessment of the weight of the structure that must be supported in absence of bearing. The walls or beam sections that correspond with potential failure modes must be capable of spanning from the uplifted ground to the nearest point of bearing. The capacity of the wall or brace frame sections may be evaluated through calculation of the shear through the weakest plane. For structures without walls or braces such as a moment frame, beams and columns may be subject to increased forces and experience an increased vulnerability to element and building failure. For wall buildings, perforations in the exterior should be considered in this calculation as the transfer of forces around the openings may not be possible without significant damage and could lead to collapse.

\section{Step G: Recommend retrofit and strengthening}

If a structure is found to be deficient, multiple options for retrofit and strengthening exist. Refer to Section 0 for retrofit strategies and their applicability. If a structure requires strengthening, the strengthened structure should be re-evaluated using the procedure to verify adequate strength is achieved by modifications to the structure. 


\subsection{Variables \& Their Effects}

Case studies and structural evaluations of structures subject to fault offset provide insight into causative variables. Table 6-A lists some key variables and their effect on structural behavior.

Table 6-A: Structural Variables \&Effects

\begin{tabular}{|c|c|}
\hline Variable & Effect \\
\hline Fault Offset & Greater offset typically leads to more damage. \\
\hline Soil Strength & Stronger soil increases the imposed soil loading on the structure. \\
\hline $\begin{array}{l}\text { Location of Fault } \\
\text { Trace }\end{array}$ & $\begin{array}{l}\text { The greater the area or mass of building overlying the fault offset } \\
\text { the greater the forces can be that tend to pull a structure apart. }\end{array}$ \\
\hline Weight of Structure & $\begin{array}{l}\text { Heavy structures generate more frictional forces underneath their } \\
\text { foundations but can be influential in directing the fault rupture } \\
\text { path away from the structure. }\end{array}$ \\
\hline Foundation System & $\begin{array}{l}\text { Foundation systems with a strong interconnection between } \\
\text { elements better resist imposed forces. }\end{array}$ \\
\hline Structure Properties & $\begin{array}{l}\text { Stronger materials and elements are better resist forces imposed by } \\
\text { fault offset. }\end{array}$ \\
\hline Ductility & $\begin{array}{l}\text { Ductile structures have a greater ability to redistribute and } \\
\text { accommodate imposed displacements without collapse. }\end{array}$ \\
\hline
\end{tabular}




\section{Fault Offset}

The amount of fault offset expected typically shows a direct correlation to the amount of structural damage that may occur. Often, larger offsets will produce more damage. Yet, two outcomes are possible with large displacements: number one is maximum displacement is limited by collapse of structure thus being the upper bound, and number two is the possibility that the structure may accommodate large displacements with minimal damage. A well detailed structure can tolerate a certain degree of displacement until enough strength degradation occurs in the main structural system collapse is initiated. Fig. 6.2-A represents this idea conceptually. Within the margin of displacement, the structure can tolerate the displacement, but once the displacement is too great the tipping point is reached and the structure collapses. Note, however, that the strength of the soil is a major factor in the aforementioned scenario which assumes that the soil will not fail in shear. Alternatively, Fig 6.2-B shows that a great amount of displacement can be accommodated by the structure, yet it is not dependent on the strength of the structure. Rather, the soil can displace a great deal through fault offset but because it is either weak, unconfined, or some combination of those the structure is relatively unaffected. 


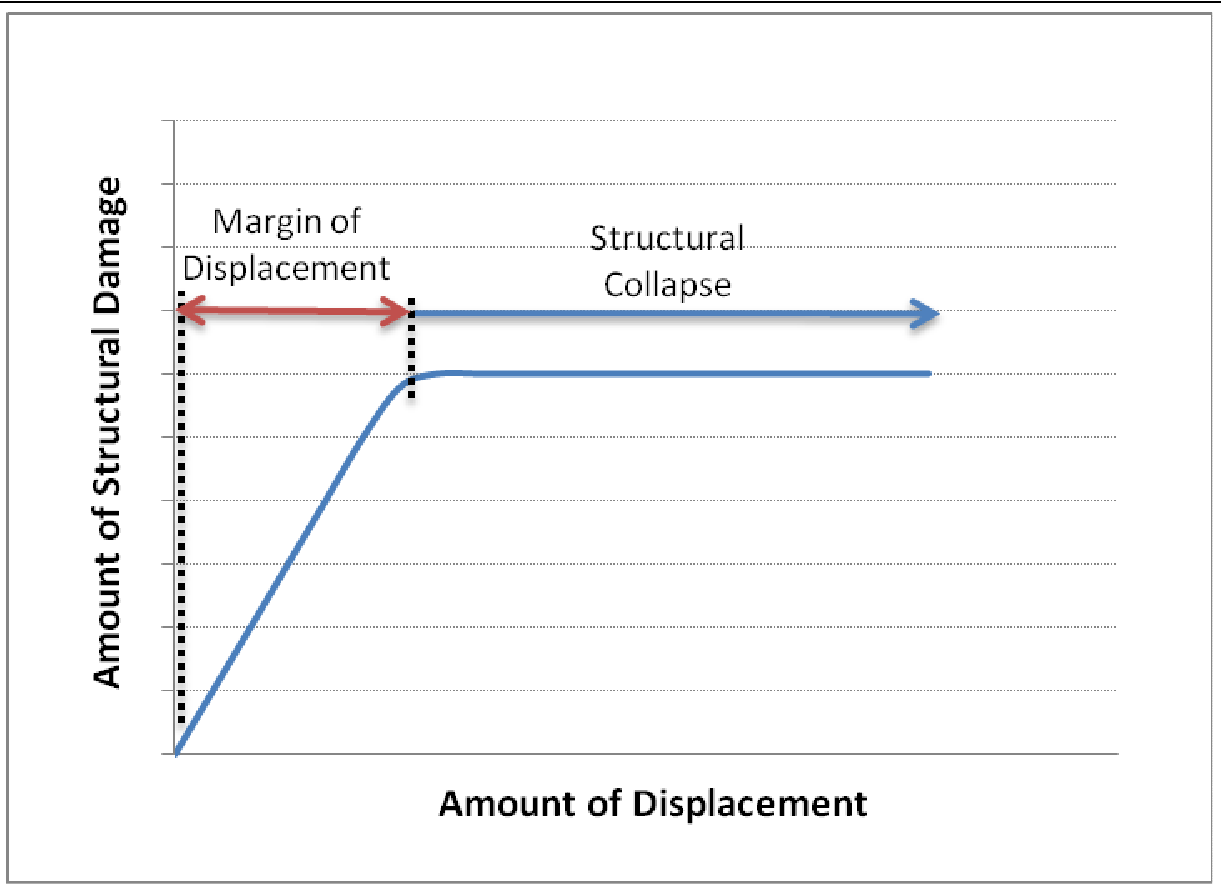

Fig. 6.2-A: Amount of ground displacements versus amount of structural damage.

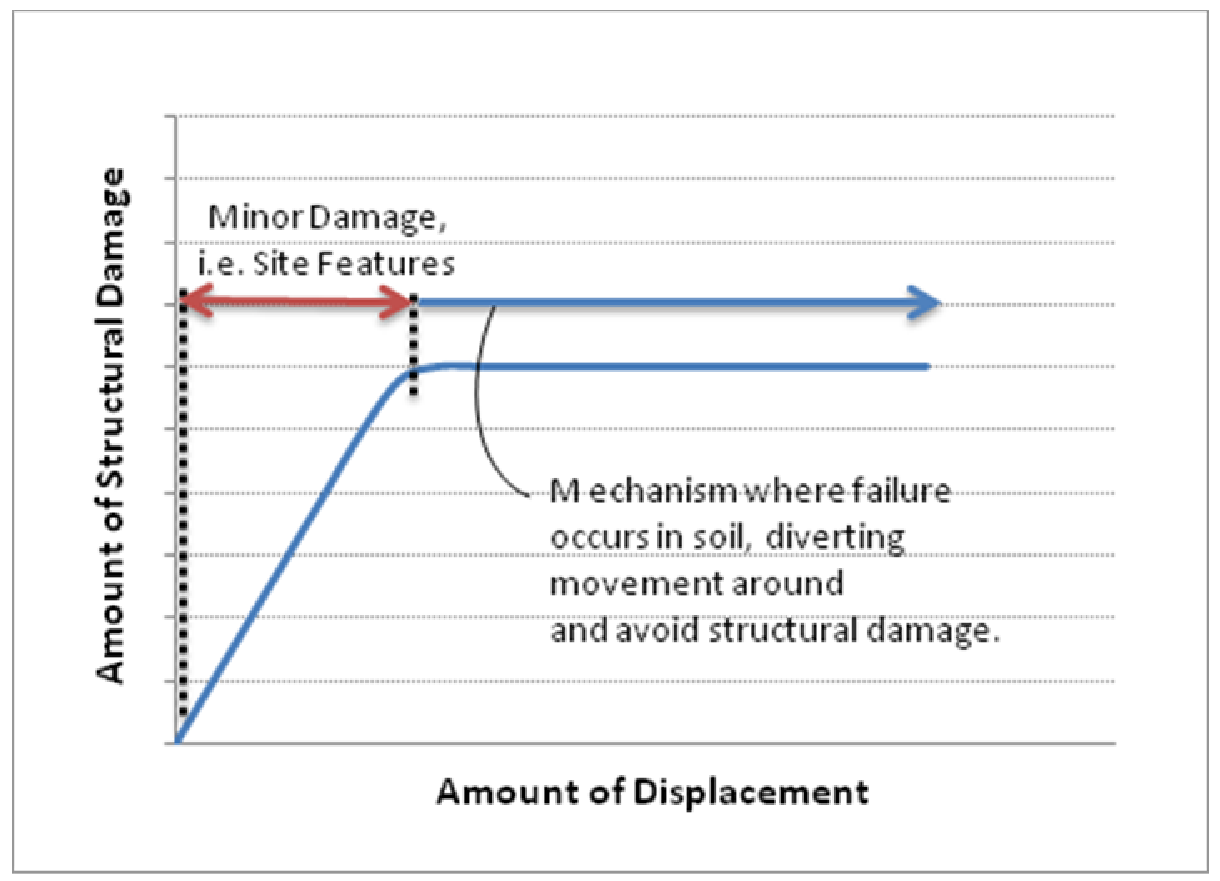

Fig. 6.2-B: Amount of deformation in the ground near structure. 
A factor that governs the direction of dominate offset is the type of fault. For example, in a strike-slip fault, either side of the fault will move opposite in a shearing fashion. Horizontal movement tends to dominate in this mechanism.

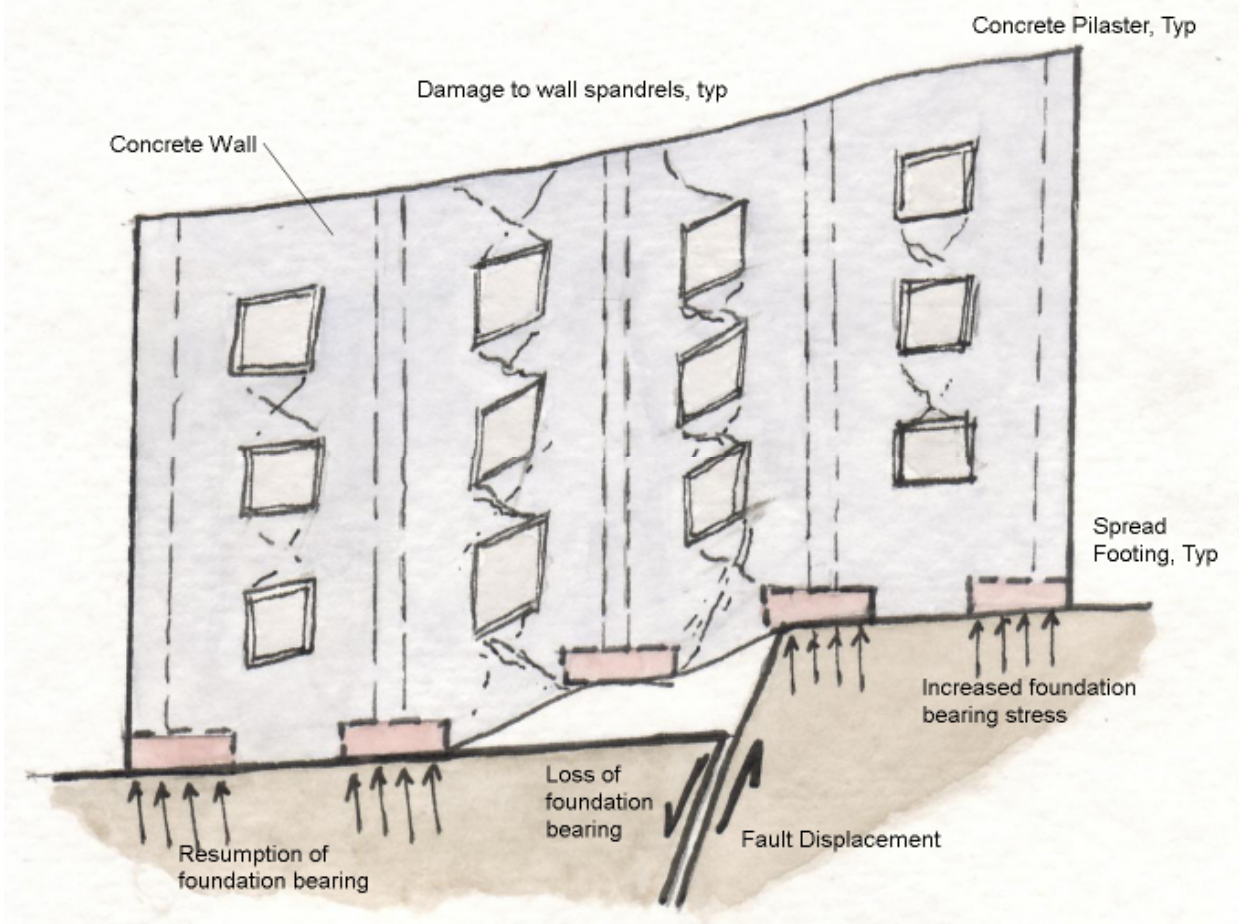

Fig. 6.2-C: Effect of vertical fault offset on a concrete wall and pilaster building.

In normal and thrust fault scenarios (Fig. 6.2-C), vertical movement tends to dominate as the hanging wall displaces relative to the footwall. Research from the ChiChi, Taiwan earthquake of 1999 (Section 4.4) revealed that in a thrust fault scenario the damage levels varied dramatically with position in respect to the surface rupture.

Structures located on the hanging wall within the folding scarp region had more damage than those located on the footwall. Structures located a few meters back from the main 
fault and on the foot wall portion escaped the faulting unscathed. Whereas structures of similar construction situated directly on the scarp folding suffered collapse.

\section{Soil Strength}

The shear strength of the soil is dependent on the soil type. An approximation for the shear strength of a soil can be calculated using the Coulomb equation:

$$
\mathrm{s}=\mathrm{c}+\sigma^{\prime} \tan \varphi^{\prime}
$$

where

$$
\begin{aligned}
& s=\text { shear strength } \\
& c=\text { cohesion } \\
& \sigma^{\prime}=\text { effective intergranular normal pressure } \\
& \varphi^{\prime}=\text { angle of internal friction } \\
& \tan \varphi^{\prime}=\text { coefficient of friction }
\end{aligned}
$$

This equation indicates that the strength of soil is dependent on two main parameters: the cohesion of the soil and the angle of internal friction. These properties are evaluated through laboratory and field testing. Cohesive soils with high coefficients of friction tend to exhibit high shear strengths. It is expected that soils with high shear strengths can exert large forces onto the vertical surfaces of a structure during offset. Likewise, the high coefficient of friction results in greater frictional forces generated on the underside of the structure. In contrast, less cohesive soils with low coefficients of friction will fail in shear earlier than stronger soils and reduce the demand on vertical surfaces and underneath the structure.

\section{Location of Fault Trace}

For structures spanning a fault trace, the position of the structure with respect to the fault will influence how the structure responds to fault offset. When only a small portion of the structure is located over the offsetting fault, damage is typically isolated to 
the area over the fault and is less likely to lead to collapse of the entire structure (Fig.

6.2-F). If a small portion overhangs the offsetting fault, imposed forces from horizontal offset have a reduced magnitude as the total amount of soil force that is imposed is relatively smaller. When the proportion overhanging the offsetting fault is small relative the entire structure, the small portion has a better chance of remaining attached to the rest of the structure. In the case where the structure has a greater portion overlapping the fault trace, the outcome can be more severe as larger areas tend to develop more force underneath their footprint and therefore risk retention of a larger amount of soil (Fig. 6.2-D \& Fig. 6.2-E).

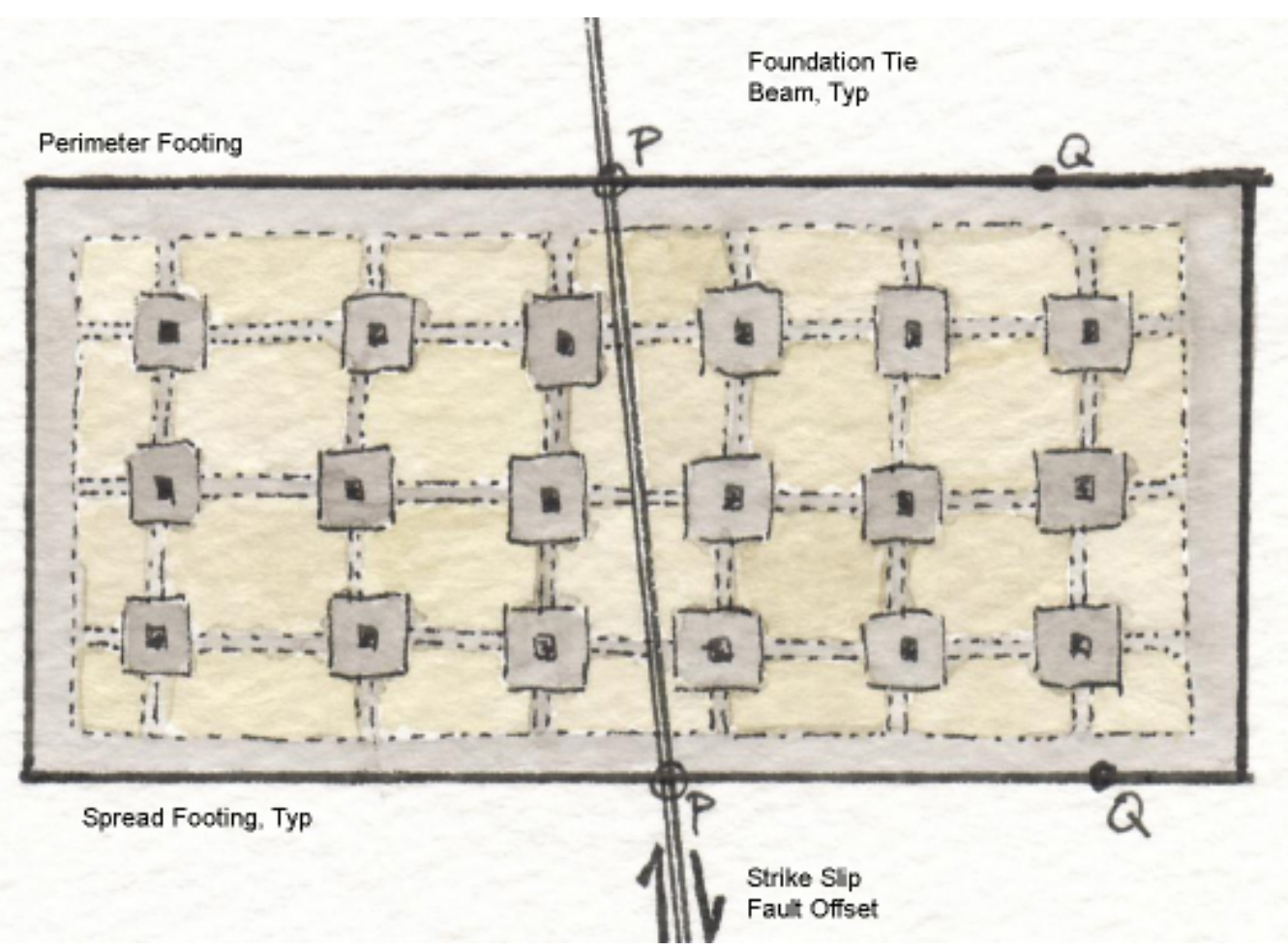

Fig. 6.2-D: Case of structure with a strike-slip fault passing through center of building. 


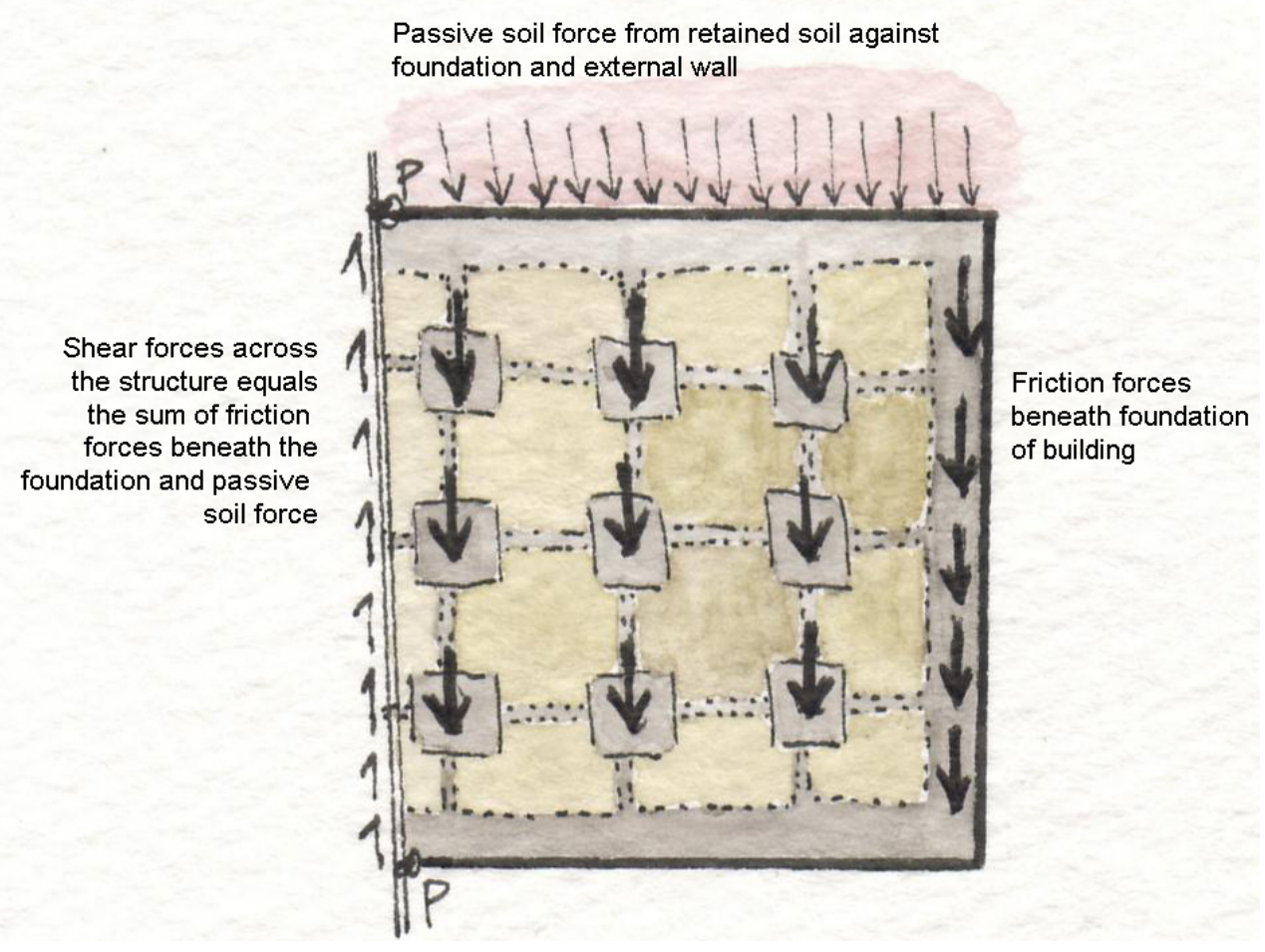

Fig. 6.2-E: Free body diagram showing shear force through section P-P.

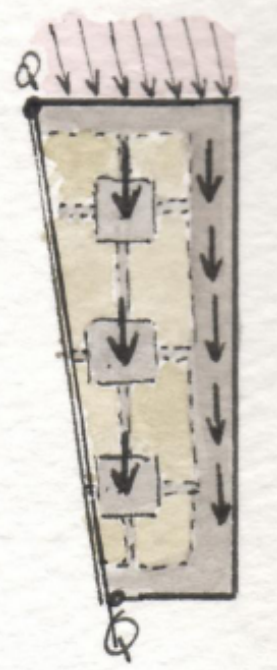

Fig. 6.2-F: Free body diagram with strike-slip near the edge of the building. 


\section{Weight of the Structure}

The weight of the structure could either aid or hinder the structure's capacity to withstand fault rupture. As a fault rupture propagates through overlying soil, the path shears through the weakest planes in the soil. A heavier superstructure compresses the soil below to higher stresses, and therefore increases the strength of the soil. As the rupture moves through different soil horizons and encounters higher stresses, the path may be altered away from the structure because of the increase in soil strength from compression. Anastapoulis and Gazetas (Section 3.3) have demonstrated this effect through finite element modeling of soil subjected to fault rupture. In other cases where the fault rupture is not diverted around the structure at some depth, and instead the weakest path for movement would be directly under the structure, the increase in weight of the structure will elicit greater frictional forces on the underside, thus increasing the shear and tensile capacity required in the foundation.

\section{Foundation System}

Foundation systems with a strong interconnectedness better resist loads imposed during fault offset. This is due to the fact that forces exerted by the soil are capped by their own shear capacity; it is therefore beneficial to have a rigid structure that is sufficiently strong in comparison to the soil. A rigid structure is achieved through tying foundation elements together and is commonly seen practiced in high seismic regions.

Small homes that have been traversed by a fault that are compact and stiff have seen less damage than large warehouses and factories with similar structure-fault ratios. Generally, the interior openness of warehouse structures increases their vulnerability to damage. The combination seen in warehouses, or similar structures with expansive, open 
interiors, of increased flexibility in the foundation and a reduced number of vertical elements to resist offset, lend to the increase in vulnerability of this type of large structure. Thus, a larger footprint is not always an indicator for good performance, but rather having a rigid and tied foundation will dramatically improve resistance. Refer to Table 6-B and Table 6-C for graphics.

\section{Structure Properties and Ductility}

Construction materials and configuration of the superstructure will participate in the structure's ability to resist offsetting forces. Destruction is often amplified when poor construction techniques and brittle materials make up the building under consideration. Elements constructed of strong materials have an increased capacity and can withstand larger forces exerted by the soil. Alternative load paths and redundancy in the superstructure may prevent collapse as support locations shift with the offsetting soil. Ductility, especially at joint connections, better redistributes and accommodates imposed displacements without collapse. This is especially true of concrete moment resisting frame structures. 
Table 6-B: Comparative Structural Foundation Configurations in Plan

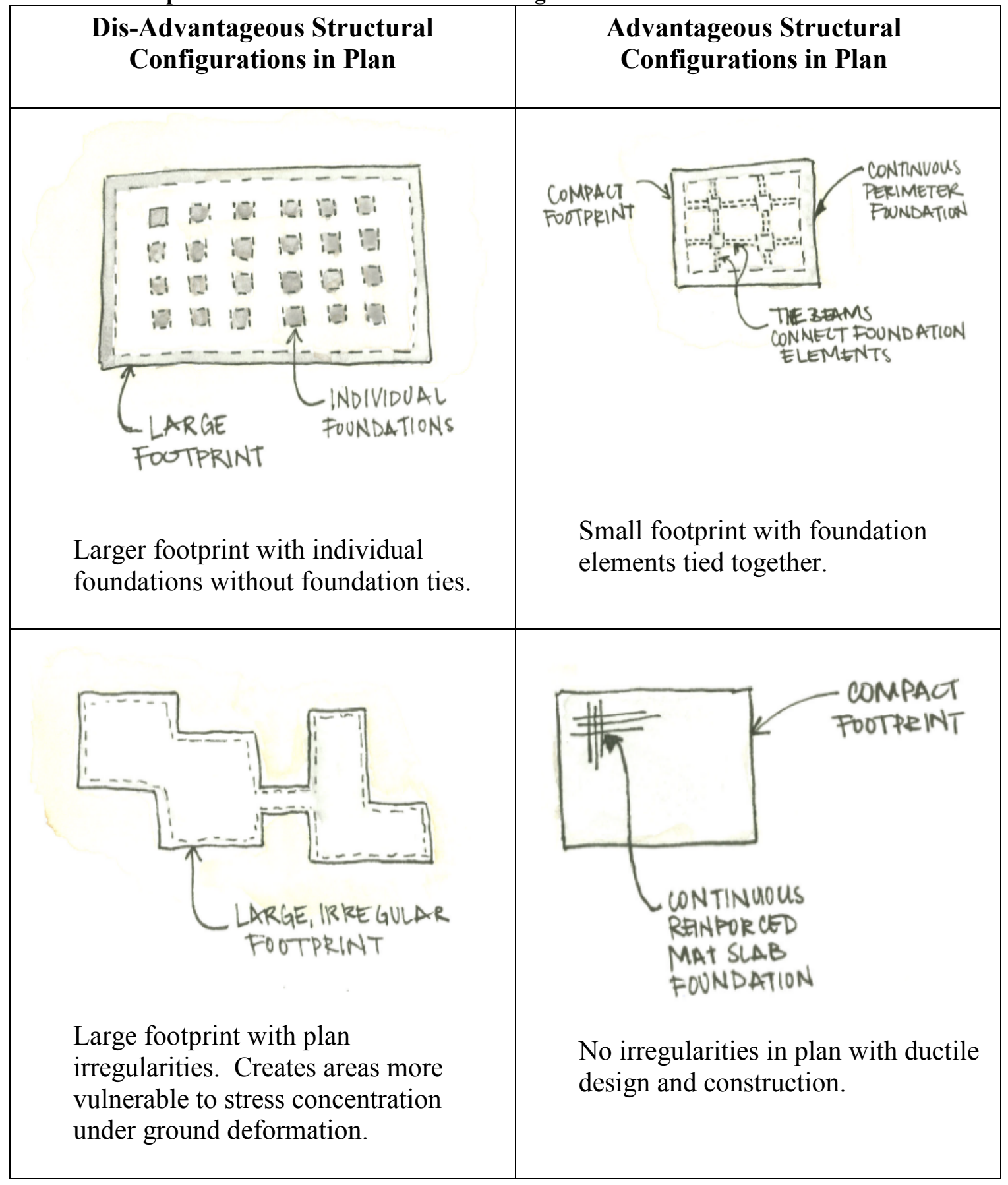


Table 6-C: Comparative Structural Foundation Configurations in Section

Dis-Advantageous Structural Foundation Configurations in Section

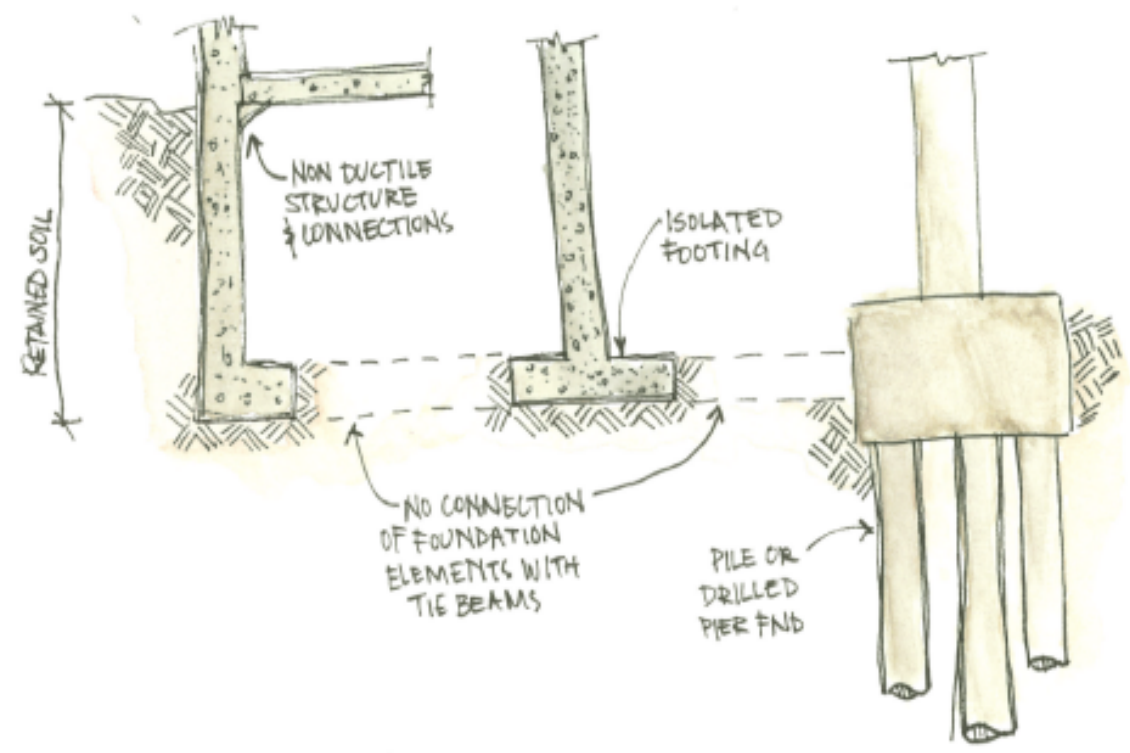

(From L to R): Non ductile foundation wall with retained soil, individual footing not tied to another foundation element, and pile/drilled pier foundation.

\section{Advantageous Structural Foundation Configuration in Section}

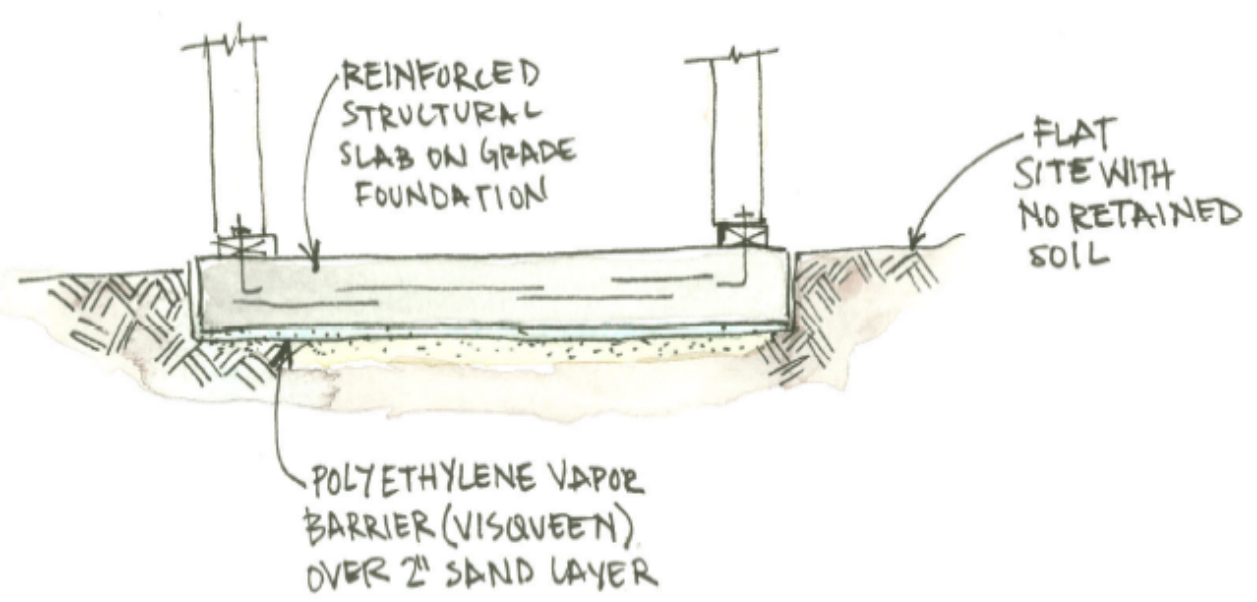

Reinforced structural slab on grade, constructed over a 2" layer of sand and a polyethylene vapor barrier. None to very little soil retained. 


\section{Retrofit and Mitigation Strategies for Existing and New Buildings}

Under current California law in the Alquist-Priolo Act, new structures intended for human occupancy are not permitted to be built in known fault zones where rupture potential is determined through trenching. The question arises: what should be done about existing structures found to have fault traces passing under them. In cases where the structure is of historic or iconic relevance, efforts should be made to preserve the structure and mitigate the potential for damage due to fault offset. Table 6-D lists retrofit and design strategies that may be employed after structural evaluation has deemed it necessary. Many of the tactics listed are easier to incorporate into new design. For existing structures, it is not always as easy or possible.

Table 6-D: Applicable Retrofit Strategies

\begin{tabular}{l|c|c}
\multicolumn{1}{c|}{ Retrofit \& Design Strategy } & $\begin{array}{c}\text { Applicable to New } \\
\text { Structure? }\end{array}$ & $\begin{array}{c}\text { Applicable to Existing } \\
\text { Structure? }\end{array}$ \\
\hline Locate Building Away from Fault & Yes & Yes \\
\hline Tie Foundation Together & Yes & No \\
\hline Post-tension Foundation Slab & Yes & Yes \\
\hline Strengthen Structure to Span Vertical Offset & Yes & Difficult \\
\hline Add Ductility to Structural Elements & Yes & Difficult \\
\hline $\begin{array}{l}\text { Reduce Friction Under Structure } \\
\text { Independent Movement }\end{array}$ & Yes & Yes \\
\hline $\begin{array}{l}\text { Reduce Passive Pressure from Retained Soil on } \\
\text { Vreate Intended Separation Joints to Allow }\end{array}$ & Yes & Difficult \\
\hline
\end{tabular}




\section{Locate building away from fault}

Fault maps are available through the USGS which display known active fault traces. The associated hazard maps indicate the zones that prohibit the new building for structures intended for human occupancy. Likewise, the Alquist-Priolo act states that property buyers need be informed that the plots lie within a state mapped hazard area prior to purchase. The availability of this information reduces the likelihood that new structures will be built atop an active fault trace. It is the recommendation of most professionals that new structures be located away from faults when possible.

For existing structures, relocation of the structure is typically not an option. Evaluation first per Section 6.1 is recommended for existing structures to identify the amount of hazard to the structure. If the hazard level and risk of damage is high, retrofit measures may be implemented to meet demands likely seen by a structure during fault offset. When retrofit techniques are found to be inadequate, demolition and if possible rebuilding in another location is advised.

\section{Tie foundation together}

A main contributor to reduce damage from fault offset is the foundation, as mentioned in previous sections. The more tied together the greater the ability to resist forces generated by offsetting soil. In a new structure, the lateral resistance of isolated footings and pile caps through ties is required by code:

Individual pile caps, drilled piers, or caissons shall be interconnected by ties. All ties shall have a design strength in tension or compression at least equal to a force equal to 10 percent of $\mathrm{S}_{\mathrm{DS}}$ times the larger pile cap or column factored dead plus factored live load unless it is demonstrated that 
equivalent restraint will be provided by reinforced concrete beams within slabs on grade or reinforced concrete slabs on grade or confinement by competent rock, hard cohesive soils, very dense granular soils, or other approved means (ASCE 7-05 §12.13.5.2).

Tying isolated footings to each other helps to increase the lateral stability of elements by providing continuity and increasing the stiffness of the entire foundation system against fault offset.

In the case of an existing structure, the options are more limited but are possible. In the example of Bowles Hall, demolition of the existing floor slab and excavation to the bottom of footings was recommended with the addition of a thick mat slab. For structures where isolated footings are not integral to perimeter stem walls and a mat foundation is not desired, localized sawcutting of the existing slab may be used to construct subgrade tie beams that can be doweled into existing foundation elements. A less invasive alternative is to use the existing slab to tie isolated footings together, but calculations must prove the slab has the capacity to do so.

Another mitigation technique suggested by Bray (2001) is to post-tension foundation slabs where possible. The slabs tolerate differential settlement well and are less prone to in-plane shear failures. This technique is suggested for new construction and not seen as a possibility for existing structures

\section{Strengthen structure and add ductility}

In a new structure the required strength for fault offset can be accounted for in the design to mitigate expected damage. Additionally, new structures can be detailed to ensure ductile performance. 
Existing structures that pre-date seismic codes have structural components which likely require strengthening. If the floor plan allows, seismic resisting elements can be added to reduce demand on current elements. Existing architectural programs and code requirements may reduce this feasibility and strengthening may require less invasive techniques. Individual members may be strengthened using fiberwrap, which can be directly applied to the exterior of existing columns, beams, and walls to increase confinement and shear strength. Shotcrete can be applied to exiting walls to increase the capacity of the wall for bending out-of-plane and in-plane shear. Adding internal ductility to existing beams and columns is not possible.

\section{Reduce friction under the structure}

In a mat foundation, a layer of sand or a polyethylene vapor barrier are intended to reduce water transfer through the slab but are also beneficial in reducing strain transfer by creating a deformable boundary during fault offset. For new structures where mat foundations are used, the layers are always added. In an existing structure where the foundation system is composed of strip footings, it is not unlikely that friction under the footings can be reduced. In an existing structure, a decoupling layer can be inserted during foundation renovations if the renovation includes a new mat foundation. If no renovations are being made to the existing structure foundation, it is unlikely that a decoupling layer can be added.

\section{Reduce passive pressure from retained soil on vertical surfaces}

Reducing the force demand on the structure due to passive pressure is possible for both existing and new structures. Removing the soil retained on vertical surfaces will alleviate the demand the structure must resist. However, site conditions may impose 
limitations of the practicality of the technique. For examples, steep sites may not have access for large construction equipment needed for excavation. Additionally, slope stability of retained soil should be reviewed.

\section{Create intended separation joints to allow independent movement}

Many lifelines that span active faults have been constructed to withstand an expected amount of offset. Structural configuration and specially designed joints allow the structure to deform with the offsets while remaining undamaged. In the Trans-Alaska Pipeline, the structural support of the pipeline was designed to allow the ground to offset and the pipeline to "re-adjust." Seismic joints are widely used in structures in seismic zones and decouple the structure to facilitate an isolated response. Strategically placed joints in new structures could be used as a mitigation to fault offset, but are harder to achieve in existing structures.

\subsection{Simplified Building Code Requirement for Integrity of Foundations}

The following is a preliminary example of code language that may be introduced to building codes to verify a structure has adequate tensile capacity to resist the hazards associated with horizontal fault offset. The language is as follows:

Structures located where permanent ground movement from fault offset or liquefaction is expected such that $\gamma_{6}$ is greater than $1 / 2500$, shall meet these requirements. Alternatively, it is permitted to explicitly design for permanent ground displacement by providing a movement joint or joints in the structure that allow the ground displacement to occur without damaging the structure. 
For any planar vertical section taken through the structure, the foundation and below-grade structure shall have a total design horizontal tension strength across the section, $\phi T_{n}$ as required below.

The horizontal tension strength $T_{n}$ shall be computed perpendicular to the vertical section being considered. Structural elements assumed to contribute to $T_{n}$ shall be located below a horizontal plane that is 6 feet above the average ground surface at the perimeter of the building. The strength reduction factor $\phi$ shall be taken from applicable requirements in the material standards.

For structures with pile or drilled-pier foundations, horizontal tension strength shall be provided such that:

$$
\phi T_{n} \geq C_{g} W_{1}
$$

For structures with shallow foundations, such as footings or mat slabs, horizontal tension strength shall be provided such that:

$$
\phi T_{n} \geq C_{g}\left(C_{f}+C_{e}\right) W_{l}
$$

Where

$W_{l}=$ The total weight of the structure on the side of the section that has smaller weight

$\gamma_{6}=$ Annual frequency of permanent ground displacement exceeding six inches at the site.

$C_{g}=$ Coefficient related to ground displacement hazard, taken equal to 0.1 for $\gamma_{6}$ equal to $1 / 2500$, equal to 0.4 where $\gamma_{6}$ exceeds $1 / 250$, and interpolated for 
intermediate values of $\gamma_{6}$.

$C_{f}=$ Coefficient related to shear strength of the soil and expected amount of force that the soil can transmit to the building, ranging from 0.4 for soil with low shear strength to 0.7 for structures with high shear strength.

For structures on slab foundations, for which the structure is entirely founded on a low friction layer such as a polyethylene vapor barrier and/or a sand layer, $C_{f}$ is permitted to be taken as 0.3 . If exact value is not known, a default value may be selected from Table 6-E.

$C_{e}=$ Coefficient related embedment of the structure in the surrounding soil, equal to 0 when the foundation extends no deeper than 2 feet below the highest perimeter grade, equal to 0.3 when the foundation extends more than 8 feet below the highest perimeter grade, linearly interpolated for intermediate values.

The quantity $\left(C_{f}+C_{e}\right)$ need not exceed 0.8 . Where permanent ground displacement is expected from liquefaction, but fault rupture or offset at the site is not expected, it is permitted to take $C_{e}$ equal to 0 . 
Table 6-E: Soil Type Coefficient

\begin{tabular}{|c|c|}
\hline $\mathbf{C}_{\mathbf{f}}$ & Soil Profile Type \\
\hline 0.4 & Soft Soil Profile \\
\hline 0.5 & Stiff Soil Profile \\
\hline 0.6 & Very Dense Soil and Soft Rock \\
\hline 0.7 & Rock \\
\hline
\end{tabular}

Fig. 6.3-A: Coefficient of Embedment, Ce

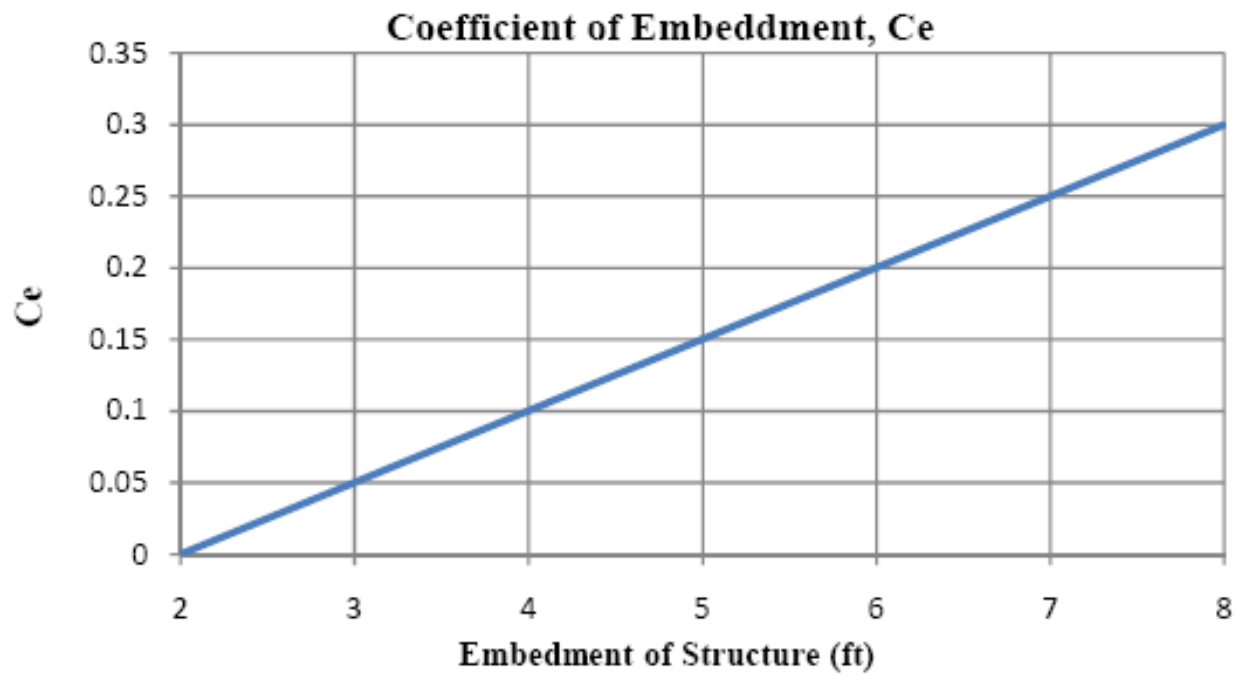




\subsection{CONCLUSION}

The intent of this report is to provide information, examples, and design guidance that can be utilized by industry professionals. Through the compilation of case studies of structures subject to fault rupture of varying natures and the commentary on response behavior observed, this paper provides recommendations in how to address design problems for structures that are at risk for surface rupture. A major task facing the design professional in this situation is to identify parameters that influence structural performance during fault rupture.

Previous studies detailed in Section 3.0 provide a base level of understanding as to how fault rupture impacts structures. Primarily, imposed soil forces on vertical surfaces are capped by the soil's maximum passive pressure, essentially the strength of the soil. Additional research has documented structure response to faulting based on structure configuration and materials. The individual case studies pulled from the literature and several reconnaissance reports for major earthquakes serve as the foundation for Section 4.0. The compilation of these combined sections allow for a broader perspective on how soil forces are triggered by fault offset and subsequent structure response to these imposed earth pressures. An additional investigation into variation in faulting mechanisms reveals the types of methods of failure that typically develop.

The case studies illustrate the principal factors controlling structural response and are explored in Section 6.0. Structure response may be summarized as being sensitive to the following parameters:

- the amount of fault offset

- the soil strength 
- location of the fault trace with respect to the structure

- the foundation system

- the weight and mass of the structure

- the structural material properties

Once the relationship of the factors is understood for a given structure, structural engineers are able to perform a competent analysis to identify deficiencies and strengths within the structure. The analysis of Bowles Hall, summarized in Section 5.0, provides a detailed example leading to the development of an evaluation process for that particular structure's resistance capacity. It demonstrates how the sensitive parameters were identified for that building and targeted where retrofit measures should be applied. The economy of this approach should not be overlooked.

The resulting evaluation process is outlined in Section 6.1. The procedure involves determining the forces that will be exerted on the structure and defining critical failure modes. The evaluation procedure and recommendations may be applied to new structures and existing structures as explained in Section 6.0 with the noted restrictions. Many of the techniques used to mitigate earthquake shaking damage in current practice are also viable options for hazards of surface fault rupture. For example, foundation rigidity allows for a continuous load path into the soil from shaking but is also a major contributor to resisting fault offset. It is recommended that the strength of the foundation exceed the strength of the soil it is founded in and typically this is easy to achieve.

Preliminary code language has consequently developed through research of the case studies and development of the structural evaluation procedure. There is room to continue to develop these equations and contributions of the factors, however, it starts the 
ball rolling with a solid and conservative number to cover the unknowns. As written, this language is sensitive to beneficial factors such that reduction in the required strength is allotted for shallow foundations and reduced probability of faulting. Deep foundations do not allow for as much of a reduction as displacement and rotation that originates at the foundation depth translates into amplified stresses at the superstructure level. It is suggested that further efforts be made to develop code language in aims of tailoring current laws regarding fault rupture.

While the behavior of surface faulting is complex and not entirely understood, steps can be taken to mitigate damage to structures at risk from surface fault rupture. The unpredictability of the phenomenon can be attributed to all the components which relate to how rupture will occur: type of fault, overlying soil types, angle of dip, etc. While it is always recommended to build away from active faults when possible, it should be acknowledged that discovery of faults may not come until a considerable sum of money has been invested and extensive site investigations have taken place. At this stage, implementing the techniques recommended for new structures is plausible. In California, however, current laws may need to be altered to allow the implementation of strengthening as an alternative for the method of avoidance. 


\subsection{APPENDIX}

\subsection{Glossary}

Adhesion: Shearing resistance between two different materials. For example, for piles driven into clay deposits, there is adhesion between the surface of the pile and the surrounding clay.

Allowable BearingPressure: The maximum pressure that can be imposed by a foundation onto soil or rock supporting the foundation. It is derived from experience and general usage, and it provides an adequate factor of safety against shear failure and excessive settlement.

Alluvium: Detrital deposits resulting from the flow of water, including sediments deposited in riverbeds, canyons, floodplains, lakes, fans at the foot of slopes, and estuaries.

Blind Fault: A blind fault is defined as a fault that has never extended upward to ground surface. Blind faults often terminate in the upward region of an anticline.

Blind Thrust Fault: a blind reverse fault where the dip is less that or equal to 45 degrees.

Characteristic Earthquake: Surface rupturing earthquakes occurring on a known tectonic structure, within a relatively narrow range of magnitudes at an increased frequency over that which would be estimated from the Gutenberg-Richter relationship.

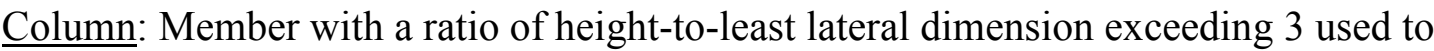
support axial compressive load.

Concrete: A mixture of Portland cement of any other hydraulic cement, fine aggregate, coarse aggregate, and water, with and without admixtures.

Dip-Slip Fault: A fault which experiences slip online in the direction of its dip, or in other words, the movement is perpendicular to the strike. Thus a fault could be described as a "dip-slip normal fault," which would indicate that it is a normal fault with the slip online in the direction of its dip.

Ductility: A property of a material, structural element, or structure by which it can withstand inelastic straining without failure.

Ductile Detailing: Special requirements such as, for reinforced concrete and masonry, close spacing of lateral reinforcement to attain confinement of a concrete core, appropriate relative dimensioning of beams and columns, 135 degree hooks on lateral reinforcement, hooks on main beam reinforcement within the column, etc. 
Ductile Frames: Frames required to furnish satisfactory load-carrying performance under large deflections.

Embedment length: Length of embedded reinforcement provided beyond a critical section.

En Echelon: A geologic feature that has staggered or overlapping arrangement. An example would be surface fault rupture, where the rupture is in a linear form but there are individual features that are oblique to the main trace.

Fault Scarp: This generally only refers to a portion of the fault that has been exposed at ground surface due to ground surface fault rupture. The exposed portion of the fault often consists of a thin layer of "fault gouge," which is a clayey seam that has formed during the slipping or shearing of the fault and often contains numerous slickensides.

Fragility: The probability of a specific level of damage given a specified level of hazard.

Isolation Joint: A separation between adjoining parts of concrete structure, usually a vertical plane, at a designed location such as to interfere least with performance of the structure, yet such as to allow relative movement in three directions and avoid formation of cracks elsewhere in the concrete and through which all or part of the bonded reinforcement is interrupted.

Longitudinal Step Fault: A series of parallel faults. These parallel faults develop when the main fault branches upward into several subsidiary faults.

Modulus of elasticity: Ratio of normal stress to corresponding strain for tensile or compressive stresses below proportional limit of material.

Moment frame: Frame in which members and joints resist forces through flexure, shear, and axial force.

Mitigation: Literally the moderating of a force or intensity of something that causes suffering; used in earthquake engineering as synonymous with reducing earthquake risk.

Normal Fault: The "hanging wall" is defined as the overlying side of a non-vertical fault. Thus, the hanging wall block is the part of the ground on the right side of the fault and the footwall black is that part of the ground on the left side of the fault. A normal fault would be defined as a fault where the hanging wall block has moved downward with respect to the footwall block.

Oblique-Slip Fault: A fault which experiences components of slip in both its strike and dip directions. A fault could be described as an "oblique-slip normal fault," which would indicate that it is a normal fault with components of slip in both the strike and dip directions. 
Paleoseismicity: Prehistoric earthquakes; since there is no human record, these earthquakes are identified via geologic trenching and other evidence.

Reverse Fault: A reverse fault would be defined as a fault where the hanging wall black has moved upward with respect to the footwall block.

Return Period: The reciprocal of the annual probability of occurrence; earthquake probabilities of occurrence are commonly stated in terms of a return period, which misleads some people since they infer the earthquake occurs on a regular cycle equal to the return people.

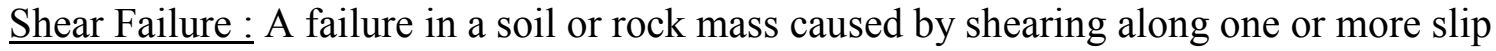
(rupture) surfaces.

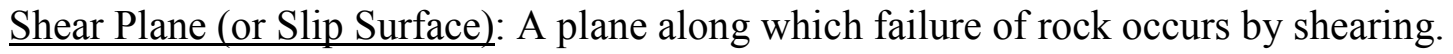

Shear Strength: The maximum shear stress that a soil or rock can sustain. Shear strength of soil is based on total stresses (i.e., undrained shear strength) or effective stresses (i.e., effective shear strength).

Shear Stress: Stress that acts parallel to the surface element.

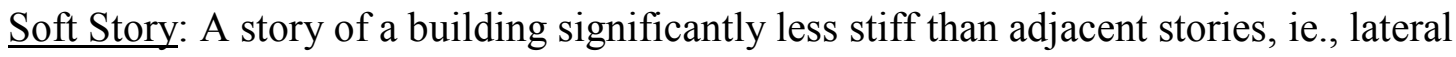
stiffness is $70 \%$ or less than that in the story above, or less than $80 \%$ of the average stiffness of the three stories above.

Strain: A dimensionless measure of deformation within a material or member, reflective of the percent elongation or contraction of the material or member under applied loading.

Strike-Slip Fault: During the discussion of the transform boundary, a strike-slip fault was defined as a fault on which the movement is parallel to the strike of the fault.

Thrust Fault: A thrust fault is defined as a reverse fault where the dip is less than or equal to 45 degrees.

Transform Fault: A fault that is located at a transform boundary. Yeats et al. define a transform fault as a strike-slip fault of plate-boundary dimensions that transforms into another plate-boundary structure at is terminus. 


\subsection{REFERENCES}

(Anastasopoulos and Gazetas 2007) Anastasopoulos, Ioannis and George Gazetas.

"Foundation-structure systems over a rupturing normal fault: Part I. Observations after the Kocaeli 1999 earthquake.” Bulletin of Earthquake Engineering. (April 2007): 253-275.

(Anastasopoulos and Gazetas 2007) Anastasopoulos, Ioannis and George Gazetas.

"Foundation-structure systems over a rupturing normal fault: Part II. Analysis of the Kocaeli case histories." Bulletin of Earthquake Engineering. (April 2007): 277-301.

(Bray 1989) Bray, Jonathan D. (1989) The Effects of Tectonic Movements on Stresses and Deformations in Earth Embankments. Dissertation Doctor of Philosophy,University of California, Berkeley, 414.

(Bray 2000) Bray, Jonathan.D. and Stewart, J.P., coordinators, 2000, "Damage patterns and foundation performance in Adapazari," 1999 Kocaeli, Turkey, Earthquake Reconnaissance Report, EERI, Earthquake Spectra, Supplement A to Volume 16, p. 163-189.

(Bray 2001) Bray, Jonathan D., "Developing Mitigation Measures for the Hazards Associated with Earthquake Surface Fault Rupture." Workshop on Seismic FaultInduced Failures-Possible Remedies for Damage to Urban Facilities, University of Tokyo, Japan, pp. 55-79, January 11-12, 2001 [Invited Paper].

(Bray and Kelson 2006) Bray, Jonathan D., Keith I. Kelson, “Observations of Surface

Fault Rupture from the 1906 Earthquake in the Context of Current Practice." Earthquake Spectra, Volume 22, No. S2., (April 2006): S69-S89.

(CGS 2007) California, Department of Conservation, California Geological Survey. Fault-Rupture Hazard Zones in California, 2007 Interim Revision.(Sacramento, 2007).

(Chen and Scawthorn 2003) Chen, Wai-Fah, and Charles Scawthorn, ed. Earthquake Engineering Handbook. New York: CRC Press, (2003).

(Day 2002) Day, Robert W., Geotechnical Earthquake Engineering Handbook. New York: McGraw Hill, (2002).

(DGGS) Alaska Division of Geological \& Geophysical Surveys. www.dggs.alaska.gov/, September 2008.

(Duncan and Lefebvre 1973) Duncan, J.M. and Lefebvre, G. "Earth Pressure on Structures Due to Fault Movement,"Journal of Soil Mechanics and Foundation Division, ASCE, Paper 10237, 99(SM12): 1153-63. 
(Honegger 2004)Honegger, Douglas G., et. al. "Trans-Alaska Pipeline System

Performance in the 2002 Denali Fault, Alaska, Earthquake.” Earthquake Spectra.

Volume 20, No 3, (August 2004): 707-738.

(Kayen 2004) Kayen, Robert, et. al., "Geotechnical Reconnaissance of the 2002 Denali

Fault, Alaska, Earthquake.” Earthquake Spectra. Volume 20, No 3, (August 2004): 639-667.

(Kelson 2003) Kelson, Keith I. et.al. "Surface Deformation Produced by the 1999 ChiChi(Taiwan) Earthquake and Interactions with Built Structures.” William Lettis \& Associates, Inc. U.S. Geological Survey National Earthquake Hazards Reduction Program. (December 2003).

(Lettis et al. 2000) Lettis, W. and 21 other authors [2000] "Surface Fault Rupture," Earthquake Spectra, Chapter 2 in the Special Volume on the Turkey Earthquake of August 17, 1999 Reconnaissance Report,(August 1999) 11-52.

(Lettis \& Associates 2003) William Lettis \& Associates, Inc. "Surface Deformation Produced by the 1999 Chi-Chi(Taiwan) Earthquake and Interactions with Built Structures.” U.S. Geological Survey National Earthquake Hazards Reduction Program. December 2003.

(Lettis \& Associates 2007) William Lettis \& Associates. "Fault Displacement Hazard Analysis. Bowles Hall, University of California, Berkeley." William Lettis \& Associates. Walnut Creek, CA. October 2007.

(Loh and Tsay 2001) Loh, Chin-Hsiung, and Ching-Yen Tsay, "Responses of the Earthquake Engineering Research Community to the Chi-Chi(Taiwan) Earthquake." Earthquake Spectra. Volume 17, No 4, (November 2001): 635-656.

(Maffei et al. 2008) Maffei, Joe, Ann Roche, and Jury Shin. "UC Berkeley Bowles Hall: Seismic Evaluation and Conceptual Retrofit Design.” Rutherford \& Chekene. San Francisco, CA. February 2008.

(Meehan 1973) Meehan, John F., et al. "Managua, Nicaragua Earthquake of December 23, 1972." Earthquake Engineering Research Institute Reconnaissance Report. (May 1973).

(Murbach 1999) Murbach, Diane, Thomas K. Rockwell, and Jonathan D. Bray, "The Relationship of Foundation Deformation to Surface and Near-Surface Faulting Resulting from the 1992 Landers Earthquake." Earthquake Spectra, Volume 15, No 1, (February 1999): 121-144.

(Park 2004) Park, S.W., et. al. "Simulation of the seismic performance of the Bolu Viaduct subjected to near-fault ground motions." Earthquake Engineering and Structural Dynamics. (2004): 1249-1270. 
(Roussi 2003) Roussi, Panayiotis C. et. al. "Assessment of Performance of Seismic Isolation System of Bolu Viaduct." Journal of Bridge Engineering (C ASCE. (July/August 2003): 182-190.

(Sezen 2000) Sezen, Halil, et al. "Structural Engineering Reconnaissance of August 17, 1999 Earthquake: Kocaeli (Izmit), Turkey.” Pacific Earthquake Engineering Research Center. University of California, Berkeley. (December 2000).

(Tang 2000) Tang, Alex K., ed. 'Izmit (Kocaeli), Turkey, Earthquake of August 17, 1999, Including Duzce Earthquake of November 12, 1999_Lifeline Performance." Technical Council on Lifeline Earthquake Engineering. Monograph No. 17. ASCE (March 2000).

(Uzarski and Arnold 2001) Uzarski, Joe and Christopher Arnold. "Chi-Chi, Taiwan, Earthquake of September 12, 1999 Reconnaissance Report.” Earthquake Spectra, Supplement A to Volume 17, (April 2001).

(Wells \& Coppersmith 1994) Wells, Donald, and Kevin Coppersmith, "New Empirical Relationships amoun magnitude, rupture length, rupture width, rupture area, and surface displacement." Bulletin of the Seismological Society of America August 1994 vol. 84 no. 4 974-1002

(Yeats 1997) Yeats, Robert S., Kerry Sieh, and Clarence R. Allen. The Geology of Earthquakes. New York: Oxford University Press, (1997).

(Youd et al. 2002) Youd, T.L., Hansen, M.C. and Bartlett, F.S., Revised Multilinear Regression Equations for Prediction of Lateral Spread Displacement, ASCE Journal of Geotech. and Geoenvironmental Engineering., Vol. 128, No. 12: 10071017. 